\title{
THE EFFECT OF IMPLICIT STEREOTYPES ON THE PHYSICAL PERFORMANCE IN OLDER ADULTS
}

Gabriele R. Moriello

Virginia Commonwealth University

Follow this and additional works at: https://scholarscompass.vcu.edu/etd

Part of the Medicine and Health Sciences Commons

(C) The Author

\section{Downloaded from}

https://scholarscompass.vcu.edu/etd/2042

This Dissertation is brought to you for free and open access by the Graduate School at VCU Scholars Compass. It has been accepted for inclusion in Theses and Dissertations by an authorized administrator of VCU Scholars Compass. For more information, please contact libcompass@vcu.edu. 
Gabriele R. Moriello 2010 All Rights Reserved 


\section{THE EFFECT OF IMPLICIT STEREOTYPES ON THE PHYSICAL PERFORMANCE IN OLDER ADULTS}

A dissertation submitted in partial fulfillment of the requirements for the degree of Doctor of Philosophy at Virginia Commonwealth University.

by

Gabriele R. Moriello

B.S. in Physical Therapy

Ithaca College, 1988

M.S. in Allied Health

University of Connecticut, 2001

Director: J. James Cotter, PhD

Assistant Dean for Distance Education and

Director, Doctoral Program in Health Related Sciences

Virginia Commonwealth University

Richmond, Virginia

January, 2010 


\section{ACKNOWLEDGMENTS}

It is a pleasure to thank those people who have played an integral role in my professional life the past few years. First, I would like to thank my advisor and chair, Dr. J. James Cotter, for his continuous help and guidance throughout this whole process. I would like to thank my committee members, Dr. Nathalie Shook, Dr. Diane Dodd-McCue, and Dr. E. Ayn Welleford for their encouragement, support, and advice over the past $2 \frac{1 / 2}{2}$ years. I would like to acknowledge Laura Gras PT, DSc, GCS and Kerri Maloney PT, DPT, NCS for volunteering their time to complete the outcome measures, and James Brennan PT, PhD and Michelle Haller PT, DPT for providing the interventions. I am grateful for the participants because without them, the study would not be possible. And lastly, but definitely not least, I would like to give a special thank you to my family and friends for understanding that I have not had much time for them over the past few years. I would especially like to thank my husband, Chris, for his love, support, and patience and my mom, who was my editor, for reading my dissertation several times over. This dissertation would not have been possible without everyone's help. 


\section{TABLE OF CONTENTS}

LIST OF TABLES.....................................................

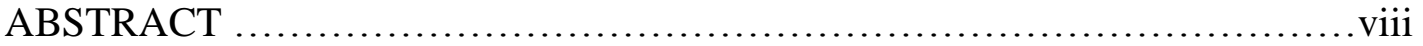

CHAPTER 1: INTRODUCTION ...........................................

Research Questions ............................................6

Methods...........................................................6

Significance of the Study..........................................8

Delimitations................................................... 9

Definition of Terms................................................. 9

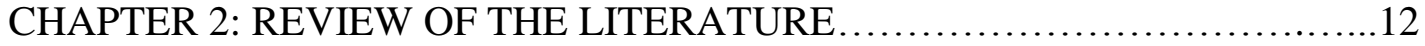

Demographics and Trends of the Older Adult Population .................12

Stereotypes................................................... 14

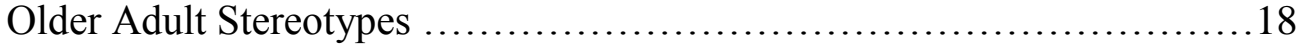

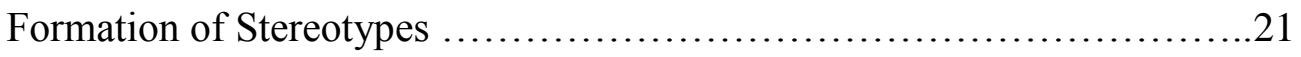

Internalization of Aging Stereotypes ..............................26

Effect of Aging Stereotypes on Behavior ............................27

Stereotype Activation ........................................... 33

Factors Which Can Moderate the Stereotype to Behavior Link ..............37

Physical Performance of the Older Adult Population .......................39

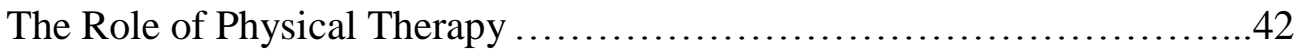

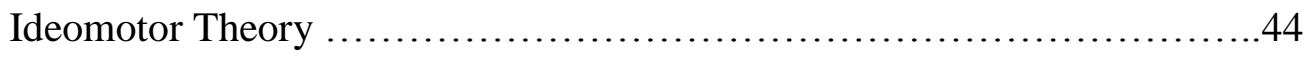

Historical Background of Ideomotor Theory ..........................45

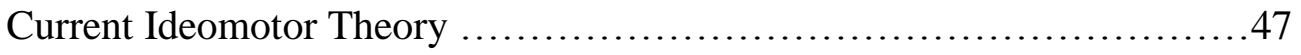

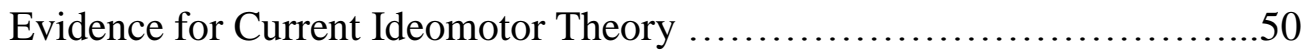


Evidence to Relate Ideomotor Theory and Social Perceptions .............54

Application of Theoretical Framework ...............................58

Theoretical Boundaries .........................................63

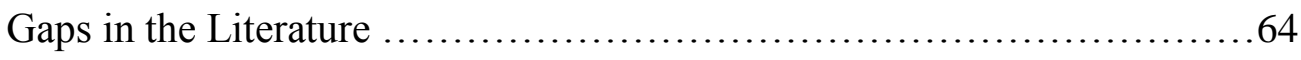

CHAPTER 3: METHODOLOGY ........................................67

Research Design ..................................................67

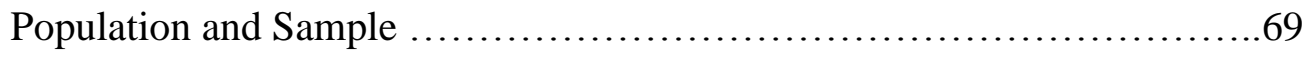

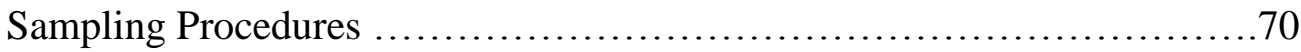

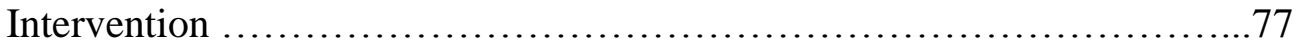

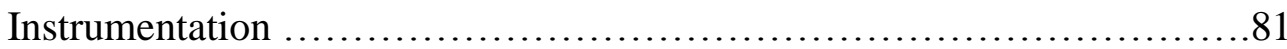

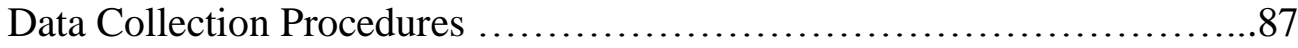

Data Analysis ................................................... 90

CHAPTER 4: RESULTS ............................................. 96

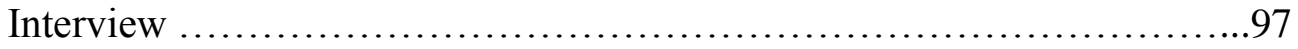

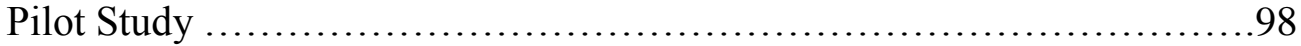

Main Study ................................................. 99

CHAPTER 5: DISCUSSION ......................................... 110

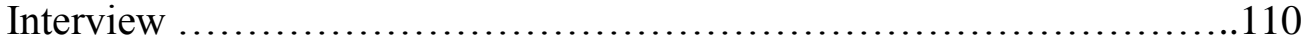

Pilot Study .....................................................110

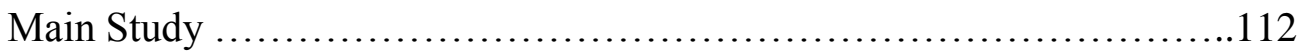

Effect of Stereotypes on Behavior.................................119

Self-relevance .................................................. 120

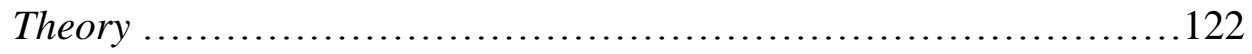

Association Between Sociodemographic Factors and Performance.....125

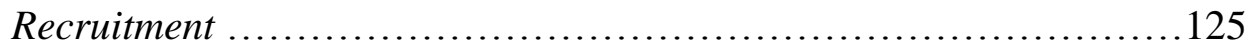

Limitations ................................................ 127

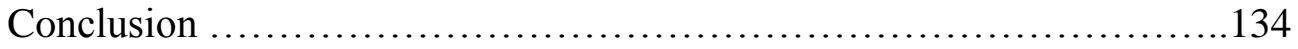

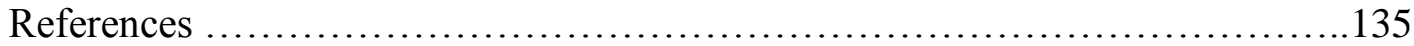

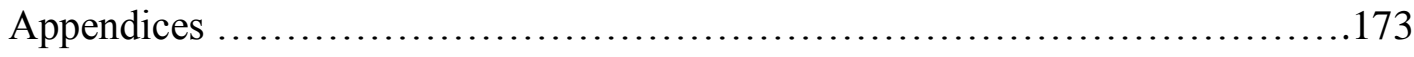




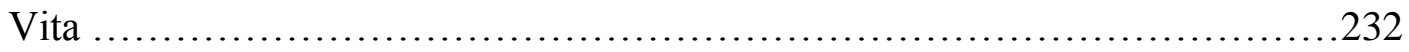




\section{LIST OF TABLES}

Table

1. Positive and Negative Stereotypes of Older Adults ...........................19

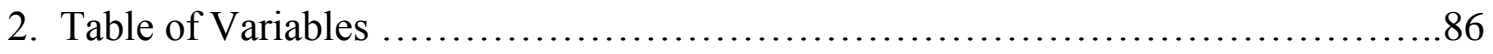

3. Overview of Measurement Tools .......................................... 88

4. Overview of Relationship Between the Hypotheses 1-9

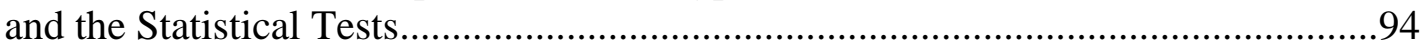

5. Overview of Relationship Between the Hypotheses 10-15 and the Statistical Tests ............................................... 95

6. Results of Chi Square Testing (Aging) ................................... 98

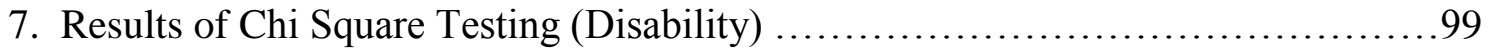

8. Baseline Characteristics of the Participants and Results of ANOVA, Kruskal Wallis and Chi Square Testing.................................... 100

9. Baseline Measures on the Outcome Variables and Results of ANOVA Testing.....101

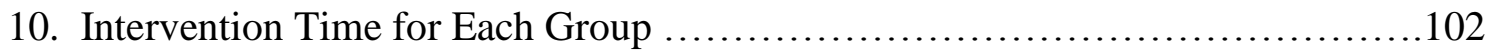

11. Results of Kolmogorov-Smirnov Test of Normality Before and After

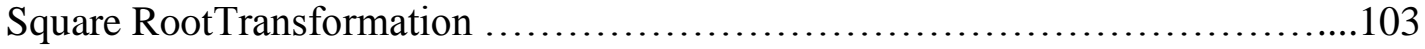

12. Results of MANCOVA Testing ........................................ 104

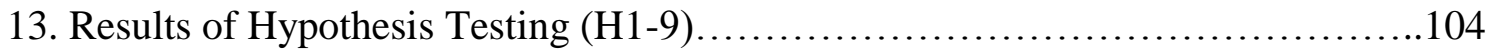

14. Results of Multiple Regression Testing ................................... 107

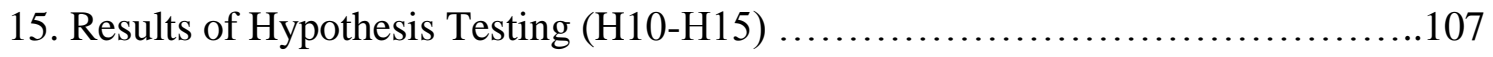




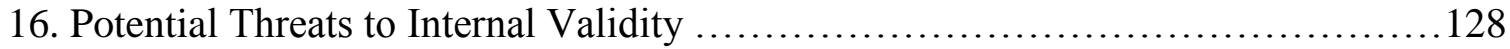




\begin{abstract}
THE EFFECT OF IMPLICIT STEREOTYPES ON THE PHYSICAL PERFORMANCE IN OLDER ADULTS

By Gabriele Moriello, Ph.D.

A dissertation submitted in partial fulfillment of the requirements for the degree of Doctor of Philosophy at Virginia Commonwealth University.

Virginia Commonwealth University, 2010.

Major Director: J. James Cotter, PhD

Assistant Dean for Distance Education and

Director, Doctoral Program in Health Related Sciences
\end{abstract}

The purpose of this study was to explore how stereotypes affect physical performance in older adults. A multigroup pretest post test design was utilized to determine whether implicit activation of positive or negative stereotypes has an effect on physical performance. Ninety six community dwelling older adults 65 years of age or older were included in the sample. Participants were randomly assigned to one of three groups: exposure to positive stereotypes of aging, exposure to negative stereotypes of aging, or a control condition. In order to simulate how older adults are exposed to stereotypes in real world settings, participants were primed with objects representing aging stereotypes. Gait speed, standing balance, and lower extremity muscle performance were tested before and 
after exposure to stereotypes. Results of MANCOVA analysis, using self-relevance as a covariate, revealed no significant differences between those exposed to positive stereotypes, negative stereotypes, or the neutral condition. Physical performance is not affected by exposure to implicit stereotypes of aging in a more real world setting. In real world settings, there are multiple factors, like motivation and self-focus, competing for the control of behavior which are not present in the lab. These psychosocial factors may lessen the effect of stereotype activation on physical performance 


\section{CHAPTER 1: INTRODUCTION}

The first goal of Healthy People 2010 is to increase the quality and years of healthy life by focusing on preventative care through a multi-disciplinary approach which includes physical therapy (U. S. Department of Health and Human Services, 2000). One way physical therapists can contribute to meeting the goals of Healthy People 2010 is by screening physical performance, monitoring physical decline, and intervening with educational and intervention programs as necessary (Decker \& Thompson, 2004). Preserving physical performance in the older adult population is especially important since the number of older adults is expected to dramatically increase within the next few years.

The effects of aging in the United States are projected to raise per capita health care costs 18 percent, from $\$ 2993$ per person in 2000 to $\$ 3543$ per person, by the year 2050 (Martini, Garrett, Lindquist, \& Isham, 2007). Lower levels of physical performance have been associated with higher use of health care services (Fried \& Guralnik, 1997; Mor, Wilcox, Rakowski, \& Hiris, 1994; Wolinsky et al., 1993; Wolinsky \& Johnson, 1991) and declines in physical performance are associated with lower life satisfaction (Asakawa, Koyano, Ando, \& Shibata, 2000). It is important to prevent physical decline in older adults in order to delay the need for costly care and increase quality of life. 
Past research has shown there are a number of physical and psychosocial factors that influence physical performance (Everard, Lach, Fisher, \& Baum, 2000; Hausdorff, Levy \& Wei, 1999; Rowe \& Kahn, 1997; Seeman et al., 1995; Uchino, Cacioppo, \& KiecoltGlaser, 1996; Unger, Johnson, \& Marks, 1997). Traditionally, physical therapists have done a good job screening and addressing physical risk factors but have not adequately addressed psychosocial and environmental risk factors associated with physical decline. In order to optimally serve the needs of older adults in their care, physical therapists need to be aware of all factors affecting physical performance. One of these psychosocial factors can be the effect of stereotypes.

Stereotypes are defined as "beliefs that a given object of a class possesses the characteristics of that class without regarding the degree of individual variation" (Schultz \& Fritz, 1987, p. 87). Even though stereotypes can be classified as either positive or negative, negative stereotypes are usually more common (Hummert, 1990; Kite, Stockdale, Whitley, \& Johnson, 2005; Nemmers, 2004). In the case of older adult stereotypes, it is the negative ones which are disconcerting since they can shape the way older adults perceive aging. There is growing evidence which suggests older adults can internalize these stereotypes so that they become self-stereotypes which then result in thoughts and actions consistent with those stereotypes (Hausdorff et al., 1999; Levy, 1996; Levy, 2003; Levy, Ashman, \& Dror, 1999-2000; Levy, Slade, Kunkel, \& Kasl, 2002b). These studies propose that negative stereotypes can harm the physical and cognitive status of the older population (stereotype threat), while positive stereotypes can 
actually enhance their status (stereotype lift) (Hausdorff et al., 1999; Levy, 1996; Levy et al., 1999-2000; Levy, 2000; Stein, Blanchard-Fields, \& Hertzog, 2002).

Stereotype activation can be accessed either implicitly or explicitly. Implicit activation of stereotypes is subtle and below the threshold of conscious awareness, while explicit activation is obvious and the individual is consciously aware of the stereotype. The distinction between the two is important since the response to stereotype activation can differ depending on whether stereotypes are activated implicitly or explicitly. Implicit activation results in stereotype-consistent behavior while explicit activation can result in either stereotype-consistent or stereotype-inconsistent behavior (Wheeler \& Petty, 2001).

Ideomotor theory, as applied to stereotypes, proposes that a tendency toward a behavior will automatically follow the activation of the stereotype and the behavior will be consistent with that particular stereotype (Wheeler \& Petty, 2001). For example, one older adult stereotype is that older adults are slow. After being exposed to images or words describing older adults, ideomotor theory postulates the activation of the trait "slow" will lead to behavior that is slow. A series of studies have been conducted examining the effect of activation of stereotypes on cognitive functioning (Hess, Auman, Colcombe, \& Rahhal, 2003; Hess, Hinson, \& Statham, 2004; Levy, 1996; Stein et al., 2002), gait speed and swing time (Hausdorff et al., 1999), handwriting ( Levy, 2000), cardiovascular functioning (Levy, Hausdorff, Hencke, \& Wei, 2000; Levy \& Slade, 2006), and will to live (Levy et al., 1999-2000) in older adults. These results support ideomotor theory since stereotypes did influence behavioral outcomes and physiological responses in these studies. 
To date, there has been little research on the effect of stereotypes on physical performance in the older adult population. One study which was conducted by Hausdorff, Levy, and Wei (1999) only included the measures of gait speed and swing time. They did not include other important measures of physical performance like standing balance and lower extremity muscle performance nor did they use a standardized dependent measure. The other study by Levy (2000) only included handwriting as a measure of physical performance. Several studies (Levy, 2000; Levy et al., 1999-2000) about the effect of stereotype activation on behavior did not include a pretest or neutral priming condition. Lack of a pretest prevents the determination that randomization was successful in forming equivalent groups and prevents the ability to measure change over time. When a neutral priming condition is not included, it is only possible to verify if the positively primed and negatively primed groups are different from each other. It is not clear though, whether exposure to positive stereotypes results in enhancement from normal or if exposure to negative stereotypes results in deterioration from normal.

The samples in several past studies (Hausdorff et al., 1999; Hess et al., 2003; Hess et al., 2004; Levy, 1996; Levy et al., 1999-2000; Stein et al., 2002) have not accurately represented the population of older adults in the United States. The samples tended to be younger and with a different gender ratio. Past research has neither monitored whether samples were representative of the population with regards to geographic living area. This is important, since physical performance varies among older adults who live in rural, urban, and/or suburban areas (Morala, Shiomi, \& Maruyama, 2006). 
Past research has not taken into account that certain psychosocial traits can interfere with the effect of stereotypes on behavior. There is evidence that the activation of stereotypes can be moderated if older adults find them self-relevant. Self-relevant information is processed more readily, is easier to perceive, and more likely to be used than non-relevant information. Theoretically, older adults who characterize themselves as "old" will find aging stereotypes more relevant and will be more likely to behave consistently with the activated stereotype than those who still characterize themselves as “young” (Shih, Richeson, Ambady, Fujita \& Gray, 2002). The current research will address all these issues by expanding the operational definition of physical performance, including a neutral priming condition, including a pretest, using a standardized dependent measure of physical performance that has been found to be reliable and valid, and expanding recruitment efforts to ensure the sample is more representative of typical community dwelling older adults in the United States.

Past experimental research using implicit priming techniques has been conducted using computers or sentence scrambling tasks to activate stereotypes. These methods are not characteristic of how stereotypes are activated in real life situations. One way stereotypes can be activated in everyday life is by being exposed to objects. Objects hold meanings which symbolize certain values and ideas. The presence of an object representing older adults can activate constructs that are related to it (Kay, Wheeler, Bargh, \& Ross, 2004). The use of objects to activate stereotypes has not been tested in the older adult population. 
Age, gender, socioeconomic status, race, education, and social support are all factors which have been found to predict changes in physical performance in community dwelling older adults (Seeman et al., 1994; Sibbritt, Byles, \& Regan, 2007). It is not known if older adults with different demographic characteristics are influenced differently by aging stereotypes. The current study will explore whether sociodemographic factors are associated with amount of change in physical performance after activation of stereotypes.

The purpose of this study was to explore how stereotypes affect physical performance in older adults. Based on past research about the effect of activation of stereotypes on performance, it is expected stereotypes will affect the physical functioning of older adults. A secondary purpose is to explore whether a relationship exists between certain sociodemographic variables and the amount of change in physical performance after exposure to aging stereotypes.

\section{Research Questions}

1. Does implicit activation of positive or negative stereotypes have an effect on the physical performance of older adults?

2. Are age, gender, socioeconomic status, race, education, and perceived social support associated with the amount of change in physical performance after exposure to stereotypes of aging?

\section{Methods}

The participants were community dwelling older adults 65 years of age or older who could ambulate with or without an assistive device for at least 4 meters, could stand 
without upper extremity support, could rise from a chair five times, and could follow directions in English. Exclusion criteria included those with resting oxygen saturation rates $<90 \%$, resting heart rates $<50$ or $>110$ beats per minute, symptomatic postural hypotension, systolic blood pressure $>200 \mathrm{mmHg}$, diastolic blood pressure $>110 \mathrm{mmHg}$, or those with a history of myocardial infarction, percutaneous transluminal coronary angioplasty, or coronary artery bypass surgery within the past 3 months. Physical activity may be contraindicated with these conditions and physical activity was required to complete the dependent measures. The sample was a convenience sample of 96 seniors recruited from Upstate New York.

A multigroup pretest post test design was utilized to determine whether implicit activation of positive or negative stereotypes have an effect on physical performance. The independent variable was the type of stereotype activation. Standard measures included in physical therapy assessment of functioning are gait speed as measured by the $4 \mathrm{~m}$ walk test; standing balance as measured side-by-side, semi-tandem, and tandem stance; and lower extremity muscle performance as measured by a chair stand test. These are all components of the Short Physical Performance Battery (SPPB). The control variable was self-relevance which will be measured using the Cognitive Age Scale.

Baseline measures of all outcome variables were taken. Participants were then randomly assigned to one of three groups: activation of positive stereotypes, activation of negative stereotypes, or a control condition. Participants were primed with objects representing positive stereotypes of aging, negative stereotypes of aging, or a neutral condition depending upon which group they were assigned. Post test measures of gait 
speed, standing balance, and lower extremity muscle performance were then retested. To determine whether there is a difference between the three groups on the three outcome measures, MANCOVA was utilized with self-relevance as the covariate. A secondary analysis to determine whether certain demographic factors are associated with the amount of change in physical performance utilized a multiple regression analysis.

\section{Significance of the Study}

Older adult self-stereotypes may influence their capacity to achieve high functional status and thus, maintain good health. Since a decline in function in older adults can result in increased costs to society and a decrease in quality of life, it is important to identify any factors that contribute to this decline. If stereotypes have an effect on physical performance, some decline may be prevented by minimizing their effect.

This concept is especially important for physical therapists as most physical therapists do end up working with older adults at some point in their careers. Therapists are responsible for testing physical performance in this population and they need to be aware if stereotypes elicited by implicit means can affect how older adults perform. If stereotype activation does have an effect in the expected direction, education and training will be necessary for both physical therapists and older adults themselves to increase knowledge about the effects of stereotypes on older adults if they are not controlled. If older adults become self aware about the effects of implicit stereotypes, the effect on behavior can potentially be reversed. Further research will then be necessary to address how the effects of stereotypes can be minimized in the older adult population so that physical therapists can work on minimizing these effects. In the race and gender 
stereotype literature, it has been found that giving counterstereotypic information can help people monitor when their stereotypes are activated and control their response to it (Blair \& Banaji, 1996; Aronson, Quinn, \& Spencer 1998).

\section{Delimitations}

1. The data collection for the study will take place between March and July 2009.

2. The location of the study will only take place in cities and towns of Upstate New York.

3. The sample of the study will only include community dwelling older adults.

4. The study will include only those older adults who match the selection criteria.

5. The operational definition of physical performance is limited to three components: gait speed, standing balance, and lower extremity muscle performance.

6. The sample includes only participants who self select themselves.

7. In this study, extraneous factors which are controlled are limited to self-relevance, age, gender, socioeconomic status, race, education and perceived social support.

8. This study evaluates only the effects of stereotypes in the immediate short term.

\section{Definition of Terms}

1. Older adult: Chronological age of 65 years or older at the time of the study.

2. Implicit activation of stereotypes: For the purpose of this study, the participants were aware of the objects used as primes but did not realize their potential influence on their performance on the dependent measure. 
3. Activation of positive stereotypes: Priming stereotypes with use of objects that represent positive views of aging.

4. Activation of negative stereotypes: Priming stereotypes with use of objects that represent negative views of aging.

5. Neutral condition: Priming stereotypes with use of objects which do not represent any views of aging.

6. Physical performance: For the purpose of this study, physical performance was defined as the older adults' performance on the three components of the SPPB.

A. Gait speed: The time it took to walk 4 meters (seconds).

B. Balance: The time the older adult was able to maintain side-by-side, semitandem, or tandem stance (seconds).

C. Lower extremity muscle performance: The time it took to stand up from a standard straight back chair five times while arms were folded across the chest (seconds).

7. Self-relevance: For the purpose of this study, self-relevance was defined as the score on the Cognitive Age Scale.

8. Perceived social supports: For the purpose of this study, perceived social support was defined as the score on the Multidimensional Scale of Perceived Social Support.

\section{Organization of the Remaining Chapters}

The remainder of the dissertation is organized into five chapters, a reference list, and appendixes. Chapter Two presents a review of the literature dealing with the effects of 
stereotypes on behavior. Chapter Three describes the methodology of the study and includes the research design, population and sample, sampling procedures, instrumentation, data collection procedures, data analysis, and limitations. Chapter Four will provide an analysis of the data and Chapter Five will include a discussion of the findings, conclusions, and recommendations. 


\section{CHAPTER 2: REVIEW OF THE LITERATURE}

Chapter Two provides an overview of the literature on the effects of stereotypes on behavior. This chapter will include information about the demographics and trends of the older adult population, stereotypes, physical performance of older adults, Ideomotor theory and also present gaps in the literature.

Demographics and Trends of the Older Adult Population

The number of older adults in the United States is expected to significantly increase when the first of the Baby Boomer generation reaches age 65 in the year 2011. At that point and extending to the year 2025, the annual rate of growth of those over 65 years of age is expected to be three to four times greater than those under 65 (U. S. Census Bureau, 2003). In addition to the influx of the Baby Boomer generation, older adults are living longer as a result of improved living conditions and advances in science and technology (Rice \& Fineman, 2004). In 1998, average life expectancy in the United States was 76 years of age and it is expected to increase to 86 years by the year 2070 (Lee \& Tuljapurkar, 1998; Yang, Norton, \& Stearns, 2003).

The prevalence of disability in the older adult population has declined since the 1980's due to improvements in medical care, improvements in health behavior, a decline in poverty, less exposure to infectious diseases, and an increase in social supports. Disability in this population has decreased $0.26 \%$ per year from 1982 to $1989,0.38 \%$ per 
year from 1989 to 1994, and 0.56\% per year from 1994 to 1999 (Manton \& Gu, 2001). It has been estimated that $\$ 17.3$ billion in nursing home costs have been saved due to declining disability rates (Manton, Corder, \& Stallard, 1997).

Yet, even with the decline in disability, the sheer increase in numbers is predicted to have a huge impact on the use of the health care system. Disability generally increases with age (Sibbritt et al., 2007; Atkinson et al., 2007) and is associated with an increase in number of hospital admissions, outpatient services, home health care, and skilled nursing care (Chan et al., 2002; Mor et al., 1994; Wolinsky, Callahan, Fitzgerald, \& Johnson, 1993; Wolinsky \& Johnson, 1991). It is estimated that health care for older adults will consume $10 \%$ of the gross national product by the year 2020 when in comparison, it consumed only $4.3 \%$ in 1995 (Fuchs, 1999). There is also evidence to suggest that the Baby Boomer generation uses medical services at a rate higher than previous generations when they were the same age (Shactman, Altman, Eilat, Thorpe, \& Doonan, 2003).

Delaying the onset of functional decline and disability can positively impact health care costs and improve quality of life in the older population. Those older adults who remain functionally dependent or who decline from being independent to requiring assistance in one activity of daily living (ADL) spend approximately $\$ 10,000$ more over a two year period than those who remain independent in ADL's (Fried, Bradley, Williams, \& Tinetti, 2001). Even modest decreases in functional performance are associated with higher hospital costs (Reuben et al., 2004).

Factors which reduce the risk of functional decline include engagement in social activities (Everard et al., 2000; Unger et al., 1997), social supports (Seeman et al., 1995; 
Sibbritt et al., 2007; Uchino et al., 1996), engagement in physical activity (Everard et al., 2000; Seeman et al., 1995), certain psychological traits (Rowe \& Kahn, 1997) and certain sociodemographic variables (Seeman, 1994). Another psychosocial factor which can contribute to functional status of older persons is the effect of stereotypes.

\section{Stereotypes}

Lippman introduced the concept of stereotypes and described stereotypes as pictures we have in our heads about other groups (Lippman, 1922). In the 1950's, Gordon Allport (1954) redefined stereotypes as "generalizations about the shared attributes of a group of people." Stereotypes are consistent with someone's knowledge of a group, beliefs about a group, and expectancies about how members of a group will behave. Stereotypes can be positive or negative and are acquired through personal contact with members of a social group or learned through culture. This information is stored in memory and is automatically retrieved when needed (Sherman, 1996).

Stereotypes are prevalent about many different groups in our society including those based on ethnicity/race (Rowley, Kurtz-Costes, Mistry, \& Feagans, 2007), gender (Oswald \& Lindstedt, 2006), weight (Tiggemann \& Rothblum, 1988), sexual orientation (Madon, 1997), physical attractiveness (Romano \& Bordieri, 1989), socioeconomic status (Howard \& Pike, 1986), and age (Hummert, Garstka, Shaner, \& Strahm, 1994). It has been hypothesized that stereotypes have both automatic and controlled process components which assist in the evaluation of other people (Cunnigham, Johnson, Gatenby, Gore, \& Banaji, 2003; Cunnigham et al., 2004). The automatic component is a quick response to the immediate environment. It can operate without conscious 
awareness (Cunnigham et al., 2004) and can be activated from memory by the mere presence of an object (Chen \& Bargh, 1997; Dovidio, Kawakami, Johnson, Johnson, \& Howard, 1997; Fazio, 1986). Those traits that are well learned are the ones that are easily accessible from memory and are more likely to be activated. The main purpose of automatic evaluation is to judge whether a person is on a positive or negative dimension. Automatic components of stereotypes are the basis of implicit stereotyping (Fazio, 1986).

The controlled process component of stereotypes requires active attention and reflection on part of the perceiver in order to weigh all the positive and negative information available (Fazio, 1986). Controlled processes are much more complex than automatic components and are the basis for explicit stereotypes. Automatic components of stereotypes make quick judgments and then more controlled processes take over to make accurate judgments (Cunnigham et al., 2003). As an example, the first response when first meeting an older person is to automatically assume they are slow. If the perceiver is motivated and able, they will use more controlled processes as they take in all available information in order to make a more accurate judgment about whether the older person is slow or not.

It is hypothesized that implicit and explicit components of stereotypes are not associated with each other and that they operate independently (Greenwald, McGhee, \& Schwartz, 1998; Karpinski \& Hilton, 2001). Younger adults rate older adults favorable on explicit measures but not on implicit measures (Dasgupta \& Greenwald, 2001). People can be implicitly aware of cultural stereotypes but either not believe them or are able to 
control them in order to be politically correct so they measure differently on explicit measures (Arkes \& Tetlock, 2004).

The main purpose of stereotyping is to improve "cognitive efficiency" by simplifying and organizing our complex social environment. Categorizing someone into a particular social group gives the perceiver information without much cognitive cost (Macrae, Milne, \& Bodenhausen, 1994). The perceiver then does not need to spend time paying attention to every detail about each individual person and more time and energy can be devoted to other mental activities (Allport, 1954; Macrae et al., 1994). People would not be able to function effectively if every mental process was consciously controlled (Norretranders, 1998). In fact, it has been estimated that mental processes are only consciously controlled 5\% of the time (Baumeister, Bratslavsky, Muraven, \& Tice, 1998).

Stereotypes simplify social judgments and are one of the most fundamental psychological events that decide the course of social interactions (Banaji, Hardin, \& Rothman, 1993). People stereotype due to the unfamiliarity of social situations. By using stereotypes, the perceiver relies on previously stored information that is readily made available and can make decisions about a person quickly by placing them into a category that is familiar. This allows them to fill in information (Aronson \& Steele, 2005) or infer personality traits without paying much attention to individual behavior (Brewer, 1988; Fiske \& Neuberg, 1990).

It does not matter whether stereotypes are positive or negative; they give us a narrow view of what members of a certain social category are like since they overgeneralize and 
do not take into account individual differences (Aronson \& Steele, 2005; Judd, Ryan, \& Park, 1991; Palmore, 1990). Stereotypes can be inaccurate in three ways (Judd \& Park, 1993). First, stereotypes can be false. One stereotype of older adults is that "old dogs cannot learn new tricks". Research has shown that older adults can learn well into old age and it is possible for them to "learn new tricks" (Bennett \& Howard, 2007; Seidler, 2007). Second, even though stereotypes can be based on true depictions, these depictions are often exaggerated. For example, it is true that older adults on average walk slower than younger adults, but it is often overstated how slowly they actually walk. Third, a stereotype can be accurate, but the variability of the group is underestimated. For example, it may be thought that all older adults are slow when in fact there is a wide range in their actual gait speed (Shumway-Cook et al., 2006).

Stereotypes are the cognitive component of prejudice (Brown, 1995). They influence the behavior of individuals toward stereotyped groups (Barta-Kvitek, Shaver, Blood, \& Shepard, 1986; Horowitz, Savino, \& Krauss, 1999; Rohan, Berkman, Walker, \& Holmes, 1994) and have implications for policy making (Judd \& Park, 1993). People tend to make judgments based on stereotypes and how they evaluate stereotypes about a group determines their attitude (Stephan, Ageyev, Coates-Shrider, Stephan, \& Abalakina, 1994). If the beliefs about a group are generally favorable, then attitudes will be positive and if those beliefs are generally negative, then attitudes will be negative. Attitudes will influence how someone intends to behave toward an individual and intention will determine how they do behave toward a group (Fishbein \& Ajzen, 1980). If stereotypes are generally negative about a group, it can fuel the "isms" and result in prejudice. 
In addition to influencing the behavior of others, recent research shows that stereotypes can harm members of the population they represent. There is a growing amount of evidence which suggests that stereotypes are internalized to become selfstereotypes and result in stereotypical behavior (Hausdorff et al., 1999; Levy, 1996; Levy, 2003; Levy, 2000; Levy et al., 2002).

\section{Older Adult Stereotypes}

Interestingly, age stereotypes differ from stereotypes about any other group (i.e. race, gender). At some point in time everyone will progress from being a member of the young category to the older category if they are fortunate enough to survive that long. This is not true of most stereotyped groups (Hummert et al., 1994).

Research has shown that stereotypes about older adults tend to be both positive and negative even though the negative ones are more common in Western cultures (Hummert et al., 1994; Kite et al., 2005; Levy, Kasl, \& Gill, 2004; Nemmers, 2004; Palmore, 1990, 1999). Table 1 shows examples of positive and negative stereotypes related to older adults.

Most research has outlined single stereotypes, but several studies have proposed that people tend to have various stereotypes about different types of older adults. The supercategory of "older adult" has several positive and negative sub-categories (Chasteen, Schwartz, \& Park, 2002; Hummert, 1990; Hummert et al., 1994; Schmidt \& Boland, 1986).

Hummert (1990) found that younger adults categorized older adults into seven negative subcategories and three positive subcategories. The negative sub categories are 
Table 1. Positive and Negative Stereotypes of Older Adults

\begin{tabular}{lll}
\hline Positive Stereotypes & Negative Stereotypes & Author \\
\hline $\begin{array}{l}\text { Kindness, wisdom, } \\
\text { dependability, affluence, } \\
\text { political power, }\end{array}$ & $\begin{array}{l}\text { Illness, impotency, } \\
\text { ugliness, mental decline, } \\
\text { freedom, eternal youth, } \\
\text { happiness }\end{array}$ & $\begin{array}{l}\text { mental illness, } \\
\text { uselessness, isolation, } \\
\text { poverty, depression }\end{array}$ \\
\hline $\begin{array}{l}\text { Experienced, wise, sage, } \\
\text { sentimental, generous, } \\
\text { patient, cautious, }\end{array}$ & $\begin{array}{l}\text { Senile, forgetful, fragile, } \\
\text { feeble, tired, neglected, }\end{array}$ \\
$\begin{array}{l}\text { learned, knowledge, able } \\
\text { practical, mature }\end{array}$ & lonely, helpless \\
\hline & $\begin{array}{l}\text { Ill, disabled, senile, } \\
\text { depressed, lonely, }\end{array}$ \\
& $\begin{array}{l}\text { grouchy, sexless, boring, } \\
\text { lack vitality, loss of } \\
\text { vigor, inevitable decline, }\end{array}$ \\
& $\begin{array}{l}\text { unable to learn or } \\
\text { change, unproductive }\end{array}$ \\
\hline Not competent & Cuddy, 2005 \\
\hline
\end{tabular}

severely impaired (i.e. forgetful, sick), shrew/curmudgeon (i.e. miserly, complaining), despondent (i.e. useless, sad), self-centered (i.e. prejudiced, greedy), vulnerable (i.e. poor driver, victim of crime), inflexible senior citizen (i.e. set in ways), and recluse (i.e. fixed income, live in past). The positive sub categories are John Wayne conservative (i.e. conservative, tells stories about the past), liberal matriarch/patriarch (i.e. patriotic, distinguished looking), and perfect grandparent (i.e. wise, volunteer). Older adults over the age of 75 were evaluated more negatively than those under the age of 75 which is consistent with other studies in the literature (Hummert, 1990; Hummert, Garstka, \& Shaner, 1997; Hummert, Garstka, Shaner, \& Strahm et al., 1995). 
Hummert, Garstka, Shaner, and Strahm (1994) extended the 1990 study to determine whether young adults, middle aged adults, and older adults all hold similar stereotypes about older adults. They found that all three populations had similar stereotypes about older adults except that older adults had more complex groupings of traits than the younger and middle-aged adults. In addition, middle-aged adults had more complex groupings than younger adults. Young adults developed the same categories as the 1990 group except they developed a Golden Ager subcategory (i.e. sociable, well traveled). The middle-aged adults added a positive sub category of liberal matriarch/patriarch (i.e. liberal, wealthy) and the negative subcategory of mildly impaired (i.e. forgetful, slow moving) and self-centered (i.e. greedy, snobbish). Older adults had even more complex views in that they added a positive subcategory of activist (i.e. political, liberal) and small town neighbor (i.e. old fashioned, conservative) and a negative sub category of elitist (i.e. prejudiced, snobby).

The fact that older adults have more complex stereotypes is consistent with other research that shows that people tend to have more complex representations about their own in-groups than out-groups (Brewer \& Lui, 1984). Another explanation for these results is that as people age, they have more experience in dealing with older adults so they develop more varied and true to life ideas of what being an older adult really is like (Hummert et al., 1997). Hummert's (1994) findings that both younger and older adults share similar stereotypes is consistent with other studies in the literature (Chasteen et al., 2002; Madey \& Chasteen, 2004). 
It is important to note that most research on stereotypes has clumped all older adults into one group. It is critical to remember that the older population is comprised of different groups within their own population: male/female, African American/White/ Asian/Indian, heterosexual/homosexual, upper/middle/lower class, and stereotypes within the older population may vary (Feldman, 1999). For example, older women are considered more wrinkled and more active in the community as compared to older men (Kite, Deaux, \& Miele, 1991) and older men elicit more positive stereotypes than older women except at the old-old ages (Hummert et al., 1997). Stereotypes are multidimensional.

\section{Formation of Stereotypes}

Stereotype formation is a developmental process that begins at an early age and builds as a child's thought processes and cognition matures. Children first perceive differences between groups and once these differences are realized, they begin to associate specific traits or attributes to those groups. By the age of four, children are able to categorize people based on visual traits and what they hear in everyday language (Isaacs \& Bearison, 1986). By the age of six, some children are broadly aware of specific stereotypes and by the age of ten, $93 \%$ of children are aware of specific stereotypes (McKown \& Weinstein, 2003). Children from stigmatized groups are aware of stereotypes at an even earlier age (McKown \& Weinstein, 2003).

As children mature, their earlier images of social groups become more refined and may change. The development of stereotypes depends on the beliefs of their culture, the importance that adults place on them, direct contact with the stereotyped group, and the 
media. Children automatically and implicitly acquire information about social groups from the environment (Bigler \& Liben, 2006).

One way stereotypes are continually activated is by being exposed to images through language, humor, advertisement, literature, television, motion pictures, and greeting cards (Palmore, 1999; Thornton, 2002). The English language uses many words and phrases to describe older adults in a negative light. These include "over the hill", "dirty old man", “old fart”, “old bat”, “little old lady”, “fuddy-duddy”, “geezer”, “old maid”, “oldfashioned", and "spinster" (Nuessel, 1982; Nuessel, 1984/1985) . One study found that only $3.5 \%$ of the 4,200 jokes analyzed were about older adults and the jokes in general portrayed them with declining mental abilities, physical abilities, and appearance (Bowd, 2003). Advertisements in "Time" and "Newsweek" magazines depicted older adults as passive or dependent (McConatha, Schnell, \& McKenna, 1999).

In motion pictures, older adults are represented as less friendly, less romantically involved, and as experiencing less positive outcomes than those who are younger. In addition, older women are more stereotyped than older men and are less likely to have goals (Lauzen \& Dozier, 2005). Most birthday cards contain negative images of aging which depict older adults as physically and cognitively declining and there is nothing to look forward to since life is over (Ellis \& Morrison, 2005).

Older adults are often not portrayed in popular culture which implies they do not exist or are not important enough for respect and attention (Zhang et al., 2006). An analysis of advertisements from "Life" and "Ebony" magazines found older adults were portrayed in only .9\% of the advertisements in "Life" and $1.3 \%$ of the advertisements in "Ebony" 
(Bramlett-Soloman \& Subramanian, 1999). Only 8.1\% of advertisements in "Time" and "Newsweek" magazines contained older adults and older women were even more underrepresented than older men (McConatha et al., 1999). They are also underrepresented during prime time on the major network television shows in that they only represent $3 \%$ of the television population (Harwood \& Anderson, 2002). When older adults do appear in ads, they are being portrayed in a positive light but not in as much a positive light as younger adults (Miller, Leyell, \& Mazachek, 2004).

Older adults are portrayed in a positive light in television commercials, but continue to be underrepresented (Miller et al., 2004; Roy \& Harwood, 1997) and portrayed less favorable than younger adults (Peterson \& Ross, 1997). Men are portrayed more than women and older adults of different ethnic groups are almost non-existent in both television ads and programming (Harwood \& Anderson, 2002; Roy \& Harwood, 1997).

Even though older adults are often portrayed in a positive way in the media, the products and services being advertised are often health related which can result in an association of aging and ill health (Raman, Harwood, Weis, Anderson, \& Miller, 2006). It has also been found that the themes represented in the media featuring older adults is limited to representing them as the "Productive Golden Ager" or the "Perfect Grandparent" implying that they are a homogenous population which they are not (Zhang \& Agard, 2004). It has been suggested that the portrayal of older adults in the media should be age incidental in that the age of the character has "little bearing on the purpose of the advertisement" (Zhang et al., 2006). 
In addition, children have limited exposure to older adults, especially outside their own family (Hagestad \& Uhlenberg, 2005). In modern Western cultures, people of different ages tend to be segregated from each other institutionally and spatially. Institutional segregation occurs when an institution includes age criterion for eligibility. Children spend most of the day in school with people who are mostly their age; adults spend their day with other adults; and older people are often excluded from both work and school settings. Spatial age segregation occurs when older and younger adults cannot interact face-to-face since they do not occupy the same space (Hagestad \& Uhlenberg, 2005). About $15 \%$ of older adults live in highly segregated environments like nursing homes and retirement communities (Shafer, 2000).

Children tend to have the most contact with older adults who are family members. However, the number of three generational families living together has decreased in the last century and older adults are less likely to live with their grandchildren (Hagestad \& Uhlenberg, 2005). In our highly mobile society, grandparents often live far away and the opportunity for intergenerational contact is limited. Divorce can sever ties between children and their grandparents. Age segregation is now common in American housing with many retirement communities emerging in the past 30 years (Palmore, 1999).

When separated from older adults, children are more likely to develop stereotypes since they assume they are separate because they are different (Bigler \& Liben, 2006). Separation also lessens the opportunity for intergenerational contact which is important in forming across-age relationships to decrease stereotypes and challenge the notion that all older adults are the same (Hagestad \& Uhlenberg, 2005). There is also a problem with 
family members being the main contact with older adults. People often view family members as less stereotypical than other older adults (Newman, Faux, \& Larimer, 1997) so they tend to view family members as exceptions to the rule and are still able to maintain stereotypes about other older adults.

The development of the content and accuracy of stereotypes can depend on the amount of information someone has about a group. People with little information still develop stereotypes and are confident in them (Clow \& Esses, 2005). When the media, children's books, jokes, and our experiences give us a limited view of older adults, it is difficult to fully understand the extreme heterogeneity of their population. Complete information is vital to ensure people have accurate views.

Even though stereotypes become more complex and include more subgroups as we age (Hummert et al., 1994), the basic core elements which were learned in childhood are maintained. These basic stereotypes are difficult to change. People tend to remember stereotype-consistent information and forget information that contradicts what they have learned. When counter-stereotypic information is remembered, people tend to place that older adult in a separate subcategory (Bigler \& Liben, 2006; Nelson, 2002) or offer an explanation for the inconsistent behavior (Kunda \& Oleson, 1995). Formation of a subgroup allows one to isolate the older adult from the rest of the group (Yzerbyt, Rocher, \& Schadron, 1997) and offering an explanation for the behavior gives an excuse for the inconsistency (Kunda \& Oleson, 1995). Both options allow the perceiver to maintain their basic stereotypes even though the evidence points in a different direction. 
These strategies also prevent accurate representation of the heterogeneity of the older adult population.

Another way stereotypes are maintained is through interpersonal communication. People tend to pass along stereotype-consistent information but not stereotypeinconsistent information (Harasty, 1997). Receiving stereotype-consistent information strengthens the belief in the stereotype since repetitive exposure increases the associative link and makes it less likely that someone will change their way of thinking (Lyons \& Kashima, 2003). In adulthood, those stereotypes which were formed in childhood are deeper and more well ingrained than those developed more recently (Devine, 1989).

\section{Internalization of Aging Stereotypes}

The encoding of aging stereotypes is unique when compared to race and gender stereotypes. Aging stereotypes are well learned before they are self-relevant since people learn about them before they become old. The lack of self-relevance makes it more likely that the stereotypes are encoded without question (Chanowitz \& Langer, 1981; Giles, Fox, \& Smith, 1993; Levy \& Langer, 1994; Nelson, 2002). As an individual ages, these aging stereotypes are internalized without awareness and become aging self-stereotypes (Levy, 2003; Perdue \& Gurtman, 1990). There is a relationship between the previously encoded aging stereotypes and aging self-stereotypes (Nosek, Banaji, \& Greenwald, 2002).

It has been theorized that the internalization of aging stereotypes occurs in two stages. First, someone becomes a member of the older adult age group when they reach the age that is defined by society as old. At first many people do not identify with this age group 
and it often takes time for them to do so. The amount of time it takes depends on the stereotypes they possess. The more negative the stereotypes, the more resistant they are to becoming members of the older adult age group (Levy \& Banaji, 2002). The constant reminders through the environment gradually break down the barrier of denial and during the second stage of internalization people eventually self define themselves as "old".

There is evidence to support the idea of internalization. Rothermund (2003) describes part of a longitudinal study in which participants between the ages of 54 and 77 were evaluated on how they view themselves and a typical older person on a semantic differential scale. The subjects then completed the same scale eight years later. The results showed that those who initially evaluated the typical older person more negatively rated themselves more negatively after eight years than those who initially rated the typical older adult more positively.

\section{Effect of Aging Stereotypes on Behavior}

It has been suggested that these aging self-stereotypes can result in stereotypical behavior (Hausdorff et al., 1999; Levy, 1996; Levy, 2003; Levy, 2000; Levy, Slade, Kunkel, \& Kasl, 2002b). If an older adult has internalized the belief that there is inevitable and severe physical and cognitive decline as one ages, that person may be more likely to develop a disability even if there is no biological reason for them to do so. Golub, Filipowica, and Langer (2002) illustrate this with an example; a grandfather and granddaughter both develop low back pain after gardening. The grandfather attributes his pain to arthritis and getting older. Even though the granddaughter develops the exact same pain, she attributes her pain to hours of weeding in the garden. This can be 
counterproductive since older adults often attribute symptoms to getting old and do not seek proper medical treatment for their problem. It is theorized that internalization may influence the amount of effort or strategies the older adults use to complete a behavior (Levy \& Langer, 1994).

Levy and Langer (1994) studied the effect of aging stereotypes on memory in different cultures. Participants were a group of younger and older adults from mainstream China, the American Deaf population, and mainstream America. Results showed that the older Chinese group, who had the most positive stereotypes on aging, performed best on all memory tasks, while the mainstream America participants, who had the most negative stereotypes on aging, performed the worst. There was no difference among the three groups of younger participants. The authors suggested that memory decline could have a social and psychological component. A limitation of this study is the use of pre-existing groups which limits the interpretation of cause and effect.

Yoon, Hasher, Feinberg, Rahhal, and Wincour (2000) completed a similar crosscultural project using a sample of mainstream Canadians and recently emigrated Chinese Canadians to study the effects of aging stereotypes on memory. While Chinese Canadians did have more positive views of aging, no significant findings between positive views and memory were found. These results are contrary to the Levy and Langer (1994) study. Even though Chinese Canadians had more positive views on aging than mainstream Canadians, the differences may not have been as great as the difference between the Chinese and Americans in the Levy and Langer (1994) study. This may be why the results of the two studies differ. 
Levy (1996) conducted two experiments to investigate whether implicit and explicit activation of stereotypes has an effect on memory in older adults. Implicit activation of positive stereotypes improved memory on one of the memory tests while implicit activation of negative stereotypes decreased performance on two of the memory tests. There was no influence of explicit activation of stereotypes on any of the memory tests.

In the second experiment, Levy (1996) evaluated the effect of implicit stereotype activation on younger subjects and found that activation of implicit stereotypes did not influence cognitive performance. From the results of the two experiments, Levy (1996) concluded that activation of negative stereotypes can decrease memory recall while activation of positive stereotypes can improve memory in older but not younger subjects. In order for stereotype activation to cause a change in behavior, the stereotype has to be personally relevant. Stereotypes about aging are specific to the older adults which is why there was a change in the older but not the younger group. The authors also reported that activation of stereotypes needs to be implicit to affect performance.

Another interesting finding from the two experiments described above is that both older and younger subjects took longer to respond to positive stereotypes than negative stereotypes. The authors hypothesized that positive images are less familiar and congruent with the image of older adults so it takes longer to react to them. These findings are consistent with other studies (Brewer \& Lui, 1984; Hess et al., 2003; Hummert, 1990; Perdue \& Gurtmen, 1990).

Stein, Blanchard-Fields, and Hertzog (2002) replicated the Levy (1996) study but included implicit activation of stereotypes only and added a neutral priming condition. 
Older adults who were primed with negative stereotypes did poorer on one memory task while those in the positive and neutral conditions showed no change. There was no effect in the younger group. These findings are not consistent with what Levy (1996) found and methodological differences could account for this result. Stein et al. (2002) excluded 20 younger and 32 older subjects since they were able to identify words as they flashed across the screen. It is generally thought that if more than $5 \%$ of participants can identify a prime, it is possible that the whole sample may have some awareness of the prime (Bargh \& Chartrand, 2002). If this is the case than these authors were priming the subjects explicitly, negating the implicit condition which could account for the inconsistency.

Hess, Auman, Colcombe, and Rahhal (2003) studied the effect of explicit activation of positive and negative stereotypes on memory performance in a group of older and younger adults who were randomly assigned to either a positive, negative, or control condition. When exposed to negative stereotypes, older participants performed worse on the memory task than those exposed to positive stereotypes and those in the control condition. There was no change in the younger group. These results differ from that of Levy since they found explicit activation of stereotypes can result in an assimilative change in behavior. Methodological differences between the studies may account for this difference.

Hess, Hinson, and Statham (2004) completed two experiments to determine whether implicit or explicit activation of positive and negative stereotypes has an impact on free recall in older and younger subjects. Older adults who received implicit activation of 
negative stereotypes did not perform as well as those who were implicitly exposed to positive stereotypes. There was no difference in the younger population or with explicit activation of stereotypes. The authors concluded from these two experiments that assimilation of stereotypes occurs more readily in implicit versus explicit activation of stereotypes and that memory decline in older adults should be studied in multidimensional ways.

Most of the research on the effect of stereotype activation on behavior has been conducted on cognitive performance and has shown that stereotypes can influence cognitive performance (Horton, Baker, Pearce, \& Deakin, 2008). The literature on its effect on health decisions, physiological performance, and physical performance is emerging. Levy, Ashman, and Dror (1999-2000) examined the effect of implicit activation of both negative and positive stereotypes on the will to live of older and younger adults. Older adults who were primed with negative stereotypes chose not to extend their lives through treatment when completing a case scenario, while those exposed to positive stereotypes chose life prolonging medical treatment. There was no difference in the younger group. The authors concluded that exposure to negative stereotypes can decrease an older person's will to live. Neither a neutral priming condition nor a pretest was included in this study. It is therefore impossible to determine whether negative stereotypes resulted in negative behavior as compared to normal or whether positive stereotypes resulted in positive behavior as compared to normal.

Two studies were found that evaluated the effect of stereotypes on physiological measures. Levy, Hausdorff, Hencke, and Wei (2000) examined the effects of implicit 
activation of stereotypes on systolic blood pressure, diastolic blood pressure, heart rate, and skin conductance. The group in which negative stereotypes were activated had higher systolic blood pressure, diastolic blood pressure, heart rate, and greater skin impedance up to 26 minutes following the intervention. The authors concluded that implicit activation of stereotypes can influence autonomic response in older adults and that health outcomes can be affected. Again, there was no pretest nor did the study include a neutral priming condition. As a follow up to determine if stereotypes can affect recovery in a real life situation, Levy and Slade (2006) determined that positive self stereotypes predicted physical recovery after acute myocardial infarction.

Two studies have shown that stereotype activation can also affect physical performance. Hausdorff et al. (1999) assessed the effect of stereotype activation on gait speed and swing time in a group of community dwelling older adults. Mean gait speed and swing time improved in the positively primed group but not in the negatively primed group. The authors concluded that positive stereotypes of aging can have an impact on gait but did not give a reason why negative stereotypes did not impact gait. They only looked at gait speed and swing time as a functional measure to define physical performance and did not use a standardized dependent measure.

Levy (2000) evaluated the effect of implicit priming of positive and negative age stereotypes on handwriting of older adults. Those who were negatively primed showed significant changes in the negative direction while those in the positively primed group showed significant changes in the positive direction. 


\section{Stereotype Activation}

Stereotype activation is defined as "the increased accessibility of the constellation of attributes that are believed to characterize members of a given social category" (Wheeler $\&$ Petty, 2001, p. 797). Stereotype activation can either be positive, negative, or a mixture of both (Wheeler \& Petty, 2001). In research on stereotype activation, experimental priming techniques are utilized to experimentally activate what is accessible in memory when a stereotype is presented (Bargh \& Chartrand, 1999; Perdue \& Gurtman, 1990). Priming is defined as "activation of knowledge structures such as traits and stereotypes, by the current situational context" (Bargh, Chen \& Burrows, 1996b, p. 230).

Activation of stereotypes can be primed either implicitly or explicitly (Wheeler \& Petty, 2001). Implicit activation of stereotypes is subtle and below the threshold of conscious awareness. The individual is both unaware that stereotypes are being activated and unaware of its relationship to behavior (Hull, Slone, Meteyer, \& Matthews, 2002). Explicit activation of stereotypes is obvious, and the individual is consciously aware of the stereotype and its potential relevance.

An individual's behavior can be affected differently depending on whether the stereotype is activated implicitly or explicitly, and whether the stereotype is negative or positive (Shih et al., 2002). The resultant behavior can be consistent with the activated stereotype and is called an assimilated effect or it can be inconsistent with the activated stereotype which is called a contrast effect (Wheeler \& Petty, 2001). In a review of the effect of stereotype activation on behavior of people of different gender, race, age, and profession, Wheeler and Petty (2001) found that $80 \%$ of published studies demonstrated 
that individuals assimilated their behavior from the stereotypes. Only $20 \%$ of the studies found a contrast effect and none of the published studies done specifically on aging stereotypes resulted in a contrast effect. They also found that explicit activation of a stereotype could result in either an assimilation or contrast effect but that implicit activation resulted in assimilated effects only.

Since people experience many random priming events throughout the day which implicitly activate stereotypes (Hilton \& Von Hippel, 1996) and since social behavior often works in an implicit way, it has been recommended that research on stereotype activation should include implicit primes and measures (Greenwald \& Banaji, 1995). Implicit activation of stereotypes can occur subliminally or supraliminally. With subliminal activation, the perceiver lacks awareness of the prime (Bargh \& Chartrand, 2002). Subliminal activation is usually accomplished through use of a computer in which stereotypical words are flashed across the screen but cannot be identified by the participant. Using names or images are alternate ways to prime information instead of words. A name tells the person something about the category to be judged without explicitly saying so (Banaji \& Greenwald, 1995). For example, the name "Mildred" can be used to imply "older adult" while the name "Wendy" can be used to imply "young". An image of a person is another way to prime information and some argue the use of pictures is more generalizable and produces more individualized responses (Zebrowitz, Montepare, \& LooLee, 1993). Images have been considered to result in a more personal evaluation (like attitude) instead of measuring stereotypes based on culture (Fazio, Jackson, Dunton, \& Williams, 1995). 
During supraliminal activation, the participant is aware of the priming material but does not realize its potential influence (Bargh \& Chartrand, 2002). The most common way to activate stereotypes supraliminally is through use of scrambled sentence tasks. Participants are presented with five words and are instructed to form a sentence using four of the words. The fifth word is the primer of either a stereotypical or neutral word (Banaji et al., 1993; Bargh \& Chartrand, 2002; Kobayashi, 2004).

Both subliminal and supraliminal priming result in assimilative behavior. It does not matter how the stereotypes are implicitly primed, as long as the perceiver is unaware that they are being primed with a stereotype. Supraliminal priming is a stronger manipulation than subliminal priming (Bargh \& Chartrand, 2002). The effect of a single priming task decreases with time and usually lasts up to an hour (Higgins \& Brendyl, 1995; Srull \& Wyer, 1980) unless that stereotype is activated frequently (Smith, Stewart \& Buttram, 1992).

Use of subliminal computer techniques or scrambled sentence tasks are artificial priming techniques which do not simulate the way primes are actually presented in real life situations. Some authors question if these lab situations can be generalized to the real world (Bargh \& Chartrand, 2002). It has been suggested that the use of common objects may be a better way to prime stereotypes since it is more consistent with what might actually occur in everyday life (Kay et al., 2004).

Objects hold meaning beyond what they look like and how they function (Miller, 1998). They represent values and ideas (Dant, 1999) and over time, can develop implicit meaning that is salient in a society (Graves-Brown, 2000; Miller, 1998). Objects can also 
signify the social group membership of its user (Dant, 1999). The presence of an object can produce increased accessibility of constructs related to it (Kay et al., 2004) and people's behavior can be affected when these cognitive constructs are accessed from memory (Higgins, 1996).

Kay, Wheeler, Bargh, and Ross (2004) combined the work on implicit priming with an anthropological emphasis on material culture to evaluate the effect of implicitly presented material objects on social behavior. This was the first study which investigated whether the mere presence of an everyday object can automatically influence behavior. They found that the presence of objects common in the business world influenced how competitive groups of university students acted under five different conditions. The authors suggest it is important to pay attention to material culture and how objects change the environment in which social interactions occur. A review of the literature to determine which everyday objects symbolize the older adult population resulted in no information.

People can adjust their behavior after being activated by a stereotype if they can perceive it consciously. In fact, the effects of priming on behavior can become reversed if the prime is obvious or becomes blatant (Higgins, 1996). When priming participants experimentally, it is important to make sure that participants are not able to perceive implicit primes. Funneled debriefing is necessary following priming to determine whether anyone has any suspicions about the priming or have made any connections with the primes. If greater than $5 \%$ of the participants are aware of the prime effect, it is likely that many of the others also have some degree of awareness (Chartrand \& Bargh, 1996). 
Factors Which Can Moderate the Stereotype to Behavior Link

There are potentially many factors which can modify the effects of stereotype activation on behavior. The factors include self-focus, self-consciousness, selfmonitoring, and self-relevance. Self-focus is a shift in conscious attention from the environment to one's self and in doing so, self-focused behavior can interfere with automatic actions. When people are focused on themselves, they become aware of other ways to behave and now have other options besides the automatic one (Dijksterhuis \& Knippenberg, 2000). Dijsterhuis and Van Knippenberg (2000) found that increasing selffocus did inhibit the effect of stereotypes on behavior.

Self-consciousness is awareness of one's actions or thoughts and is hypothesized to increase the tendency for one to encode information that is self-relevant (Hull et al., 2002). Hull, Slone, Meteyer, and Matthews (2002) found that differences in someone's self-consciousness can moderate the effect of stereotypical primes on behavior.

Self-monitoring is the ability to control one's behavior dependent on how best it will be best perceived socially. People who are high self-monitors are more likely to change their behavior based on public image (Inzlicht, Aronson, Good, \& McKay, 2006). Inzlicht, Aronson, Good, and McKay (2006) found that self-monitoring can play a role in moderating the effect of stereotypes on behavior and that people who are high selfmonitors are more resilient to the effects of stereotypes.

Self-relevance is how applicable the stereotype is to one's individual identity. People tend to process information that is more self-relevant since they see themselves as the main focus in the environment. Self-relevant information is perceived easier and quicker 
than non-relevant information, resulting in a lower sensitivity threshold for activation which then facilitates processing (Greenwald, 1980; Shih et al., 2002). Lower attentional thresholds allow the words to become more highly accessible in memory and make it more likely that information will be used. It has been theorized that the same holds true of the effect of stereotypes on behavior. If the stereotype is self-relevant, people are more sensitive to the activated stereotype which strengthens the association with behavior and makes it more likely that people will respond in a stereotype-consistent manner (Shih et al., 2002). If the stereotype is not self-relevant, people have a higher threshold for stereotype activation and behavior is less likely to be affected. In order for a prime to influence processing, it must be applicable to the target and processed as self-relevant (Dijksterhuis \& Bargh, 2001; Hull, 2002; Wheeler et al., 2001).

Research supports that self-relevance has a role in the perception to behavior link. The effect of priming has been found to be stronger in those for whom it is self-relevant. Levy (1996) found that age stereotypes had no effect on younger adults but did have an effect on older adults. O'Brien and Hummert (2006) found that memory performance was affected by stereotype activation only with those who identified themselves as old.

People have generalized perceptions about themselves which include traits that are personally important and self-defining (Montepare \& Clements, 2001). Research has shown that both younger and older persons have perceptions of themselves regarding their age. Older adults do not self identify and resist categorizing themselves into the older category both implicitly and explicitly (Levy \& Banaji, 2002). There is a tendency for older adults to deny membership in their own age group and many report feeling 
younger than their chronological age. Research has shown that $53-80 \%$ of older adults perceive themselves younger than their age, $29-45 \%$ the same as their age, and $2-8 \%$ older than their age (Baum \& Boxley, 1983; Hubley \& Hultsch, 1996; Uotinen, Rantanen, Suutama, \& Ruoppila, 2006).

One reason why older adult dissociate themselves from the "old" category is to avoid identifying with a group which is associated with so many negative stereotypes (Celejewski \& Dion, 1998). Second, people have individuating information about themselves and research has shown that people are less likely to apply stereotypes when they have individuating information about someone (Kite \& Johnson, 1988). When people disassociate themselves from the older age group, aging stereotypes are not selfrelevant which may protect them against stereotype-consistent behavior (Celejewski \& Dion, 1998).

\section{Physical Performance of the Older Adult Population}

The normal aging process in conjunction with disuse, chronic disease, and psychosocial issues places the older adult population at risk for developing disabilities. Forty percent of those who are disabled are over the age of 65 and disability rates are even higher in those over the age of 85 (Lewis \& Bottomly, 2008). Although there are physical, psychological, and social changes associated with normal aging, normal aging is not necessarily a period fraught with disability. There are many older adults who remain independent in ADL's and independent activities of daily living (IADL's). The older adult population is extremely heterogeneous. While there are those who are unable to get out of bed by themselves, there are those that can run marathons. 
Due to the heterogeneity of this population, it is difficult to visualize how any average older adult performs physically. The Federal Interagency Forum on Aging-Related Studies (2008) published a report in an attempt to present a picture of the health and well being of Medicare enrollees over the age of 65 . According to this report, $42 \%$ have limitations in either ADL's (bathing, dressing, eating, transferring, walking, or using the toilet) or IADL's (telephone use, light housework, heavy housework, meal preparation, shopping, or managing money). Twelve percent have limitations in IADL's only, $18 \%$ in 1-2 ADL's, 5\% in 3-4 ADL's, and 3\% in 5-6 ADL's.

Fifteen percent of men and $23 \%$ of women over the age of 65 cannot walk 2-3 blocks; $10 \%$ of older men and $18 \%$ of older women cannot stoop or kneel; $8 \%$ of older men and $23 \%$ of older women are unable to lift 10 pounds; $3 \%$ of older men and $5 \%$ of older women cannot reach overhead; and $1 \%$ of older men and $2 \%$ of older women are unable to write. The percentage of older adults who are unable to complete at least one of these tasks increases as age increases. Fourteen percent of men between the ages of 65 and 74 are unable to perform one of the five tasks, while $38 \%$ over the age of 85 are unable to do so. Twenty-two percent of women between the ages of 65 and 74 are unable to perform one of the five tasks, while $56 \%$ over the age of 85 are unable to do so (Federal Interagency Forum on Aging-Related Statistics, 2008). Approximately 10\% of older adults over the age of 75 lose independence in ADL's every year (Gill, Williams, \& Tinnetti, 1995).

Difficulties in ADL's places one at risk for nursing home placement or at need for services which can be economically and socially expensive (Wolinsky, Callahan, 
Fitzgerald, \& Johnson, 1992). Almost all nursing home residents require assistance with at least one ADL. In 2004, 94\% of nursing home residents required assistance with bathing, $84 \%$ with dressing, $73 \%$ with transfers, $80 \%$ with toileting, and $36 \%$ with eating. In general, those who live in nursing homes require greater assistance than those who live in community housing with services and those who live in community housing with services require more assistance than those living in traditional housing. Ninety four percent of those in long term care facilities have functional limitations, $60 \%$ of those in community housing with services have functional limitations, and only $36 \%$ living at home have functional limitations. The percentage of Medicare enrollees who are in longterm care facilities is $5 \%$, who live in community housing with services is $2 \%$, and who live in traditional housing in 93\% (Federal Interagency Forum on Aging-Related Statistics, 2008).

In addition to being at risk for nursing home placement or in need for services, people with disabilities use more home health services (Branch et al., 1988) and are hospitalized more often (Ferrucci, Guralnik, Pahor, Corti, \& Havlik, 1997). It is estimated that the average American older adult with disability spends \$6,212 per year more that the older adult without disability. In 2000 , the associated increase in health care costs to society was \$42 billion (Janssen, Shepard, Katzmarzyk, \& Roubenoff, 2004). Between 2000 and 2040, it is estimated that the number of older adults receiving home health services will increase from 2.2 million to 5.3 million and those receiving nursing home care will increase from 1.2 million to 2.7 million significantly increasing formal long-term care 
costs (Johnson, Toohey, \& Weiner, 2007). These do not even consider the costs associated with informal caregiving or costs in terms of quality of life.

It has been hypothesized that older adults exhibit a period of preclinical disability where minor impairments are noted but they are still able to function well in ADL's and IADL's. A sign of preclinical disability puts one at risk for functional dependence. Physical performance measures can identify those with preclinical disability (Gill et al., 1995) and these measures can include tests of ambulation, standing balance, and lower extremity muscle performance (Gill et al., 1995; Guralnik, Ferrucci, Simonsick, Salive, \& Wallace, 1995; Guralnik et al., 1993).

Gait speed is often used as a measure of ambulation, side-by-side, semi-tandem, and tandem stance as measures of standing balance, and five chair stands as a measure of lower extremity muscle performance. Average gait speed in the older adult population is $.60-1.15$ m/s (Atkinson et al., 2007; Puthoff \& Nielson, 2007). Average time to complete five chair stands for men between the ages of 60-69 is 12.7 seconds, for women between the ages of $60-69$ is 13.2 seconds, for men between the ages of 70-79 is $13.2-13.4$ seconds, for women between the ages of 70-79 is 14.2-14.4 seconds, for men over 80 is 14.7-15.0 seconds, and for women over 80 is 16.1-16.6 seconds (Guralnik, Simonsick, \& Ferrucci, 1994; Ostchega et al., 2000). Most community dwelling older adults are able to maintain tandem stance for at least 10 seconds (Guralnik et al., 1994).

The Role of Physical Therapy

The benefits of avoiding declines in physical performance are socially and economically enormous. Requiring assistance to perform ADL's can affect quality of life 
in the older adult population (Wilson \& Cleary, 1995). Avoiding disability allows one to stay in the workplace longer, lessens the psychological and economic costs associated with caregiving, and reduces medical spending (MBER Progress Report, 2004). The main goal for health care providers working with older adults is to restore or maintain the highest physical performance possible in order to lessen disability. Physical therapists are one of the most common health care providers who work with older adults to meet this goal.

According to The Guide to Physical Therapist Practice (American Physical Therapy Association, 2001), physical therapists are concerned with improving physical function in those who are injured or ill, as well as preventing functional limitations through health promotion. Disability is not something that is absolutely expected and physical therapists are able to identify risk factors for disability through their evaluations and then work to prevent the disablement process through intervention (American Physical Therapy Association, 2001). Examining and evaluating physical performance and diagnosing functional limitations is a large part of a physical therapist's responsibilities (Lewis \& Bottomly, 2008). Through evaluation, physical therapists are able to identify older adults at risk for functional decline and they commonly use performance measures in order to do so. Once someone is identified at risk for functional decline, a plan of care is developed based on the client's goals. This plan can include education, energy conservation techniques, adaptive equipment, environmental modifications, and direct interventions like therapeutic exercise, endurance exercises, flexibility exercises, balance training, functional training, and interventions to reduce pain (American Physical 
Therapy Association, 2001). Since there are many factors that influence the disablement process, physical therapists must also take into account all biological, demographic, environmental, and psychosocial factors (American Physical Therapy Association, 2001; Verbrugge \& Jette, 1994).

\section{Ideomotor Theory}

The three major theories on stereotypes are the psychodynamic, sociocultural, and social cognitive perspective (Hummert, 1999). The psychodynamic approach was the original stereotype theory and proposes that personality and affective factors are responsible for stereotyping certain groups (Jussim, Manis, Nelson, \& Soffin, 1995). One prominent psychodynamic approach proposes that stereotypes emerge in those with authoritarian personalities (Adorno, Frenkel-Brunswik, Levinson, \& Sanford, 1950). It is believed that people displace their pent up frustrations against their strict and powerful parents onto people who are perceived to be weaker. The sociocultural approach proposes that stereotypes are unconsciously developed through the culture within which one lives and are adopted by all people within that particular culture (Hummert, 1999; MacNeil, Ramos, \& Magafas, 1996). Since they are omnipresent, it is difficult to avoid learning the accepted stereotypes of different groups.

In the mid-1970's, stereotype theory shifted toward social cognition, which is the major theory used in stereotype research today. At this point in time, people who stereotype are no longer considered irrational beings (Henwood, Giles, Coupland, \& Coupland, 1993). Social cognitive theories state that humans perceive, encode, transform, and process information. With regards to stereotyping, humans categorize different types 
of people in their heads (Jones, 1982). Even though stereotypes have a basis in cultural beliefs, stereotypes exist in the cognitive representations of people and are dependent on what is stored in memory. One of these social cognitive theories is ideomotor theory.

\section{Historical Background of Ideomotor Theory}

Ideomotor theory is based on the works of Lotze (1852), Carpenter (1874), and James (1890/1981), which describe how voluntary action occurs as a result of cognitive antecedents. They proposed that voluntary actions are automatically generated as a result of some type of central representation, an image or idea, of the sensory feedback they produce. Every voluntary action produces some type of sensation and an association will develop between the voluntary action and the sensory feedback. This association is then activated in the opposite direction in that the anticipatory sensory image can activate the voluntary action. For example, throwing a boomerang will produce kinesthetic, visual, and perhaps auditory feedback and an association develops between the act of throwing the boomerang and its sensory feedback. This association then develops in the opposite direction in that the image of the sensory feedback will result in a tendency for the action to occur.

The resultant automatically generated action is consistent with the image, unless

conflicting information is present (Baars, 1988). These conflicting images or competing elements can either inhibit an action from occurring or prolong the time before an action takes place (James, 1890/1981).

James (1890/1981) believed the cognitive antecedents of an act are automatic and result from previous learning. He also believed that images are conscious goals which 
result in execution of a movement. They occur by thinking about the anticipatory sensory image of the way someone feels when they accomplish an action.

In the early $20^{\text {th }}$ century, ideomotor theory took a back seat when behaviorism became prominent. Ideomotor theory did not comply with behaviorist thought that voluntary actions are a result of input-output relationships that occur in the outside world.

Behaviorists claim that movement occurs as a result of a sensory stimulus and the thought that an image or idea could initiate movement was not respectable in rigorous behaviorial theory (Knuf, Aschersleben, \& Prinz, 2001; Taylor et al., 1982). In addition, the evidence backing up the ideomotor mechanism at this point in time was based on paranormal mental phenomena like the pendulum swing, spinning table in séances, mind racing, and Saint Vitus’s Dance which were not taken seriously (Knuf et al., 2001). Behaviorists claimed ideomotor theory was a present day version of magic thinking (Prinz, 1987). There were other criticisms of ideomotor theory as it was shown that people are unable to identify images in their head prior to completing a motor act, which contradicts James belief that the images are conscious goals. The production of conscious mental images also takes too much time to trigger voluntary movements (Taylor et al., 1982).

Ideomotor theory found new life in the 1960's when Greenwald (1970b, 1972) extended the theory by suggesting that movement could be influenced by perception and not only by images or ideas. He believed that activation of a central representation could be perceived and not only thought about actively as originally believed by James. Greenwald also termed the phrase "ideomotor compatibility", which is defined as "the extent to which a stimulus corresponds to sensory feedback from its required response" 
(Greenwald, 1972, p. 52). When the central representation resembles sensory feedback from the action, the two are more compatible since highly learned associations are present. There is a "translation" in the nervous system from the perception to the action codes and when the perception and action codes in the nervous system are similar, this transition occurs without much effort (Greenwald \& Shulman, 1973). This concept of ideomotor compatibility explains some of the earlier criticism of the theory. The tendency to produce an act from a perception is the result of overlap in the nervous system so they become active at the same time. This explanation allows ideomotor theory to be conceived as less magical and less mysterious (Knuf et al., 2001).

Greenwald (1970b, 1972) based his concept of ideomotor compatibility on the budding stimulus-response research. When the response and the stimulus triggering that response are compatible, processing time is decreased thereby increasing the speed of the action response. Perceiving the stimulus of an action creates a tendency to carry out that action (Greenwald, 1970b, 1972). When flashing a red light requires a manual response, the response will be quicker when it triggers a red flash than when it triggers a green flash. According to Greenwald (1970b, 1972), the red feedback flash acts as a perceived consequence of the response and since it is similar to the stimulus, it is quicker.

\section{Current Ideomotor Theory}

Current ideomotor theory is consistent with James' (1890/1981) idea that voluntary action is an automatic result of some anticipated mental representation of the intended action and that the action is initiated and controlled by this image. Movements occur as a result of some internally generated goal, not due to stimulation from the environment. 
The mental representation of the intended action and motor output are linked through learning and activation of one will lead to activation of the other. Since they are linked, the only processing required is what is necessary to activate the anticipated mental representation; no processing is required to produce the action itself. Originally, James (1890/1981) was resistant to the idea that mental representations could be below conscious awareness. However, current theory does accept that mental representations can occur subconsciously which explains why people are unable to identify images in their head prior to movement (Baars, 1988). Current theory is also consistent with Greenwald's (1970b, 1972) additions of ideomotor compatibility as well as the concept that voluntary action can be influenced by perceptions, and not only images or ideas. Competing elements, which are events that have the potential to redirect the mental representation of the intended action were originally part of James' theory but are no longer mentioned in the literature today.

The two major components of current ideomotor theory include the mental representation of the intended action, and the action itself (Baars, 1992). The mental representation of the intended action is the mental image of the outcome of an action which is typically visual but can include any auditory, kinesthetic, tactile, gustatory, or olfactory sense. When an action is performed, it results in perceivable sensory effects (visual, auditory, kinesthetic, tactile, gustatory, olfactory) that are directly related to carrying out the action (tactile and/or kinesthetic sensation) or indirectly related at a distance (seeing a light turn on) (Knoblich \& Prinz, 2005). Once coded in the brain, these sensory effects have the potential to become anticipatory mental representations of the 
intended action. Functionally, anticipatory actions are important since we are social animals. It is often more important to know what is going to happen in the future than what occurred in the past or is occurring in the present (Knoblich \& Prinz, 2005). An action is defined as the "goal directed movements that bring about effects in the environment” (Koch, Keller, \& Prinz, 2004, p. 362). The purpose of an action is to perform a specific task.

In humans, the mental representation of the intended action-to-action link is flexible and modifiable. As a result, even though there is a tendency for an action to occur following a mental representation, it will not happen all the time. What ultimately decides the action is the strength of association between the mental representation of the intended action and the action itself as well as the accessibility of the mental representation of the intended action (Norman \& Shallice, 1986).

According to ideomotor theory, the mental representation of the intended action code becomes associated with the motor action code (Knoblich \& Prinz, 2005) and this association occurs through learning (Prinz, 2002). It is possible that any sensory representation can be linked to any action (Prinz, 1990). The degree to which an action is carried out will depend on the similarity between the perception of the action and the action and the amount of learning that has taken place (Knoblich \& Prinz, 2005). The association between the mental representation of the intended action and the action itself can vary in strength depending on usage and importance. The stronger the association, the quicker and more likely an action will take place (Prinz, 1990). Priming research has shown that participants who are presented with primes for nine minutes respond faster 
than those exposed to primes for only two minutes (Dijksterhuis \& Van Knippenbuerg, 1998). In addition, the strength and whether a behavior will take place are dependent on the accessibility of the mental representation of the intended action. The more accessible the representation, the more likely a behavior will occur.

The association between the mental representation of the intended action and the action is bidirectional. It allows behavior to occur through the anticipatory sensory effects (Kunde, Koch, \& Hoffman, 2004) and allows us to predict the consequences of movement (Knoblich \& Prinz, 2005). Figure 1 shows the components and associations of ideomotor theory.

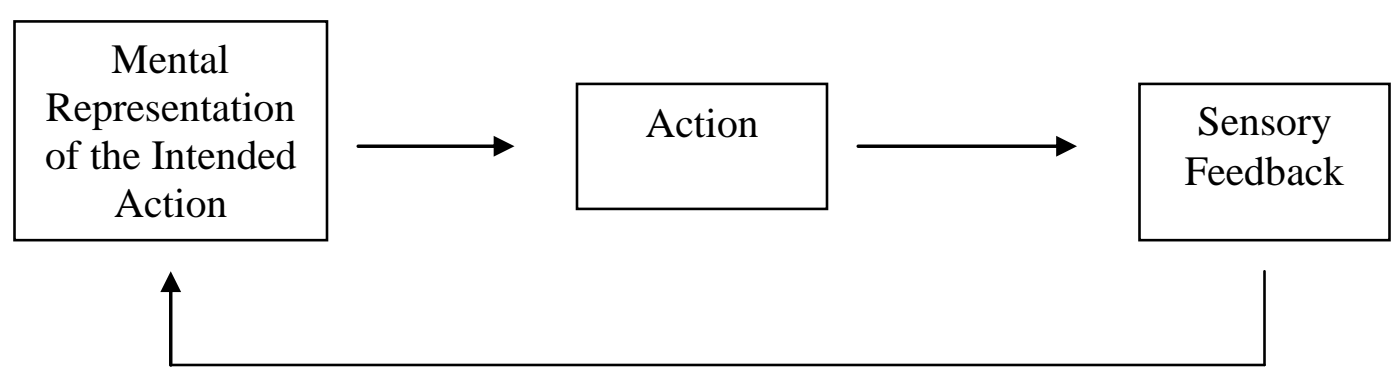

Figure 1. Components of Ideomotor Theory

\section{Evidence for Current Ideomotor Theory}

Originally, ideomotor theory was criticized for lack of evidence to back up its claims. When Greenwald (1970a) extended the theory over 40 years ago, he provided empirical support for ideomotor compatibility. In his experiments, visual or auditory stimuli were presented to participants who had to respond as quickly as possible by naming or copying the stimulus. His results showed that reaction times were quicker when visual stimuli preceded the copying response and auditory stimuli preceded the auditory response. 
There are several other stimulus response studies designed using various stimuli and responses which all found that participants tend to respond quicker when the perception and the motor response are compatible (Brass, Bekkering, \& Wrinz, 2001; Elsner \& Hommel, 2001; Hoffman, Sebald, \& Stocker, 2001; Koch \& Kunde, 2002; Sebanz, Knobloch \& Prinz, 2002; Tsai, Kuo, Hung, \& Tzeng, 2006). In addition, research has found that dual task paradigm responses tend to be faster overall when the stimulus and response of both tasks are ideomotor compatible (Greenwald \& Shulman, 1973; Lien, Proctor \& Allen, 2002). These results are consistent with ideomotor compatibility in that reaction times are quicker when someone is exposed to a similar situation that has been previously learned (Knuf et al., 2001). Incompatible conditions result in a slower response time, as there is a conflict between the perceptual stimulus code and the response code. Subjects must inhibit responses for the irrelevant perceptual stimulus dimensions first before they select responses for the relevant action dimension (Tsai et al., 2006).

Although the above mentioned studies provide evidence for ideomotor compatibility, they do not provide direct evidence that the mental representation of the intended action actually guided the action. The stimuli in these studies are presented physically and are not selected based on anticipated mental representations. Kunde (2001) provides evidence that ideomotor compatibility is not only restricted to conditions presented physically but extends to situations in which the effect is anticipated. Participants were instructed to forcefully press a computer key when a red stimulus was presented and softly press the key when a green stimulus was presented. Subsequently, a loud or soft 
tone followed. In the compatible condition, a loud tone followed a forceful response and a quiet tone followed a soft response. In the incompatible condition, a loud tone followed a soft response and a quiet tone followed a forceful response. The authors found that a certain force is reproduced quicker when it produced tones compatible with the response. These results are consistent with ideomotor theory in that they show the anticipatory effects of the auditory tones influenced the force produced. Kunde, Koch, and Hoffman (2004) completed similar experiments which replicate these findings.

Since 1970, literature on the Chevreul pendulum, mental practice, and recent neurophysiological findings all provide additional evidence for ideomotor theory. Easton and Schor (1975) investigated the Chevreul pendulum phenomenon in which subjects were exposed to three conditions while holding a pendulum bob between the thumb and index fingers. One group imagined it swinging; one group imagined it completely still; and a third group had a neutral attitude to the swinging. Photographic time exposure imaging showed that those who imaged it swinging swung the pendulum 10 times more than those in the other two conditions.

Baars (1988) extended these studies and found that if subjects were instructed to swing the pendulum bob along a North to South axis, it moved along the North to South axis. When asked to imagine movement along an East to West axis, the movement occurred along an East to West axis without any visible movement of the hand. The authors from both studies concluded that the mental representation of the swinging pendulum automatically triggered the response of swinging the pendulum even though the subjects were instructed to hold it still. 
Additional support for ideomotor theory is evident from the mental practice literature (Baars, 1988) which demonstrate that imagining an action can improve physical performance in athletes (Beauchamp, Bray, \& Albinson, 2002; Blair, Hall, \& Leyshon, 1993; Kim \& Chung, 1998), people who are healthy (Tunney et al., 2006; Zijdewind, Toring, Laan, \& Diercks, 2003), and those with neurological conditions (Braun, Beurskens, Borm, Schack, \& Wade, 2006; Page, Levine, \& Hill, 2007; Tamir, Dickstein, \& Huberman, 2007). Mental practice is defined as the "voluntary rehearsal of imagery scenes or tasks" (Dickstein \& Deutsch, 2007, p. 943). Neurophysiological evidence using functional magnetic resonance imaging (f-MRI) studies have found that mental practice activates similar parts of the cerebral and cerebellar sensorimotor areas of the brain as when actually performing the task (Lacourse, 2005; Lacourse, Turner, Orr, Schandler, \& Cohen, 2004). Positron emission tomography (PET) scan studies have shown that completing mental practice training increases activity in the orbitofrontal cortex and decreases activity in the cerebellum which is consistent with what happens with physical practice (Jackson, Lafleur, Malouin, Richards, \& Doyon, 2003).

According to the ideomotor principle, perceiving an action will result in the tendency to actually perform the action. Neurophysiological evidence supports that perceiving an action activates neural structures involved in the planning of action including the premotor area (Decety et al., 1994; Gallese, Fadiga, Fogassi, \& Rizolatti, 1996; Rizzolatti, Fogassi, \& Gallese, 2001), and cerebellum (Decety et al., 1994; Grossman et al., 2000). Executing, observing, and imagining a movement all result in activation of mirror neurons in the premotor cortex in monkeys (Rizzolatti, Fadiga, Gallese, \& 
Fogassi, 1996). It is theorized that mirror neurons may form an internal representation of the movement (Jeannerod, 1994). It has been postulated that humans have a similar area in the premotor cortex as studies have shown that observing, simulating, or producing an action activate certain parts of the premotor cortex (Buccino et al., 2001; Decety, Jeannerod, Germain, \& Pastene, 1991; Fadiga, Fogassi, Pavesi, \& Rizzolatti, 1995; Jeannerod, 1994, 1997; Rizzolatti \& Arbib, 1998). This provides evidence that there is some type of "common coding" for perception and action at the neurophysiological level.

Neurophysiological evidence also provides support that the association between the perception and action is a result of learning and occurs automatically. When people perceive a learned action, neural activity in the rostral supplemental motor area (SMA) proper and hippocampus increases (Elsner et al., 2002). The rostral portion of the SMA proper is responsible for planning simple hand movements so when perceiving a learned action, the area responsible for planning that movement is activated. Those areas in the brain involved in conscious or voluntary activation of a motor response are not activated. The increase in neural activity in the hippocampus indicates that learned associations were retrieved during the task.

In addition, neurophysiological studies have shown there is an increase in mental work load just prior to movement (Baars, 1988). When people are instructed to mentally simulate pressing a pedal, motor neuron excitability increases, indicating that the motor system is anticipating movement (Bonnet, Decety, Requin, \& Jeannerod, 1997).

Evidence to Relate Ideomotor Theory and Social Perceptions 
Ideomotor theory has been applied to many other fields including imitation.

Consistent with the theory, observing someone else's actions in the environment should create a mental representation of the action which will create the tendency to perform the action. The strength of the resultant action will be dependent on the degree of association between the perceptual representation and the action and how well learned the association is (Prinz, 2002).

There are many everyday occurrences that can be perceived and result in the tendency to imitate. These include things we can literally perceive like facial expressions, gestures, and speech patterns; and things we cannot literally perceive like trait inferences and social stereotypes. All three of these social perceptions occur naturally and automatically and once pre-conditions are met, no consciousness is needed for the behavior to occur (Bargh, 1997; Dijksterhuis \& Bargh, 2001).

The classic example of our innate tendencies to imitate what we perceive is yawning. It is very common to yawn when seeing or perceiving someone else yawn. Dijksterhuis and Bargh (2001) argue that the imitated behavior is represented mentally which results in automatic initiation of movement. Initiating a yawn is an inherent consequence of seeing or perceiving someone else yawn.

There is much evidence to back up the claim that we do imitate facial expressions like yawning (Provine, 1986) and smiling (Chartrand \& Bargh, 1999; Tamura \& Kameda, 2006); gestures and movements (Chartrand \& Bargh, 1999); and speech patterns (Neumann \& Strack, 2000). When subjects are exposed to a happy facial expression, EMG readings record an increased activity in those muscles that cause smiling. When 
exposed to sad or angry facial expressions, EMG readings record an increased activity in those muscles associated with frowning or anger (Dimberg, 1990; Dimberg \& Lundquist, 1990). These facial mimicries occur in under $400 \mathrm{~ms}$ (Dimberg \& Thunberg, 1998), are unconscious (Dimberg, Thunberg, \& Elmehed, 2000), and cannot be voluntarily avoided (Dimberg, Thunberg, \& Grunedal, 2002). This data supports the resultant facial expressions are an automatic response to exposure to someone else's facial expressions.

Chartrand and Bargh (1999) found that strangers were more likely to rub their own nose or shake their foot when another person in the room also rubbed their nose or shook their foot. In a study by Neumann and Strack (2000), participants adopted the speech pattern of a stranger on a tape when asked to repeat what was heard.

Trait inferences are perceived characteristics about a person's behavior in the current environment. If someone is seen helping an older adult cross the street safely, that person is automatically characterized as "nice, helpful, and considerate". Mental representation of trait inferences are coded in the brain immediately, spontaneously, unintentially, and subconsciously (Bargh \& Ferguson, 2000, Bargh, Bond, Lambardi, \& Tota, 1986).

Priming research provides evidence that personality traits are automatically activated through imitation. Priming increases the accessibility of the trait and creates a sense of readiness to act in an assimilated fashion through perception (Bargh, 1989). When people were primed with aggressive cues, they administered longer "shocks" to a confederate when the confederate gave a wrong answer than those who were not primed with aggressive cues (Carver, Ganellen, Froming, \& Chambers, 1983). When primed with words related to "rudeness", people were more likely to interrupt a conversation than 
those primed with words related to "politeness" (Bargh et al., 1996b) and those primed with words related to "helpfulness" were more likely to behave in a more helpful manner than those who were not primed (Macrae \& Johnston, 1998).

Stereotypes are activated through easily detectable features of a group not based on the current environment but based on past experiences. Stereotypes are activated in a similar fashion as trait inferences since stereotypes consist of several different traits which are descriptive of the stereotyped group. When a stereotype is activated, the associated trait characteristics are also activated (Blair et al., 1993; Devine, 1989; Dijksterhuis \& Van Knippenberg, 2000). It is the activation of these traits which triggers the central representation which ultimately affects behavior in an assimilated fashion (Dijksterhuis, Aarts, Bargh, \& Van Knippenberg, 2000; Dijksterhuis \& Bargh, 2001; Wheeler \& Petty, 2001). For example, one older adult stereotype is that older adults are slow. After being exposed to images or words describing older adults, the activation of the trait "slow" will lead to behavior that is slow. Research has shown that when primed with elderly negative stereotypes, participants walked slower (Bargh et al., 1996b), reacted slower (Dijksterhuis, Spears, \& Lepinasse, 2001), and performed worse on memory tests (Dijksterhuis et al., 2000; Levy, 1996; O'Brien \& Hummert, 2006).

The entire process from social perception to behavior occurs automatically without conscious choice or guidance so that activation of a stereotype will increase the likelihood of activating the corresponding behavior (Bargh, 1994; Bargh et al., 1996b; Brewer, 1988; Chartrand \& Bargh, 1999; Devine, 1989). Stereotypes are stored 
assumptions and beliefs which occur through learning and accessibility depends on prior or chronic use.

As the above evidence shows, there is an association between central representations and automatic voluntary behavior. However, strength of this association varies and humans are able to occasionally overcome the tendency for automatic behavior (Elsner \& Hommel, 2001; Macrae \& Johnston, 1998). Behaviors are less likely to be initiated and the magnitude of change is smaller when stereotypes are not highly accessible. Research has shown that the amount of behavior change is greater when the stereotype is selfrelevant and behavior is less likely to occur when not self-relevant (Dijksterhuis \& Van Knippenberg, 1998).

\section{Application of Theoretical Framework}

Ideomotor theory provides a theoretical framework to investigate whether exposure to stereotypes has an effect on the physical performance of older adults. The theory proposes that a tendency toward a voluntary action will automatically follow the mental representation of the intended action in an assimilative fashion (Wheeler \& Petty, 2001).

The current study utilized the mental representation of the intended action to action link as its basis. Mental representation of the intended action is defined as the type of stereotype activation. Stereotypes can be activated in either an explicit or implicit manner and the current study will address implicit stereotype activation only. Older adults will be primed with positive, negative, or neutral aging stereotypes using material objects. The construct of an action is defined as physical performance, which will be measured by the three components of the Short Physical Performance Battery which are gait speed, 
standing balance, and lower extremity muscle performance. The association between the two will result in a behavior that is consistent with the type of stereotype activation. Those exposed to negative aging stereotypes will physically perform worse than those who are primed with positive stereotypes or the neutral condition. Those exposed to positive aging stereotypes will physically perform better than those who are primed with negative stereotypes or the neutral condition. Figure 2 shows the constructs and corresponding variables of ideomotor theory.

The constructs of current ideomotor theory do not account for any factors which may influence the link between the mental representation of the intended action and the action itself, nor does it account for any other factor that can influence the action itself. It has been hypothesized that certain psychosocial factors can moderate the effect of stereotypes on performance (Shih et al., 2002) and that certain sociodemographic factors can account for changes in physical performance (Seeman et al., 1994; Sibbritt et al., 2007). A new model was constructed based on ideomotor theory to account for these factors. Figure 3 shows the proposed model with the addition of psychosocial and sociodemographic characteristics .

From the constructs mentioned above, several hypotheses have been developed.

Hypothesis 1: There will be a significant difference in gait speed between older adults who are exposed to positive stereotypes of aging and those in the neutral condition while controlling for self-relevance.

Hypothesis 2: There will be a significant difference in gait speed between older adults who are exposed to negative stereotypes of aging and those in the neutral condition while 


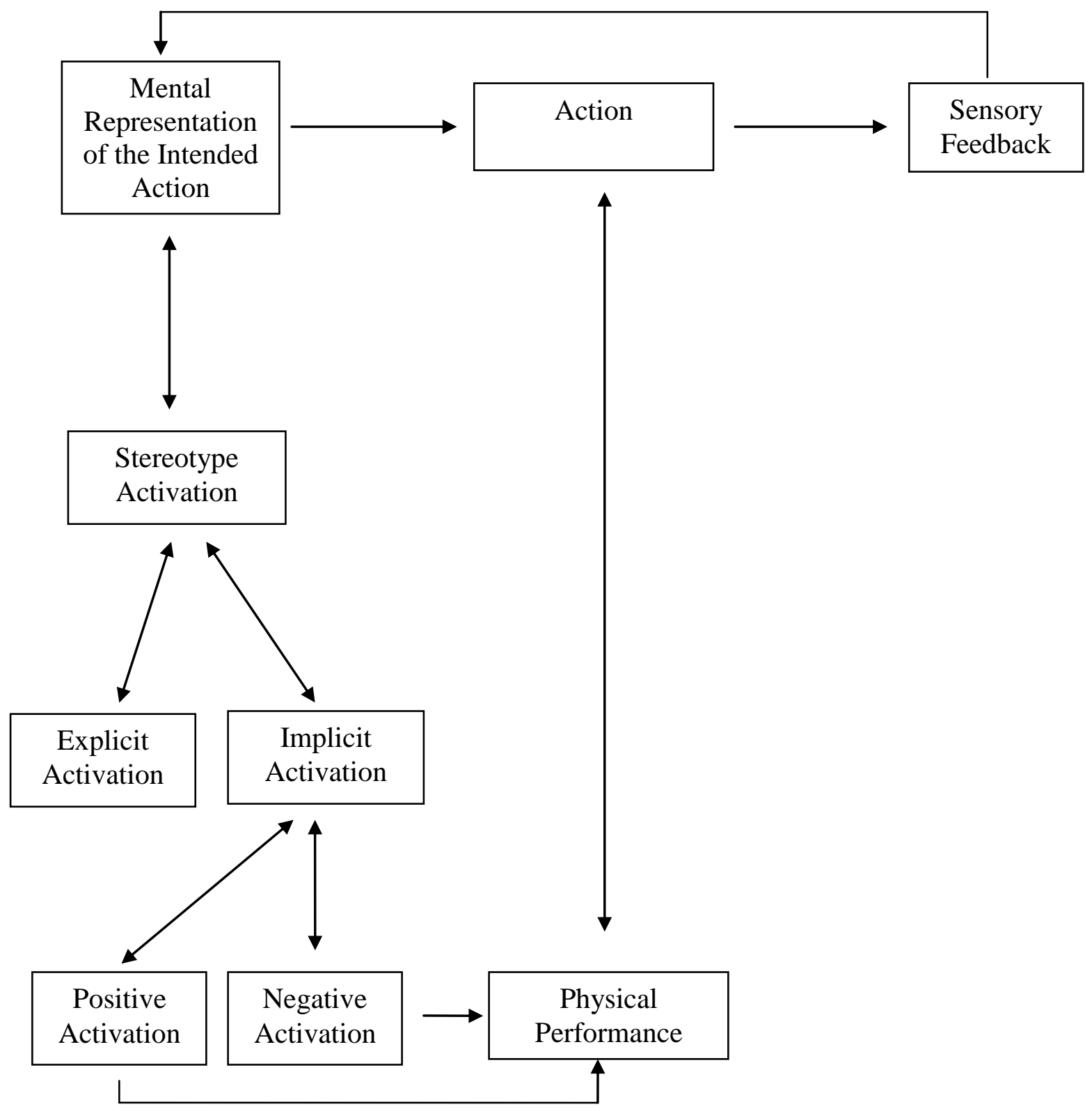

Figure 2. Bacharach Model of Ideomotor Theory: Constructs and Corresponding Variables 


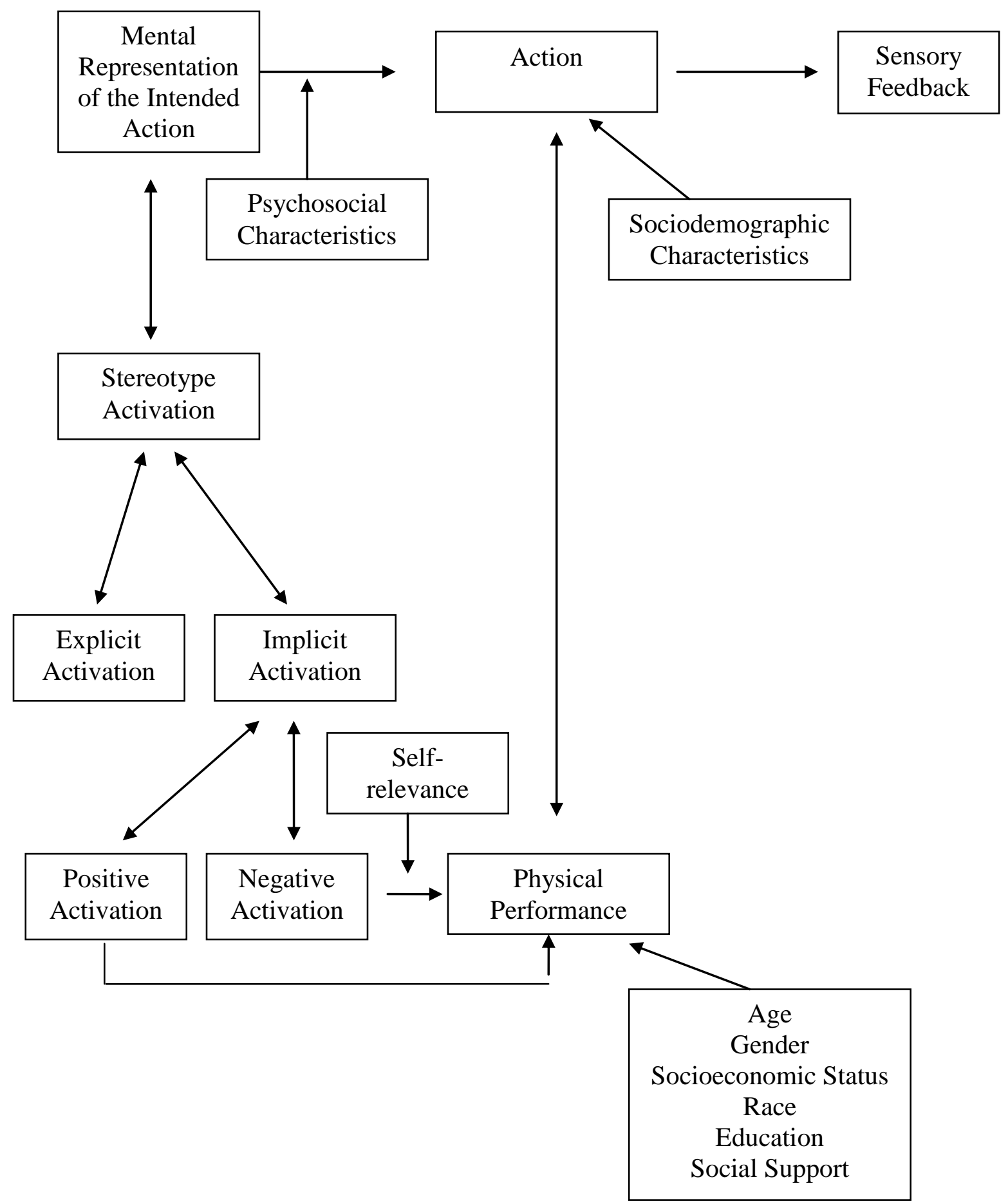

Figure 3: Proposed Model for the Current Study with Addition of Psychosocial and Sociodemographic Characteristics 
controlling for self-relevance.

Hypothesis 3: There will be a significant difference in gait speed between older adults who are exposed to negative stereotypes of aging and those exposed to positive stereotypes of aging while controlling for self-relevance.

Hypothesis 4: There will be a significant difference in standing balance between older adults who are exposed to positive stereotypes of aging and those in the neutral condition while controlling for self-relevance.

Hypothesis 5: There will be a significant difference in standing balance between older adults who are exposed to negative stereotypes of aging and those in the neutral condition while controlling for self-relevance.

Hypothesis 6: There will be a significant difference in standing balance between older adults who are exposed to negative stereotypes of aging and those exposed to positive stereotypes of aging while controlling for self-relevance.

Hypothesis 7: There will be a significant difference in lower extremity muscle performance between older adults who are exposed to positive stereotypes of aging and those in the neutral condition while controlling for self-relevance.

Hypothesis 8: There will be a significant difference in lower extremity muscle performance between older adults who are exposed to negative stereotypes of aging and those in the neutral condition while controlling for self-relevance.

Hypothesis 9: There will be a significant difference in lower extremity muscle performance between older adults who are exposed to negative stereotypes of aging and those exposed to positive stereotypes of aging while controlling for self-relevance. 
Hypothesis 10: There will be a significant association between age and amount of change in physical performance after exposure to stereotypes of aging while controlling for gender, socioeconomic status, race, education, and perceived social support.

Hypothesis 11: There will be a significant association between gender and amount of change in physical performance after exposure to stereotypes of aging while controlling for age, socioeconomic status, race, education, and perceived social support.

Hypothesis 12: There will be a significant association between socioeconomic status and amount of change in physical performance after exposure to stereotypes of aging while controlling for age, gender, race, education, and perceived social support.

Hypothesis 13: There will be a significant association between race and amount of change in physical performance after exposure to stereotypes of aging while controlling for age, gender, socioeconomic status, education, and perceived social support.

Hypothesis 14: There will be a significant association between education and amount of change in physical performance after exposure to stereotypes of aging while controlling for age, gender, socioeconomic status, race, and perceived social support.

Hypothesis 15: There will be a significant association between perceived social support and amount of change in physical performance after exposure to stereotypes of aging while controlling for age, gender, socioeconomic status, race, and education.

Theoretical Boundaries

There are particular boundaries that will affect the generalizability of the study. The majority of research on ideomotor theory with regards to stereotypes has been conducted on participants who were unconsciously or subconsciously primed with aging stereotypes 
(Bargh et al., 1996b; Wheeler \& Petty, 2001). It may not be appropriate to generalize the result to participants who have been explicitly primed.

In addition, participants must be aware of a stereotype and learned it in the past in order for the prime to automatically activate the behavior. In some cultures, older adult stereotypes are more positive than they are here in mainstream America (Boduroglu, Yoon, Luo, \& Park, 2006; Levy \& Langer, 1994; Yoon et al., 2000). It may not be appropriate to generalize the results to subjects from different cultures and/or from all parts of the world.

\section{Gaps in the Literature}

Research has demonstrated that activation of aging stereotypes can influence the behavior of older adults. Most of the research has been conducted on the effect of stereotype activation on cognitive performance (Hess et al., 2003; Hess et al., 2004; Levy, 1996; Levy \& Langer, 1994), but only two studies were found evaluating the effect of stereotypes on physical performance (Hausdorff et al., 1999; Levy, 2000). Horton, Baker, Pearce, and Deakin (2008) reviewed the literature on the effect of stereotypes on the behavior of older adults and they report that further examination of the effect of stereotypes on physical skills is warranted.

Another issue that deserves attention is the method by which the stereotypes are being activated. The research studying the effect of stereotypes on physical performance was conducted in the laboratory setting and results of these studies need to be taken with caution since activation of stereotypes in the real world does not occur across computer screens or in word scrambling tasks. Often, stereotypes in everyday life are activated with 
visual images and none of these studies assessed the effect of stereotype activation using pictures or objects.

The Guide to Physical Therapist Practice defines physical performance as "whole body effort intended to accomplish an action, task, or activity" (American Physical Therapy Association, 2001). One shortcoming of the literature is that the studies using physical performance as an outcome measure have limited the operational definition of physical performance to gait speed and swing time or quality of handwriting. The operational definition of physical performance needs to be broadened to include components of physical performance like standing balance and lower extremity muscle performance.

Another shortcoming of the literature is that most of the research on the effect of implicit stereotype activation uses positive and negative priming techniques and does not include a neutral condition with which to compare the results. From these studies it is impossible to determine whether activation of positive stereotypes results in better performance from normal or if performance is just better when they receive the negative prime. Horton et al. (2008) also recommend that more studies should include a control group and/or a pretest/post test design.

It has been theorized that certain psychosocial factors like self-relevance can modify the effect of stereotype activation on performance (Shih et al., 2002). Those older adults who believe they are old are more likely to find the stereotype self-relevant and the effect of stereotype activation is stronger. When studying the effect of aging stereotypes on 
behavior, it is important to account for the role of self-relevance, yet none of the studies found have controlled for its effect.

And lastly, it is not known whether older adults with different sociodemographic characteristics are influenced differently by activation of aging stereotypes. It is important to determine whether certain characteristics like age, gender, socioeconomic status, race, education, and social support are associated with the amount of change in physical performance following activation of stereotypes. 


\section{CHAPTER 3: METHODOLOGY}

Introduction

Chapter Three describes the methodology used in the current study. This section includes a description of the research design, population and sample, sampling procedures, instrumentation, data collection procedures, and data analysis.

The purpose of this study was to explore how stereotypes may affect physical performance of older adults. The research questions include 1) Does implicit activation of positive, or negative stereotypes of aging have an effect on the physical performance of older adults? and 2) Are age, gender, socioeconomic status, race, education, and perceived social support associated with the amount of change in physical performance after exposure to stereotypes of aging?

\begin{tabular}{cccc} 
& \multicolumn{3}{c}{ Research Design } \\
& O1 & X1 & O2 \\
R & O1 & X2 & O2 \\
& & & \\
& O1 & X3 & O3
\end{tabular}

A multigroup pretest post test experimental design was utilized to determine whether intrinsic activation of positive or negative stereotypes of aging had an effect on the physical performance of older adults. The independent variable was the type of implicit 
stereotype activation (positive, negative, or the neutral condition). The outcome variables were the three components of the Short Physical Performance Battery (SPPB) which include gait speed as measured by the 4 meter walk test, standing balance as measured by side-by-side, semi-tandem or tandem stance, and lower extremity muscle performance as measured by a timed chair stand.

The literature on the effect of stereotypes on the behavior of older adults has used pretest post test experimental designs, post test only experimental designs, and correlational designs (Bargh et al., 1996b; Hausdorff et al., 1999; Hess et al., 2003; Hess et al., 2004; Levy, 1996; Levy et al., 1999-2000; Levy, 2000; Levy \& Myers, 2005; Levy \& Slade, 2006; Levy et al., 2002a; Levy et al., 2002b; Stein et al., 2002). Experimental designs are more robust than correlational designs at establishing a cause and effect relationship since theoretically the groups being tested are different only in the type of intervention received. The multigroup pretest post test design was chosen for this study since it is a type of experimental design. Measuring the dependent variable at pretest and post test provides the ability to measure change in the dependent variables over time. Use of a pretest allows analysis to determine whether the groups are equivalent prior to the start of the intervention and that other factors do not account for any change in the dependent measures. While post test only designs control for the effect of pretest sensitization, it is not possible to determine whether random assignment results in equivalent groups nor can it measure the amount a change over time (Fraenkel \& Wallen, 2000). One limitation of experimental designs is they tend to add artificiality due to their 
strict controls. In real life, things are not so strictly controlled so generalizability to real life situations can be limited (Polit \& Beck, 2004).

Random assignment of the participants into three groups controls for history, maturation, testing, instrumentation, regression, selection, mortality, and selection interactions since they should occur equally in all three groups (Polit \& Beck, 2004; Portney \& Watkins, 2008). Experimental designs do not control for threats to attrition, compensatory rivalry, and diffusion of treatment. Attrition is mainly an issue when it occurs unevenly in the groups (Portney \& Watkins, 2008) which did not occur in the current study. Compensatory rivalry is not a concern since all groups received a similar intervention and participants should not have felt that being in one group was more desirable over another. To lessen the opportunity for diffusion of treatment, participants were asked not to discuss the project until everyone completed the intervention.

Additional post tests to evaluate longer term effects would strengthen the design of the study but potentially adds problems. Since some information was withheld from the participants during informed consent, additional post test measures taken on a separate day would delay debriefment which may raise some ethical concerns. In addition, attrition would increase since many people may not return another time for various reasons.

\section{Population and Sample}

The participants were 65 years of age or older who lived independently in the community. In order to be eligible for the study, participants had to be able to ambulate with or without an assistive device for at least four meters, stand without upper extremity 
support, rise from a chair five times, and follow directions in English. Participants had to perform these tasks in order to complete the three components of the SPPB which were the dependent measures in this study and a translator was not be available for people who did not speak English.

The exclusion criteria included those conditions which may prevent someone from completing the dependent measures and included resting oxygen saturation rates $<90 \%$, resting heart rates $<50$ or $>110$ beats per minute, symptomatic postural hypotension, systolic blood pressure greater than $200 \mathrm{mmHg}$, diastolic blood pressure greater than 110 $\mathrm{mmHg}$, or those with a history of myocardial infarction, percutaneous transluminal coronary angioplasty, or coronary artery bypass surgery within the past three months. These are conditions which may be contraindicated with physical activity (American College of Sports Medicine, 2005). Since the type of priming used in this study required the participants to see and identify objects, older adults with less than $20 / 100$ vision in the better eye with corrective eyewear were excluded.

This sampling plan limited the generalizability of the study to those who are 65 years of age or older and who meet the inclusion and exclusion criteria. The participants were also volunteers and volunteers can have different characteristics than those who do not volunteer (Portney \& Watkins, 2008). People with these characteristics were considered the target population.

\section{Sampling Procedures}

Statistical conclusion validity is enhanced when statistical power is adequate and statistical power is enhanced when an appropriate sample size is utilized (Portney \& 
Watkins, 2008). The optimal sample size decreases the likelihood of committing a Type I or Type II error. A power analysis was conducted and the target sample size for detecting a medium sized effect using MANOVA analysis with a .05 criterion of statistical significance and $80 \%$ power is 87 participants. To take attrition into account, 96 participants from the accessible population were recruited.

The sample consisted of seniors recruited from various senior centers, and senior housing units in the Capital Region and Adirondack regions of New York State. These are facilities where a large number of older adults with the characteristics of our population are found. Recruitment from more than one facility and geographic area also increases the generalizability of the results. The Capital Region area is mainly an urban/suburban area and the addition of participants from the Adirondack region increased the number of participants from rural areas. This is important since physical performance of older adults from rural areas is different than those from suburban and urban areas (Morala et al., 2006).

All research found which evaluates the effect of stereotypes on the behavior of older adults used convenience sampling (Bargh et al., 1996b; Hausdorff et al., 1999; Hess et al., 2003; Hess et al., 2004; Levy, 1996; Levy et al., 1999-2000; Levy, 2000; Levy \& Myers, 2005; Levy \& Slade, 2006; Levy et al., 2002a; Levy et al., 2002b; Stein et al., 2002). A limitation to the use of convenience sampling is that the sample may not represent the population of interest (Polit \& Beck, 2004; Portney \& Watkins, 2008). The participants in the research mentioned above tended to be younger than the average older American (Hausdorff et al., 1999; Hess et al., 2003; Hess et al., 2004; Stein et al., 2002), 
and the gender ratios were not representative of the older adult population in the United States (Hausdorff et al., 1999; Levy, 1996; Levy et al., 1999-2000; Stein et al., 2002).

Quota sampling is an improvement over convenience sampling in that it attempts to create a more representative sample of the population on certain demographic variables (Portney \& Watkins, 2008). Proportional stratified quota sampling was utilized as our sampling plan. This plan potentially controlled for the effect of age and gender on the dependent measures by ensuring that an appropriate number of participants from each stratum were included in the sample. The quota sampling frame was designed to represent the population of older adults in the United States (He, Sengupta, Velkoff, \& DeBarros, 2005; Federal Interagency Forum on Aging Related Statistics, 2008) and included: age (three classes: $52 \%$ between the ages of 65 and 74, 36\% between the ages of 75 and 84 and $12 \%$ over the age of 85 ), and gender (two classes: $59 \%$ female and $41 \%$ male). These variables were chosen since they have been found to have an effect on physical performance (Seeman et al., 1994) and since the samples in several studies on stereotype activation have not been representative of the older adult population on these two characteristics.

The use of quota sampling is relatively quick, convenient, and economical (Polit \& Beck, 2004; Portney \& Watkins, 2008). It is not as rigorous as the different types of probability sampling since there is a potential for non-probability bias on the variables which were not stratified as well as the potential for self selection (Portney \& Watkins, 2008). 
Successful recruitment of older adults requires different strategies than recruiting younger adults. Older adults are mostly unaware of research studies and often have problems with transportation (Arean \& Gallagher-Thomson, 1996; Boles, Getchell, Feldman, McBride, \& Hart, 2000). Successful recruitment of ethnic minorities is even more complex (Arean \& Gallagher-Thomson, 1996). In addition to lack of awareness and the difficulties noted with transportation, there is a general mistrust about research due to the Tuskegee Scandal, discrimination by medical professionals in the early 1900's, and the war atrocities in the name of science (Alvidrez, Azocar, \& Miranda, 1996; Arean, Alvidrez, Nery, Estes, \& Linkins, 2003; Arean \& Gallagher-Thomson, 1996; AustinWells, McDougall, \& Becker, 2006). A lack of culturally compatible staff involved in research projects (Arean et al., 2003; Arean \& Gallagher-Thomson, 1996; Austin-Wells et al., 2006) and the extra burden of time and effort when minorities already have multiple stressors and limited resources (Demi \& Warren, 1995) are other factors which interfere with the recruitment process.

Senior centers and senior housing units in Troy, and Saranac Lake, New York were contacted by phone for administrative approval to recruit members for this study. Specific facilities were identified through an internet and phone book search by the researcher or through contact with key community members. The purpose of this initial contact was to inform them about the project, give them the opportunity to ask questions, and discuss any potential barriers to recruitment. Once approval was given, a trusted community member who was an administrator was identified to assist in the recruitment process by providing advice about recruitment strategies and then assisting in the process. 
It has been recommended that the involvement of trusted community members is important to establish a link to the community and improve trust in order to mitigate the issues noted in the last paragraph (Arean et al., 2003; Arean \& Gallagher-Thomson, 1996; Austin-Wells et al., 2006).

The administrators from the eight facilities chose three different types of recruitment strategies based upon their experience with the older adults at their specific facility. One administrator preferred recruiting older adults through a formal presentation by the researcher. The purpose of the presentation was to increase awareness of the research, inform older adults specifically about the project, and give them the opportunity to ask questions. The administrator was present at the presentation. Presentations and endorsement from a trusted community member have been found to be successful in recruiting older adults (Groupp, Haas, Fairweather, Granger, \& Attwood, 2005). Enrollment in the study occurred following the presentation and was performed by an older adult recruiter who was different from the trusted community member and was not involved in the project in any other way. Peer recruiters have been found to be more successful in recruiting participants since potential participants may feel more comfortable around someone who is their own age (Arean et al., 2003). Use of a nonresearcher also decreases the chance of cohersion (Polit \& Beck, 2004).

A screening instrument was developed to assist the recruiter in determining whether participants met the inclusion and exclusion criteria. Appendix A includes a copy of the screening instrument. It was not intended to include members of special populations but if it was discovered during data collection that someone was mentally or cognitively 
incompetent, post screening was utilized to discard their data. The recruiter was trained by the researcher about the specifics of the recruitment process, which includes how to interact with potential participants, how to dress, and in all documentation procedures. The recruiter must be pleasant, courteous, and respectful. It is recommended that first impressions should be positive to enhance enrollment and training will most likely enhance any first impressions (Resnick et al., 2003). All participants were informed that they do not have to decide at the time of the presentation and may enroll after reflecting on it. Appendix B includes the table of contents for the peer recruiter training.

Face to face recruitment has been found to be more successful than other methods of recruitment, especially in minority populations (Arean et al., 2003; Polit \& Beck, 2004; Resnick et al., 2003; Zhu, Hunter, Bernard, \& Payne-Wilks, 2000). During face to face recruitment, the research can be more clearly explained. It allows potential participants to gain more knowledge about the research, give them the ability to ask more informed questions, and facilitate trust. On the down side it is more costly and time consuming but may be worth the extra effort since enrollment rates tend to be higher than with other methods (Zhu et al., 2000).

Another administrator preferred recruitment through an announcement in a newsletter. Appendix $\mathrm{C}$ includes the newsletter announcement. The participants then signed up with the administrator prior to the data collection date. The other six administrators preferred that fliers be distributed throughout their facility. The participants then signed up with the administrator prior to the data collection date. Appendix D includes the flier. On the data collection day, the researcher recruited on the spot when there were any empty spots in 
the schedule. Some participants thus enrolled on the day of data collection. In addition, an e-mail blast was sent to The Sage College's alumni in an attempt to recruit people who do not attend senior centers or who do not live in senior housing. E-mail blasts are usually a cost effective way to recruit participants but yielded only five participants in the current study.

Transportation to the research facility can be a problem for the older adult population due to cost, disability, and health concerns. (Arean \& Gallagher-Thomson, 1996; Groupp et al., 2005). Providing free transportation can be costly for the researchers. Instead, the data collection facilities were located in convenient community locations to ease some of the burden of traveling. In addition, participants were reimbursed $\$ 10$ to help defray the cost of transportation and give them a small token to let them know their assistance in the project was appreciated.

In order to enhance enrollment, participants were assured that confidentiality will be maintained. Any code sheets were destroyed immediately following data collection. Since participation in the study is a commitment, data collection times were available over multiple days of the week and a variety of times during the day in order to enhance convenience for the participants. Individuals had the option to receive their scores on the SPPB to see if they exhibited any signs of preclinical disability and were at risk for functional decline. All participants received Exercise \& Physical Activity (2009), a book developed by the National Institute of Aging. Those who were determined to be at risk for disability were given an additional brochure developed by the researcher on preclinical disability and were instructed on what they can do to prevent disability. 
The results of the research will be made available to the administrators of all involved facilities once the results are written. Being aware of the results facilitates trust among community members about the research process since they are more likely to feel part of it and that they made a contribution to their community (Arean et al., 2003). The results of the research will also be available to the individual participants if interested. In order to increase participation rates, it has been recommended the benefits of research to society be emphasized (Resnick et al., 2003). The benefits to society were explained to all potential participants reminding them they are helping others.

\section{Intervention}

Stereotypes can be primed through the use of a computer where stereotypical words (Hausdorff et al., 1999; Levy, 1996; Stein et al., 2002), names (Banaji \& Greenwald, 1995), or faces (Zebrowitz et al., 1993) are flashed subliminally across the screen; through scrambled sentence tasks (Banfield, 2003; Bargh, Chaiken, Raymond, \& Hymes, 1996a; Hess et al., 2003); or through use of objects (Kay et al., 2004). Stereotypes in the real world are not activated by words, names, or faces that are flashed across computer screens nor through use of word scrambling tasks. In the current study, the use of objects representing older adult stereotypes was utilized to increase generalizability to real world situations.

The intervention was modeled after the intervention designed by Kay et al. (2004) who determined that material objects representing the business world increased the cognitive accessibility of the stereotype "competition". Participants who were primed with objects from the business world acted more competitively than those primed with 
neutral objects. Participants in the current study were instructed that they were performing two separate experiments. One experiment tested common associations while the second tested visual perception. During the first task, participants were exposed to seven objects representing either positive stereotypes of aging, negative stereotypes of aging, or a neutral condition depending upon their group assignment. The objects were numbered from 1-7. Each participant was instructed to read a description of each object and place the number of the object next to its description.

To increase exposure of the primes, participants performed a second task using the same seven objects. The strength of stereotype activation is improved by increasing the length of exposure to the prime (Dijksterhuis \& Van Knippenberg, 1998). During the second task, participants were instructed to place the objects in terms of their height from shortest on the left to tallest on the right.

The type of objects utilized was determined by interviewing a group of 18 older adults from a senior center in Cohoes, New York and a senior Art class in Clifton Park, New York. These adults were not part of the accessible population but demonstrated similar characteristics. They were instructed to "list all objects that come to mind when you think about older adults". Once the list was compiled, the same group of people rated the valence of the object on a 7 - point Likert scale with " 1 " representing a strongly negative view of older adults and "7" representing a strongly positive view. Appendix E includes the form utilized to collect the list of objects. The seven most negative and seven most positive objects were utilized for the study. 
The objects representing the neutral condition were the same objects utilized as neutral objects in the Kay et al. study (2004) and included a kite, stapler, sheet music, whale, electric plug, toothbrush, and phone. The process of administering the intervention was standardized and written in a manual to ensure consistency. The two people administering the priming manipulation were trained by the researcher. Training and standardization enhances statistical conclusion validity and precision (Polit \& Beck, 2004). Appendices $\mathrm{F}$ and $\mathrm{G}$ include the table of contents for the training and script for carrying out the intervention.

In order to ensure that older adult stereotypes were activated by the objects chosen, the manipulation was pretested as a pilot study. A group of 23 older adults were recruited from a senior center in Clifton Park, New York and two senior housing units in Cohoes, New York. An older adult peer recruiter was utilized to recruit participants in the pilot study. Participants were randomly assigned to a prime or no-prime group. Participants in both groups were told they were performing three separate experiments. One tests common associations, the second tests visual perception, and the third tests visual and recognition processing of words.

The participants in the prime group were exposed to the objects representing older adult stereotypes and those in the no prime group were exposed to a neutral condition as outlined above. All participants then completed a paper and pencil word fragment completion task. Appendix H includes a copy of the word fragment completion task. Word fragment completion tasks have been used to activate stereotypes in past research (Gilbert \& Dixon, 1991; Spencer, Fein, Wolfe, Fong, \& Dunn, 1998; Steele \& Aronson, 
1995) and are sensitive to recently activated constructs (Tulving, Schacter, \& Stark, 1982).

During the word fragment task, participants were instructed to complete 24 word fragments to create 24 actual words. Of the 24 word fragments, 9 were associated with older adult stereotypes and the other 15 were unrelated to older adult stereotypes. The reason for non-stereotypical words is to limit the chance that participants will figure out the purpose of the task (Steele \& Aronson, 1995). For example, the fragment S _ O W can be completed as "slow" or "snow". If the object primes are working, the participants who are primed will be more likely to complete the word as "slow". The older adults were debriefed as to the purpose of the pilot study.

The words utilized in the pilot study were identified by asking a group of eight older adults to list all words which come to mind when they think about older adults. Appendix I includes a copy of the survey. From that list, the nine most common words that can be easily filled with words that are non-stereotypical of older adults were used. When possible two spaces were left blank since that limits the amount of words which can be used and reduces the chance of a ceiling effect (Steele \& Aronson, 1995). The stereotypical words chosen after this process were senile, slow, lonely, ill, weak, confused, decline, crabby, and helpless.

Since it is possible that some of the objects used to prime the participants may prime the construct of physical disability instead of aging, a group of 24 older adults were recruited from a senior center in Pittsfield, Massachusetts in another pilot. The participants were exposed to objects representing older adult stereotypes and then 
completed a word fragment task related to physical disability instead of aging. Appendix $\mathrm{J}$ includes a copy of the word fragment task. The words utilized in this pilot study were identified by asking a group of five older adults to list all words that come to mind when you think about someone who is disabled. Appendix K includes a copy of the survey. The stereotypical words chosen after this process were bitter, victim, cripple, retarded, lame, pitty, hurt, unfit and sad. These results were then compared to the results of those completing the word fragment completion task related to aging.

Instrumentation

The Guide to Physical Therapist Practice defines physical performance as "whole body effort intended to accomplish an action, task, or activity" (American Physical Therapy Association, 2001, p. 689). Declines in physical performance in the older adult population can lead to disability and affect the quality of life of this population. In addition, even modest declines in physical performance can result in great costs to society (Reuben et al., 2004). Since the evaluation of physical performance and disability is a critical part in evaluating older adults, physical therapists commonly use physical performance measures. There is a wide variety of these outcome measures to choose from.

Two types of physical performance measures are self-report measures and performance-based measures. Self-report measures are more subjective and rely on the perception of the person completing them. The person is required to answer questions about how they perform various activities. The responses are either yes/no responses to whether they have difficulty performing a task or on a Likert Scale rating of the difficulty 
of the task. Examples of self-report measures are The Katz ADL Index (Katz, Ford, Moskowitz, Jackson, \& Jaffe, 1963), the Barthel Index (Mahoney \& Barthel, 1965) and the Rosow-Breslau Scale (Rosow \& Breslau, 1966).

The major advantage of using self-report measures is that most are self-administered and require minimal time on the part of the therapist. They do not require much training and evaluate real life tasks like shopping or bathing. Self-report measures are able to identify older adults who are moderately to severely disabled but are not as useful in nondisabled older adults since there is a tendency for a ceiling effect (Suthers \& Seeman, 2004). Another disadvantage of self-report measures is that the definitions of the tasks are often not clear. One person may have a different definition of what constitutes eating or dressing than another person. In addition, sometimes participants have to guess whether they can perform a task or not since they have not performed the task in question in some time (Guralnik, Branch, Cummings, \& Curb, 1989). Self-report measures are also susceptible to response bias. In one study, $13.6 \%$ of those who were not able to walk 8 feet on a performance-based measure reported that they could walk $1 / 2$ mile on a selfreport measure (Guralnik et al., 1994).

Performance-based measures are objective tests of standardized tasks where the tasks are timed or repetitions are counted by trained observers. Performance-based measures can be categorized into upper body and lower body measures. Upper body performance based measures can include tests of manual dexterity, grip strength, and the ability to reach or lift. Lower body performance based measures can include tests which evaluate 
lower extremity muscle performance, measures of balance, and tests of walking (Suthers \& Seeman, 2004).

Performance-based measures are less susceptible to response bias and are better at discriminating higher functioning older adults than self-report measures (Reuben et al., 2004; Suthers \& Seeman, 2004). There are less confounding factors from poor cognitive functioning, culture, language, and education level (Guralnik et al., 1989). They also tend to be more sensitive than self-report measures since the tasks are timed, allowing for continuous data and use of more robust statistics. These are the reasons why a performance based measure is utilized in the current study.

The disadvantages to using performance-based measures are that they are performed in a lab setting which can make them somewhat artificial, they are more time consuming, they are poor at discriminating those older adults at lower level functioning, and there is a risk for injury even though that risk is small (Guralnik et al., 1989; Suthers \& Seeman, 2004). In the current study, no one was injured.

One lower body performance-based measure which has commonly been used in research on aging is the SPPB. It includes a measure of standing balance, a timed four meter walk, a timed test of the ability to rise from a chair five times, and a summary score. The protocol for each of the tasks is standardized. A CD is available to train the assessors to assure uniformity and make sure that all tests are completed as safely as possible (Guralnik et al., 1995; Guralnik et al., 1994). During the measure of standing balance, participants are timed while maintaining a side-by-side, semi-tandem, and tandem stance. During the measure of timed walking, participants are instructed to walk 
four meters at their usual pace twice. The faster of the two tests is recorded. During the chair stand task, participants are instructed to stand up from a standard straight-backed chair while their arms are folded across their chest as quickly as possible five times. All tests are measured with a stopwatch to the nearest hundredths of a second. Normally, each subtest is scored by categorizing it on a scale from $0-4$ based on pre-established protocols. A summary performance score is determined by adding the scores from each subtest. Summary scores can range from 0-12; higher scores indicating better performance (Guralnik et al., 2000). It has been suggested that the results can be interpreted as continuous measures for each subtest (Guralnik et al., 1994) which is what occurred in the current study.

Interrater reliability for gait speed is high (r=.93) (Nevitt, Cummings, Kidd, \& Black, 1989). Intrarater reliability is excellent for gait speed ( $r=.89$; ICC $=.80-.89$ ) (Nevitt et al., 1989; Ostir, Volpato, Fried, Chaves, \& Guralnik, 2002), good to excellent for chair stands (r =.73; ICC = .76-.90) (Ostir et al., 2002; Seeman et al., 1994), and good to excellent for standing balance (r=.97; ICC=.70-.82) (Ostir et al., 2002; Winograd et al., 1994). Each subtest has face validity (Studenski et al., 2003) and the summary scale has been found to have good predictive validity in the non-disabled older adult population for disability 4-6 years later (Guralnik et al., 2000; Guralnik et al., 1995), hospitalization (Penninx et al., 2000; Studenski et al., 2003), institutionalization (Guralnik et al., 1994), and mortality (Guralnik et al., 1994). The summary scale is also highly sensitive to change (Ostir et al., 2002). Using tests with adequate reliability and validity is important 
since those with low reliability cannot reliably measure true change in the dependent variable.

Advantages of the SPPB are that it only takes 5-15 minutes to complete (Guralnik et al., 1994; Studenski et al., 2003) and is portable and inexpensive. A disadvantage is the possibility for a ceiling effect of the standing balance subtests since it is capped at 10 seconds. There is the potential that many participants will achieve a perfect score. In the current study, the protocol was changed to cap tandem stance at 60 seconds to decrease the likelihood of a ceiling effect.

Both evaluators performing the SPPB with the participants were trained by the researcher in order to enhance precision. Appendices L and M include the table of contents for the training and for instructions to complete the SPPB.

Demographic information on age, gender, socioeconomic status, race, and education was gathered using a written survey. Table 2 presents a list of the variables and how they were measured. The coding for socioeconomic status, race, and education was modeled after the coding system used with the United States Census Data (U.S. Census Bureau; Panel on DHHS Collection, 2004). Appendix N includes the demographic survey.

In this study, self-relevance was operationalized as self perceived age and was measured using the Cognitive Age Scale (Barak, 1987). Using this written scale, participants had to choose which age group (pre-teen, teens, 20s, 30s, 40s, 50s, 50s, 60s, 70 s, 80, 90s) they identified with in four different dimensions: how they feel, how they look, what they are able to do, and what their interests are. The total score was determined by using the midpoint of each decade and then averaging these scores on each 
Table 2. Table of Variables

\begin{tabular}{|c|c|c|c|}
\hline Construct & Variable & How measured & $\begin{array}{c}\text { Level of } \\
\text { measurement }\end{array}$ \\
\hline Action & $\begin{array}{l}\text { Physical } \\
\text { Performance: Gait } \\
\text { speed }\end{array}$ & $\begin{array}{l}\text { 4-meter walk portion of the Short Physical } \\
\text { Performance Battery }\end{array}$ & Continuous \\
\hline Action & $\begin{array}{l}\text { Physical } \\
\text { Performance: } \\
\text { Standing balance }\end{array}$ & $\begin{array}{l}\text { Balance portion of the Short Physical } \\
\text { Performance Battery }\end{array}$ & Continuous \\
\hline Action & $\begin{array}{l}\text { Physical } \\
\text { Performance: } \\
\text { Lower extremity } \\
\text { muscle performance }\end{array}$ & $\begin{array}{l}\text { Chair stand portion of the Short Physical } \\
\text { Performance Battery }\end{array}$ & Continuous \\
\hline $\begin{array}{l}\text { Psychosocial } \\
\text { Characteristic }\end{array}$ & Self-relevance & Cognitive Age Scale & Continuous \\
\hline $\begin{array}{l}\text { Sociodemographic } \\
\text { Characteristic }\end{array}$ & Age & Months & Continuous \\
\hline $\begin{array}{l}\text { Sociodemographic } \\
\text { Characteristic }\end{array}$ & Gender & $\begin{array}{l}0=\text { Male } \\
1=\text { Female }\end{array}$ & Nominal \\
\hline $\begin{array}{l}\text { Sociodemographic } \\
\text { Characteristic }\end{array}$ & $\begin{array}{l}\text { Socioeconomic } \\
\text { Status }\end{array}$ & $\begin{array}{l}\text { Self reported household income from all } \\
\text { sources during the previous tax year } \\
0=<\$ 20,000 \\
1=\$ 20,000-\$ 34,999 \\
2=\$ 35,000-\$ 49,999 \\
3=\$ 50,000-\$ 99,000 \\
4=>\$ 100,000\end{array}$ & Ordinal \\
\hline $\begin{array}{l}\text { Sociodemographic } \\
\text { Characteristic }\end{array}$ & Race & $\begin{aligned} 0= & \text { White } \\
1= & \text { Black, African American, or } \\
& \text { Negro } \\
2= & \text { American Indian or Alaskan } \\
& \text { Native } \\
3= & \text { Asian (Asian Indian, Chinese, } \\
& \text { Japanese, Korean, Vietnamese) } \\
4= & \text { Pacific Islander } \\
5= & \text { Other }\end{aligned}$ & Nominal \\
\hline $\begin{array}{l}\text { Sociodemographic } \\
\text { Characteristic }\end{array}$ & Education & $\begin{aligned} 0 & =\text { No high school diploma or GED } \\
1 & =\text { High school diploma or GED } \\
2 & =\text { Some college but no bachelor's } \\
& \text { degree } \\
3 & =\text { Bachelor's degree or higher }\end{aligned}$ & Ordinal \\
\hline $\begin{array}{l}\text { Sociodemographic } \\
\text { Characteristic }\end{array}$ & Social Support & $\begin{array}{l}\text { Multidimensional Scale of Perceived } \\
\text { Social Support }\end{array}$ & Continuous \\
\hline
\end{tabular}

of the four dimensions. The resultant score is a continuous measure. Appendix $\mathrm{O}$

includes a copy of the Cognitive Age Scale. 
The Cognitive Age Scale has been shown to have good internal consistency with an alpha coefficient ranging from .86-.91 and test-retest reliability of .88 (Barak, 1987). Barak (1987) also provided evidence of construct validity, predictive validity, and face validity.

Perceived social support was measured using the Multidimensional Scale of Perceived Social Support (MSPSS) (Zimet, Dahlem, Zimet, \& Farley, 1988). It is a 12-item scale that rates how one perceives the adequacy of social support received from family, friends and a significant other. Participants rate each item on the Likert scale from "1" to "7", where " 1 " is "very strongly disagree" and "7" is "very strongly agree". These items are then averaged to create a total score. A higher score indicates a greater perceived level of social support. The scale takes 5-10 minutes to complete. Appendix P includes a copy of the MSPSS.

The MSPSS has good internal consistency with alpha levels ranging from .87-.94 and good test-retest reliability ( $\mathrm{r}=$.73-.85) (Stanley, Beck, \& Zebb, 1998; Zimet et al., 1988). Zimet (1988) provides evidence of content and convergent validity. Table 3 presents an overview of all the measurement tools.

\section{Data Collection Procedures}

IRB approval was obtained through Virginia Commonwealth University and The Sage Colleges prior to data collection. The informed consent process began at the time of recruitment when a description of the study was communicated to all potential research participants. At that time, potential participants had the opportunity to ask questions and clarify any information. On the day of data collection, the informed consent document 
Table 3. Overview of Measurement Tools

\begin{tabular}{|c|c|c|}
\hline Measurement Tool & Variable it pertains to & Reliability/Validity \\
\hline $\begin{array}{l}\text { 4-meter walk portion of the } \\
\text { SPPB }\end{array}$ & $\begin{array}{l}\text { Physical Performance: Gait } \\
\text { speed }\end{array}$ & $\begin{array}{l}\text { Interrater reliability }(\mathrm{r}=.93) \\
\text { Intrarater reliability } \\
(\mathrm{r}=.89 ; \mathrm{ICC}=.80-.84) \\
+ \text { face validity } \\
\text { Good predictive validity }\end{array}$ \\
\hline $\begin{array}{l}\text { Balance portion of the } \\
\text { SPPB }\end{array}$ & $\begin{array}{l}\text { Physical Performance: } \\
\text { Standing Balance }\end{array}$ & $\begin{array}{l}\text { Intrarater reliability } \\
(\mathrm{r}=.97 ; \mathrm{ICC}=.70-.82) \\
+ \text { face validity } \\
\text { Good predictive validity }\end{array}$ \\
\hline $\begin{array}{l}\text { Chair stand portion of the } \\
\text { SPPB }\end{array}$ & $\begin{array}{l}\text { Physical Performance: } \\
\text { Lower Extremity Muscle } \\
\text { Performance }\end{array}$ & $\begin{array}{l}\text { Intrarater reliability } \\
(\mathrm{r}=.73 ; \mathrm{ICC}=.76-.90) \\
+ \text { face validity } \\
\text { Good predictive validity }\end{array}$ \\
\hline Cognitive Age Scale & Self-relevance & $\begin{array}{l}\text { Test retest reliability } \\
\qquad(\mathrm{r}=.88) \\
\text { Internal consistency } \\
\quad(.86-.91) \\
+ \text { construct validity, } \\
\text { predictive validity, and face } \\
\text { validity }\end{array}$ \\
\hline $\begin{array}{l}\text { Multidimensional Scale of } \\
\text { Perceived Social Support }\end{array}$ & Perceived Social Support & $\begin{array}{l}\text { Test retest reliability } \\
\qquad(\mathrm{r}=.73) \\
\text { Internal consistency } \\
\quad(.87-.94) \\
+ \text { content and convergent } \\
\text { validity }\end{array}$ \\
\hline
\end{tabular}

was reviewed with the participants and they again had the opportunity to ask any questions. The document included the purpose of the study, procedures, risks and benefits, alternatives, confidentiality, rights, and study contact information. If the participant agreed to be included in the study at that point, the document was signed and dated. Confidentiality of participants was maintained by using number identifiers on all 
tools. Appendices Q and R include the cover letters and informed consent forms for the pilot and main studies.

Demographic information was obtained at the time of recruitment and participants filled out the Cognitive Age Scale and the MSPSS at this time. Participants enrolled in the project until the quota of each strata was filled. On the day of the intervention, the participants were told the study involved collecting baseline data for a study about performance. They were told they were participating in two different experiments, the first set in one room, the second in another room, and then the original measures will be repeated in the first room. They were instructed that additional information about the study will be presented at a debriefing at the end of data collection.

Consent was obtained and then heart rate, blood pressure, and oxygen saturation rates were taken to ensure they met the inclusion criteria. Baseline measures of all dependent measures were taken. Participants were then randomly assigned to one of three groups using a table of random numbers: positive implicit stereotype activation, negative implicit stereotype activation, or a neutral group.

Stereotypes were activated via implicit methods using objects and then all dependent measures were re-tested for post test measurements. Participants were given their score on the SPPB and if the score indicated they were at risk for disability, they were educated on what they can do to prevent physical decline. A manipulation check was completed as outlined in Hess et al. $(2003 ; 2004)$. Participants were questioned by the researcher to determine if they were aware of any relationship between the priming manipulation and the dependent measures. The three questions were: "What do you think the purpose of the 
study was?", "How do you think the objects affected your behavior on the tests", and "Do you feel the objects represented a certain group of people?’. All participants were then debriefed about the real purpose and hypotheses of the study by the researcher. Appendix $\mathrm{S}$ and $\mathrm{T}$ include the debriefing protocols. They were thanked for their time and participation, instructed not to share the content of the sessions with others, and received the $\$ 10$ renumeration.

In an attempt to control for bias, evaluators who were not researchers, and were unaware of group assignment performed the outcome measurements. The evaluators were two physical therapists with at least 10 years experience working with older adults. They received a thorough training in measurement of the dependent measures, which included viewing the CD designed by the originators of the SPPB. Identical study protocols were used by both evaluators and a test was given at the end of the training. Both evaluators passed the test. Training assists in minimizing measurement error (Polit \& Beck, 2004).

\section{Data Analysis}

Statistical analysis was completed using the statistical package for the social sciences version 17.0 (SPSS). Data entry was performed by the researcher and then rechecked by a graduate assistant not involved in the research process.

For pretesting, a Chi Square analysis was utilized to determine whether there was a relationship between participants who were exposed to stereotypes of aging and those in the neutral condition to determine whether the participants chose to make a stereotypical word on the word completion task. A Chi Square analysis was chosen because we wanted to determine whether there was a relationship between two categorical variables. The 
assumptions of the Chi Square analysis are that each person contributes only to one cell of the contingency table and the expected frequencies in each cell are above five (Field, 2005).

Means and standard deviations were computed for all dependent measures and sociodemographic variables which were continuous. Missing data was analyzed to determine if a pattern exists. If a pattern was found, the data was handled by deleting cases which was appropriate to the situation.

The presence of univariate or multivariate outliers was determined through use of boxplots, Z-scores and Mahalanobis distance, respectively. Any identified outliers were examined to determine its cause. If the error was due to an error in data entry, the error was corrected, otherwise they were dropped. Selection bias was evaluated using ANOVA to determine whether randomization yielded equal groups with regards to age and perceived social support, using Kruskal-Wallis to determine whether randomization yielded equal groups with regards to socioeconomic status, and education; and using Chi Square analysis to determine whether randomization yielded equal groups with regards to gender and race.

In order to address the first research question, MANCOVA was utilized to determine whether there was a difference between the three groups on the three outcome measures. MANCOVA was chosen since there are three dependent variables at a continuous level and one independent variable which is categorical. Use of MANCOVA decreases fishing and error rate problems since it takes into account multiple comparisons of mean differences among the three dependent variables. Use of a covariate in MANOVA 
controls for the effect of the covariate on the dependent variables (Mertler \& Vannatta, 2002). Since self-relevance has been identified as influencing the effect of stereotype activation (O'Brien \& Hummert, 2006; Shih et al., 2002), it was utilized as a covariate and was measured using the Cognitive Age Scale. The alpha level was set at .05 which is interpreted as a 5\% chance of incorrectly rejecting the null hypothesis.

The assumptions for MANCOVA were investigated to determine whether observations were independent of each other, the dependent variables follow a normal distribution in each group, there was homogeneity of variance-covariance, and the relationship between the dependent variables and the covariate was linear (Mertler \& Vannatta, 2002). Normality was tested for each independent DV by reviewing boxplots and histograms as well as completing the Kolmogorov-Smirnov test of normality. Homogeniety of variance-covariance was tested through use of Box's Test. Linearity was tested through the use of scatterplots and Pearson correlation coefficients.

In order to address the second research question, multiple linear regression was used to determine whether there was a relationship in the amount of change on each dependent variable with age, gender, socioeconomic status, race, education, and perceived social support. These sociodemographic variables have been shown to predict changes in physical performance in community dwelling older adults (Seeman et al., 1994; Sibbritt et al., 2007). Amount of change on the dependent variables was the outcome variable. Age, gender, socioeconomic status, race, education, and perceived social support were the predictor variables. The multiple regression formulas for the current study are as follows: 


$$
\begin{aligned}
& \mathrm{Y}_{\Delta \text { gait speed }}=\left(\mathrm{B}_{0}+\mathrm{B}_{1} \text { age }+\mathrm{B}_{2} \text { gender }+\mathrm{B}_{3} \text { socioeconomic status }+\mathrm{B}_{4} \text { race }+\mathrm{B}_{5}\right. \text { education } \\
& \left.+\mathrm{B}_{6} \text { social support }\right)+\mathrm{Ei} \\
& \mathrm{Y}_{\Delta \text { balance }}=\left(\mathrm{B}_{0}+\mathrm{B}_{1} \text { age }+\mathrm{B}_{2} \text { gender }+\mathrm{B}_{3} \text { socioeconomic status }+\mathrm{B}_{4} \text { race }+\mathrm{B}_{5}\right. \text { education } \\
& \left.+\mathrm{B}_{6} \text { social support }\right)+\mathrm{Ei} \\
& \mathrm{Y}_{\Delta \text { LE performance }}=\left(\mathrm{B}_{0}+\mathrm{B}_{1} \text { age }+\mathrm{B}_{2} \text { gender }+\mathrm{B}_{3} \text { socioeconomic status }+\mathrm{B}_{4} \text { race }+\mathrm{B}_{5}\right. \\
& \text { education } \left.+\mathrm{B}_{6} \text { social support }\right)+\mathrm{E} i
\end{aligned}
$$

In order to determine whether self-relevance interacts with the manipulation to predict physical performance, a second group of regression analyses were run. Amount of change on the dependent variables was the outcome variable. Self-relevance and the interaction between self-relevance and type of manipulation were the predictor variables. The multiple regression formulas for the current study are as follows:

$\mathrm{Y}_{\Delta \text { gait speed }}=\left(\mathrm{B}_{0}+\mathrm{B}_{1}\right.$ self-relevance $+\mathrm{B}_{2}$ type of manipulation $+\mathrm{B}_{3}$ self-relevance*type of manipulation) $+\mathrm{Ei}$

$\mathrm{Y}_{\Delta \text { balance }}=\left(\mathrm{B}_{0}+\mathrm{B}_{1}\right.$ self-relevance $+\mathrm{B}_{2}$ type of manipulation $+\mathrm{B}_{3}$ self-relevance $*$ type of manipulation) $+\mathrm{Ei}$

$\mathrm{Y}_{\Delta \mathrm{LE} \text { performance }}=\left(\mathrm{B}_{0}+\mathrm{B}_{1}\right.$ self-relevance $+\mathrm{B}_{2}$ type of manipulation $+\mathrm{B}_{3}$ self-relevance *type of manipulation) $+\mathrm{Ei}$

The alpha level was set at .05 for both sets of analyses, which is interpreted as a 5\% chance of incorrectly rejecting the null hypothesis. The assumptions of multiple linear regression including multicollinearity, homoscedasticity, independence of outcome variables, and linearity between the independent variables and the dependent variable were tested. Multicollinearity among the predictor variables were analyzed using the tolerance statistic. A cut off of 0.1 was utilized to determine whether multicollinearity exists. Histograms and a normal probability plot of the residuals were utilized to 
determine whether the assumptions of linearity and homoscedasticity have been met.

Table 4 presents an overview of the relationship between the hypotheses and the statistical tests for hypotheses 1-9 while Table 5 presents the relationship for hypotheses

10-15.

Table 4. Overview of Relationships Between the Hypotheses 1-9 and the Statistical Tests

\begin{tabular}{|c|c|}
\hline Hypothesis & Statistical test \\
\hline $\begin{array}{l}\text { H1: There will be a significant difference in gait speed between } \\
\text { older adults who are exposed to positive stereotypes of aging and } \\
\text { those in the neutral condition while controlling for self-relevance. }\end{array}$ & MANCOVA post hoc testing \\
\hline $\begin{array}{l}\text { H2: There will be a significant difference in gait speed between } \\
\text { older adults who are exposed to negative stereotypes of aging and } \\
\text { those in the neutral condition while controlling for self-relevance. }\end{array}$ & MANCOVA post hoc testing \\
\hline $\begin{array}{l}\text { H3: There will be a significant difference in gait speed between } \\
\text { older adults who are exposed to negative stereotypes of aging and } \\
\text { those exposed to positive stereotypes of aging while controlling } \\
\text { for self-relevance. }\end{array}$ & MANCOVA post hoc testing \\
\hline $\begin{array}{l}\text { H4: There will be a significant difference in standing balance } \\
\text { between older adults who are exposed to positive stereotypes of } \\
\text { aging and those in the neutral condition while controlling for self- } \\
\text { relevance. }\end{array}$ & MANCOVA post hoc testing \\
\hline $\begin{array}{l}\text { H5: There will be a significant difference in standing balance } \\
\text { between older adults who are exposed to negative stereotypes of } \\
\text { aging and those in the neutral condition while controlling for self- } \\
\text { relevance. }\end{array}$ & MANCOVA post hoc testing \\
\hline $\begin{array}{l}\text { H6: There will be a significant difference in standing balance } \\
\text { between older adults who are exposed to negative stereotypes of } \\
\text { aging and those exposed to positive stereotypes of aging while } \\
\text { controlling for self-relevance. }\end{array}$ & MANCOVA post hoc testing \\
\hline $\begin{array}{l}\text { H7: There will be a significant difference in lower extremity } \\
\text { muscle performance between older adults who are exposed to } \\
\text { positive stereotypes of aging and those in the neutral condition } \\
\text { while controlling for self-relevance. }\end{array}$ & MANCOVA post hoc testing \\
\hline $\begin{array}{l}\text { H8: There will be a significant difference in lower extremity } \\
\text { muscle performance between older adults who are exposed to } \\
\text { negative stereotypes of aging and those in the neutral condition } \\
\text { while controlling for self-relevance. }\end{array}$ & MANCOVA post hoc testing \\
\hline $\begin{array}{l}\text { H9: There will be a significant difference in lower extremity } \\
\text { muscle performance between older adults who are exposed to } \\
\text { negative stereotypes of aging and those exposed to positive } \\
\text { stereotypes of aging while controlling for self-relevance. }\end{array}$ & MANCOVA post hoc testing \\
\hline
\end{tabular}


Table 5. Overview of Relationships Between the Hypotheses 10-15 and the Statistical Tests

\begin{tabular}{|c|c|}
\hline Hypothesis & Statistical test \\
\hline $\begin{array}{l}\text { H10: There will be a significant association between age } \\
\text { and amount of change in physical performance after } \\
\text { exposure to stereotypes of aging while controlling for } \\
\text { gender, socioeconomic status, race, education, and } \\
\text { perceived social support. }\end{array}$ & Multiple Linear Regression \\
\hline $\begin{array}{l}\text { H11: There will be a significant association between gender } \\
\text { and amount of change in physical performance after } \\
\text { exposure to stereotypes of aging while controlling for age, } \\
\text { socioeconomic status, race, education, and perceived social } \\
\text { support. }\end{array}$ & Multiple Linear Regression \\
\hline $\begin{array}{l}\text { H12: There will be a significant association between } \\
\text { socioeconomic status and amount of change in physical } \\
\text { performance after exposure to stereotypes of aging while } \\
\text { controlling for age, gender, race, education, and perceived } \\
\text { social support. }\end{array}$ & Multiple Linear Regression \\
\hline $\begin{array}{l}\text { H13: There will be a significant association between race } \\
\text { and amount of change in physical performance after } \\
\text { exposure to stereotypes of aging while controlling for age, } \\
\text { gender, socioeconomic status, education, and perceived } \\
\text { social support. }\end{array}$ & Multiple Linear Regression \\
\hline $\begin{array}{l}\text { H14: There will be a significant association between } \\
\text { education and amount of change in physical performance } \\
\text { after exposure to stereotypes of aging while controlling for } \\
\text { age, gender, socioeconomic status, race, and perceived } \\
\text { social support. }\end{array}$ & Multiple Linear Regression \\
\hline $\begin{array}{l}\text { H15: There will be a significant association between } \\
\text { perceived social support and amount of change in physical } \\
\text { performance after exposure to stereotypes of aging while } \\
\text { controlling for age, gender, socioeconomic status, race, and } \\
\text { education. }\end{array}$ & Multiple Linear Regression \\
\hline
\end{tabular}




\section{CHAPTER FOUR: RESULTS}

Chapter Four provides a description of the results of data analysis for the interview about stereotypes, the pilot study and the main study. The purpose of the interview was to determine which objects should represent positive and negative stereotypes of aging. These objects were then utilized in both the pilot and main studies. The purpose of the pilot study was to determine whether exposure to objects representing stereotypes of aging truly elicited stereotypes of aging. Chapter Four includes the results of Chi Square testing to determine whether a group of older adults exposed to objects representing stereotypes of aging were more likely than a group exposed to a neutral condition to complete words as stereotypical. An additional Chi Square analysis was run to determine whether those who were exposed to objects representing stereotypes of aging were more likely to complete words stereotypical of disability. Both results include an evaluation of the assumptions of Chi Square.

The purpose of the main study was to explore how stereotypes affect physical performance in older adults and to explore whether a relationship exists between certain demographic variables and the amount of change in physical performance after exposure to aging stereotypes. Chapter Four includes descriptive statistics, results of ANOVA, Kruskall Wallis and Chi Square testing to determine whether the groups exposed to either positive stereotypes, negative stereotypes, or a neutral condition were equal at pretest. In 
order to address the first research question and Hypotheses 1- 9 (H1-H9), MANCOVA was utilized to determine whether implicit activation of stereotypes has an effect on the physical performance of older adults. Chapter Four includes the results of MANCOVA testing to determine whether there was a difference between the groups at post test while controlling for self-relevance. In addition, the results include an evaluation of the assumptions of ANOVA, Chi Square, and MANCOVA.

In order to address the second research question and Hypotheses $10-15$ (H10- H15), multiple linear regression analyses were performed to determine whether a relationship exists between certain demographic variables and the change in physical performance after exposure to aging stereotypes. Results of multiple regression and evaluation of the assumptions of multiple linear regression are included.

\section{Interview}

The seven most common negative objects chosen based upon an interview of 18 older adults were a cane, walker, wheelchair, reading glasses, hearing aid, grey hair, and medication. The older adults rated the valence of these objects on average from a " 1 " to a “ 3 " on a 7- point Likert scale with " 1 " representing a strongly negative view of aging and “3” representing a negative view. The seven most positive objects chosen were crafts, crossword puzzles, classic movies, books (especially mysteries), old time records, free health insurance (Medicare), and family/grandchildren. On average, the older adults rated the valence of these objects from a "5" to a "7" on a 7- point Likert scale with "5" representing a positive view of aging and "7" representing a strongly positive vi 


\section{Pilot Study}

All assumptions for Chi Square testing were met. Each person contributed to only one cell and the expected frequencies were greater than five. As shown in Table 6, there was a significant relationship between those who were exposed to objects representing stereotypes of aging and the amount of stereotypical words created on a word completion task, $\mathrm{X}^{2}(1, \mathrm{~N}=23)=3.84, \mathrm{p}=.05$. Those who were exposed to stereotypes of aging were more likely to develop a stereotypical word of aging on a word completion task.

Table 6. Results of Chi Square Testing $(n=24)$

\begin{tabular}{|c|l|l|l|l|}
\hline & & \multicolumn{2}{|c|}{ Stereotypical Word (Aging) } & \\
\hline \multirow{4}{*}{$\begin{array}{c}\text { Exposure } \\
\begin{array}{c}\text { To Objects of } \\
\text { Aging }\end{array}\end{array}$} & Yes & Yes & No & Total \\
\cline { 2 - 5 } & No & 45 & 57 & 102 \\
\cline { 2 - 5 } & Total & 27 & 62 & 89 \\
\hline
\end{tabular}

All assumptions for the second Chi Square analysis were also met. Each person contributed to only one cell and the expected frequencies were greater than five. As shown in Table 7, the relationship between those who were exposed to stereotypes of aging and the amount of stereotypical words of disability that were created was not significant, $\mathrm{X}^{2}(1, \mathrm{~N}=24)=3.14, \mathrm{p}=.095$. Those who were exposed to objects representing stereotypes of aging were not more likely to develop stereotypical words of disability on a word completion task. 
Table 7. Results of Chi Square Testing $(n=24)$

\begin{tabular}{|c|l|c|c|c|}
\hline & & \multicolumn{2}{|c|}{ Stereotypical Word (Disability) } & \\
\hline \multirow{4}{*}{$\begin{array}{c}\text { Exposure } \\
\text { To Objects of } \\
\text { Aging }\end{array}$} & Yes & Yes & No & Total \\
\cline { 2 - 5 } & No & 27 & 82 & 89 \\
\cline { 2 - 5 } & Total & 21 & 87 & 108 \\
\hline
\end{tabular}

\section{Main Study}

Ninety-six participants were included in the main study and underwent random assignment into three groups: positive exposure, negative exposure and a neutral condition. One participant in the control group was excluded after performing all tests since the evaluators were unsure if he understood all directions due to a language barrier. This brought the total number of participants to 95 . The study sample was mostly female (61\%), Non-Hispanic White (93\%), had received at least a high school education or GED (79\%), and made $<\$ 20,000$ during the previous tax year $(46 \%)$. The mean age of the participants was $75.0 \pm 7.4$ years. They averaged $62.8 \pm 10.3$ on the Cognitive Age Scale and $5.6 \pm 1.5$ on the MSPSS. Results of ANOVA, Kruskall Wallis, and Chi Square testing showed the groups did not differ significantly in any baseline characteristics except for race. Those who were in the group exposed to positive stereotypes of aging were more likely to be African American or Asian than those in the other two groups. Randomization was fairly successful in creating equal groups, at least on the variables tested. Table 8 presents baseline characteristics of the participants in each group and results of ANOVA, Kruskall Wallis, and Chi Square testing. 
Table 8. Baseline Characteristics of the Participants and Results of ANOVA, Kruskal Wallis, and Chi Square Testing

\begin{tabular}{|c|c|c|c|c|c|}
\hline Variable & $\begin{array}{l}\text { Group } \\
\text { exposed to } \\
\text { negative } \\
\text { stereotypes } \\
\text { of aging } \\
(\mathrm{n}=32) \\
\end{array}$ & $\begin{array}{l}\text { Group } \\
\text { exposed to } \\
\text { positive } \\
\text { stereotypes } \\
\text { of aging } \\
(\mathrm{n}=32) \\
\end{array}$ & $\begin{array}{l}\text { Control } \\
\text { Group } \\
(n=31)\end{array}$ & $\begin{array}{l}\mathrm{X}^{2} \text { or } \\
\mathrm{F}- \\
\text { value }\end{array}$ & $\begin{array}{l}\mathrm{P}- \\
\text { value }\end{array}$ \\
\hline Age $($ Mean \pm SD) & $73.8 \pm 6.9$ & $76.0 \pm 8.2$ & $75.8 \pm 7.1$ & .88 & .48 \\
\hline Gender & & & & .07 & .97 \\
\hline Women (n) & 19 & 20 & 19 & & \\
\hline $\operatorname{Men}(n)$ & 13 & 12 & 12 & & \\
\hline Race & & & & 9.5 & $.05^{*}$ \\
\hline White (n) & 31 & 26 & 31 & & \\
\hline African American (n) & 1 & 5 & 0 & & \\
\hline Asian (n) & 0 & 1 & 0 & & \\
\hline Education & & & & 8.05 & .23 \\
\hline No high school diploma or GED (n) & 6 & 8 & 6 & & \\
\hline High school diploma or GED (n) & 8 & 11 & 15 & & \\
\hline Some college but no Bachelor's (n) & 9 & 9 & 7 & & \\
\hline Bachelor's degree or higher (n) & 9 & 4 & 2 & & \\
\hline Socioeconomic status & & & & 12.3 & $.135 * *$ \\
\hline$<\$ 20,000(\mathrm{n})$ & 11 & 18 & 15 & & \\
\hline$\$ 20,000-\$ 34,999(n)$ & 7 & 5 & 9 & & \\
\hline$\$ 35,000-\$ 49,999(\mathrm{n})$ & 3 & 1 & 4 & & \\
\hline$\$ 50,000-\$ 99,999(n)$ & 5 & 2 & 0 & & \\
\hline$<\$ 100,000(\mathrm{n})$ & 2 & 0 & 3 & & \\
\hline Cognitive Age Scale (Mean \pm SD) & $62.7 \pm 9.1$ & $64.3 \pm 11.4$ & $61.5 \pm 10.4$ & .59 & .55 \\
\hline MSPSS (Mean \pm SD) & $6.0 \pm 1.1$ & $5.3 \pm 1.8$ & $5.5 \pm 1.4$ & 1.82 & .17 \\
\hline
\end{tabular}

$* \mathrm{p} \leq .05$

** Assumptions of Chi Square were violated (less than 5 expected frequency)

When examining the outcome variables at baseline, the mean time the participants were able to hold tandem stance was $31.8 \pm 25.4$ seconds, the mean time it took to walk 4 meters was $5.0 \pm 1.4$ seconds, and the mean time to stand up from a chair five times was $13.1 \pm 9.5$ seconds. Results of ANOVA testing indicate that the groups were comparable 
at baseline with regards to the outcome measures. Randomization was successful in creating equal groups with regards to physical performance. Table 9 presents baseline measures on the outcome variables for each group and results of ANOVA testing.

The mean time participants were exposed to the objects representing positive stereotypes, negative stereotypes, or the neutral condition was 183.2 seconds \pm 56.6 seconds. Results of ANOVA testing showed that exposure to the objects was not similar between the three groups $F(2,94)=4.7, \mathrm{p} .=.01$. Post hoc testing indicates that the group exposed to positive stereotypes of aging was exposed for an average of 28 seconds longer than those exposed to negative stereotypes of aging and 41 seconds longer than those in the neutral condition. Table 10 presents the average length of intervention for each group and results of ANOVA testing.

Table 9. Baseline Measures on the Outcome Variables and Results of ANOVA Testing

\begin{tabular}{|l|l|l|l|l|l|}
\hline Variable & $\begin{array}{l}\text { Group } \\
\text { exposed to } \\
\text { negative } \\
\text { stereotypes } \\
\text { of aging } \\
(\mathrm{n}=32)\end{array}$ & $\begin{array}{l}\text { Group } \\
\text { exposed to } \\
\text { positive } \\
\text { stereotypes } \\
\text { of aging } \\
(\mathrm{n}=32)\end{array}$ & $\begin{array}{l}\text { Control } \\
\text { Group } \\
(\mathrm{n}=31)\end{array}$ & $\begin{array}{l}\text { F- } \\
\text { value }\end{array}$ & $\begin{array}{l}\text { P- } \\
\text { value }\end{array}$ \\
\hline $\begin{array}{l}\text { Balance measure in seconds } \\
\text { (Mean } \pm \text { SD) }\end{array}$ & $29.1 \pm 25.7$ & $35.8 \pm 24.9$ & $30.5 \pm 25.8$ & .60 & .55 \\
\hline $\begin{array}{l}\text { Timed four meter walk in seconds } \\
\text { (Mean } \pm \text { SD) }\end{array}$ & $4.7 \pm 1.6$ & $5.4 \pm 1.4$ & $4.8 \pm 1.2$ & 2.1 & .13 \\
\hline $\begin{array}{l}\text { Chair stand test in seconds } \\
\text { (Mean } \pm \text { SD) }\end{array}$ & $12.9 \pm 9.5$ & $14.1 \pm 10.0$ & $12.2 \pm 9.1$ & .33 & .72 \\
\hline
\end{tabular}


Table 10. Intervention Time for Each Group

\begin{tabular}{|l|l|l|l|l|l|}
\hline & $\begin{array}{l}\text { Group } \\
\text { exposed to } \\
\text { negative } \\
\text { stereotypes } \\
\text { of aging } \\
(\mathrm{n}=32)\end{array}$ & $\begin{array}{l}\text { Group } \\
\text { exposed to } \\
\text { positive } \\
\text { stereotypes } \\
\text { of aging } \\
(\mathrm{n}=31)\end{array}$ & $\begin{array}{l}\text { Control } \\
\text { Group } \\
(\mathrm{n}=31)\end{array}$ & F-value & $\begin{array}{l}\mathrm{P} \\
\text { value }\end{array}$ \\
\hline $\begin{array}{l}\text { Intervention time in seconds } \\
(\text { Mean } \pm \text { SD) }\end{array}$ & $178 \pm 45$ & $206 \pm 54$ & $165 \pm 42$ & 4.7 & $.01 *$ \\
\hline
\end{tabular}

$* \mathrm{p} \leq .05$

Data was not missing for any of the outcome variables. One percent of the descriptive data was missing for education, the Cognitive Age Scale, and MSPSS and 11\% was missing for socioeconomic status. Descriptive data was analyzed by only omitting the one cell where data was missing.

Histograms, boxplots, and results of the Kolmogorov-Smirnov test of normality indicate the data was normally distributed for the timed four meter walk measure but not the balance or chair stand measures. The presence of four outliers were noted and these cases were removed from the MANCOVA analyses. A square root transformation was successful in normalizing the data for the chair stand test but not for the standing balance measure. Table 11 presents the results of the Kolmogorov-Smirnov test of normality before and after transformation. Upon further examination, it was apparent that there was a ceiling effect with the balance measure. Forty-four percent of the participants were able to hold tandem stance for 60 seconds which was the maximum time allotted by the test. Due to the high number of cases which needed to be removed from the data, the entire variable was removed from the analysis. Evaluation of independence, homogeneity of 
Table 11. Results of Komogorov-Smironv Test of Normality Before and After Square Root Transformation

\begin{tabular}{|c|c|c|c|c|c|}
\hline & & $\begin{array}{l}\text { Before } \\
\text { transformation }\end{array}$ & & $\begin{array}{l}\text { After } \\
\text { transformation }\end{array}$ & \\
\hline Measure & Group & K-S statistic & P-value & K-S statistic & $\begin{array}{l}\text { P- } \\
\text { value }\end{array}$ \\
\hline \multirow[t]{3}{*}{$\begin{array}{l}\text { Post } \\
\text { standing } \\
\text { balance }\end{array}$} & $\begin{array}{l}\text { Exposure to } \\
\text { negative stereotypes } \\
\text { of aging } \\
(\mathrm{n}=32)\end{array}$ & .25 & $.00^{*}$ & .23 & $.00^{*}$ \\
\hline & $\begin{array}{l}\text { Exposure to positive } \\
\text { stereotypes of aging } \\
(\mathrm{n}=32)\end{array}$ & .35 & $.00^{*}$ & .34 & $.00^{*}$ \\
\hline & $\begin{array}{l}\text { Exposure to neutral } \\
\text { objects } \\
(\mathrm{n}=31)\end{array}$ & .28 & $.00^{*}$ & .27 & $.00^{*}$ \\
\hline \multirow[t]{3}{*}{$\begin{array}{l}\text { Post four } \\
\text { meter walk }\end{array}$} & $\begin{array}{l}\text { Exposure to } \\
\text { negative stereotypes } \\
\text { of aging } \\
(\mathrm{n}=32)\end{array}$ & .14 & .10 & .12 & .20 \\
\hline & $\begin{array}{l}\text { Exposure to positive } \\
\text { stereotypes of aging } \\
(\mathrm{n}=32)\end{array}$ & .13 & .17 & .13 & .20 \\
\hline & $\begin{array}{l}\text { Exposure to neutral } \\
\text { objects } \\
(\mathrm{n}=31)\end{array}$ & .12 & .20 & .10 & .20 \\
\hline \multirow[t]{3}{*}{$\begin{array}{l}\text { Post chair } \\
\text { stand test }\end{array}$} & $\begin{array}{l}\text { Exposure to } \\
\text { negative stereotypes } \\
\text { of aging } \\
(\mathrm{n}=32)\end{array}$ & .15 & .08 & .11 & .20 \\
\hline & $\begin{array}{l}\text { Exposure to positive } \\
\text { stereotypes of aging } \\
(\mathrm{n}=32)\end{array}$ & .26 & $.00^{*}$ & .17 & .06 \\
\hline & $\begin{array}{l}\text { Exposure to neutral } \\
\text { objects } \\
(\mathrm{n}=31)\end{array}$ & .11 & .2 & .10 & .20 \\
\hline
\end{tabular}

$* \mathrm{p} \leq .05$, indicating data was not normally distributed

variance-covariance matrices, and homogeneity of regression slopes found that these assumptions of MANCOVA were met. 
The results of MANCOVA testing revealed no significant difference between the groups in the full model, $\mathrm{F}(4,172)=.905, \mathrm{p} .=.463$. There was no difference between those exposed to positive stereotypes, negative stereotypes, or the neutral condition at post test for the timed four meter walk and chair stand measures. These results contradict our hypotheses (H1-H3, H7-H9). Table 12 presents the results of MANCOVA testing and Table 13 presents the outcomes of hypotheses testing (H1-H9). To ensure that removing the whole standing balance variable (H4-H6) from the analysis did not affect the results, a MANCOVA analysis was run including all three variables. These results were also non significant, $\mathrm{F}=.655, \mathrm{p}=.69$.

Table 12. Results of MANCOVA Testing $(n=91)$

\begin{tabular}{|l|l|l|l|}
\hline & Pillais trace & F-value & P value \\
\hline & .04 & .91 & .46 \\
\hline
\end{tabular}

Table 13. Results of Hypothesis Testing (H1-H9)

\begin{tabular}{|l|l|l|}
\hline \multicolumn{1}{|c|}{ Hypothesis } & Statistical test & \multicolumn{1}{c|}{ Results } \\
\hline $\begin{array}{l}\text { H1: There will be a significant } \\
\text { difference in gait speed between } \\
\text { older adults who are exposed to } \\
\text { positive stereotypes of aging and } \\
\text { those in the neutral condition for } \\
\text { self-relevance. }\end{array}$ & $\begin{array}{l}\text { MANCOVA } \\
\text { post hoc testing }\end{array}$ & $\begin{array}{l}\text { There was no significant difference in } \\
\text { gait speed between older adults who } \\
\text { are exposed to positive stereotypes of } \\
\text { aging and those in the neutral } \\
\text { condition while controlling for self- } \\
\text { relevance. }\end{array}$ \\
\hline $\begin{array}{l}\text { H2: There will be a significant } \\
\text { difference in gait speed between } \\
\text { older adults who are exposed to } \\
\text { negative stereotypes of aging and } \\
\text { those in the neutral condition } \\
\text { while controlling for self- } \\
\text { relevance. }\end{array}$ & $\begin{array}{l}\text { MANCOVA } \\
\text { post hoc testing }\end{array}$ & $\begin{array}{l}\text { There was no significant difference in } \\
\text { gait speed between older adults who } \\
\text { are exposed to negative stereotypes of } \\
\text { aging and those in the neutral } \\
\text { condition while controlling for self- } \\
\text { relevance. }\end{array}$ \\
\hline $\begin{array}{l}\text { H3: There will be a significant } \\
\text { difference in gait speed between } \\
\text { older adults who are exposed to } \\
\text { negative stereotypes of aging and }\end{array}$ & post hoc testing & $\begin{array}{l}\text { There was no significant difference in } \\
\text { gait speed between older adults who } \\
\text { are exposed to negative stereotypes of } \\
\text { aging and those exposed to positive }\end{array}$ \\
\hline
\end{tabular}




\begin{tabular}{|c|c|c|}
\hline $\begin{array}{l}\text { those exposed to positive } \\
\text { stereotypes of aging while } \\
\text { controlling for self-relevance. }\end{array}$ & & $\begin{array}{l}\text { stereotypes of aging while controlling } \\
\text { for self-relevance. }\end{array}$ \\
\hline $\begin{array}{l}\text { H4: There will be a significant } \\
\text { difference in standing balance } \\
\text { between older adults who are } \\
\text { exposed to positive stereotypes of } \\
\text { aging and those in the neutral } \\
\text { condition while controlling for } \\
\text { self-relevance. }\end{array}$ & $\begin{array}{l}\text { MANCOVA } \\
\text { post hoc testing }\end{array}$ & $\begin{array}{l}\text { Not able to determine due to problems } \\
\text { with a ceiling effect }\end{array}$ \\
\hline $\begin{array}{l}\text { H5: There will be a significant } \\
\text { difference in standing balance } \\
\text { between older adults who are } \\
\text { exposed to negative stereotypes of } \\
\text { aging and those in the neutral } \\
\text { condition while controlling for } \\
\text { self-relevance. }\end{array}$ & $\begin{array}{l}\text { MANCOVA } \\
\text { post hoc testing }\end{array}$ & $\begin{array}{l}\text { Not able to determine due to problems } \\
\text { with a ceiling effect }\end{array}$ \\
\hline $\begin{array}{l}\text { H6: There will be a significant } \\
\text { difference in standing balance } \\
\text { between older adults who are } \\
\text { exposed to negative stereotypes of } \\
\text { aging and those exposed to } \\
\text { positive stereotypes of aging } \\
\text { while controlling for self- } \\
\text { relevance. }\end{array}$ & $\begin{array}{l}\text { MANCOVA } \\
\text { post hoc testing }\end{array}$ & $\begin{array}{l}\text { Not able to determine due to problems } \\
\text { with a ceiling effect }\end{array}$ \\
\hline $\begin{array}{l}\text { H7: There will be a significant } \\
\text { difference in lower extremity } \\
\text { muscle performance between } \\
\text { older adults who are exposed to } \\
\text { positive stereotypes of aging and } \\
\text { those in the neutral condition } \\
\text { while controlling for self- } \\
\text { relevance. }\end{array}$ & $\begin{array}{l}\text { MANCOVA } \\
\text { post hoc testing }\end{array}$ & $\begin{array}{l}\text { There was no significant difference in } \\
\text { lower extremity muscle performance } \\
\text { between older adults who are exposed } \\
\text { to positive stereotypes of aging and } \\
\text { those in the neutral condition while } \\
\text { controlling for self-relevance. }\end{array}$ \\
\hline $\begin{array}{l}\text { H8: There will be a significant } \\
\text { difference in lower extremity } \\
\text { muscle performance between } \\
\text { older adults who are exposed to } \\
\text { negative stereotypes of aging and } \\
\text { those in the neutral condition } \\
\text { while controlling for self- } \\
\text { relevance. }\end{array}$ & $\begin{array}{l}\text { MANCOVA } \\
\text { post hoc testing }\end{array}$ & $\begin{array}{l}\text { There was no significant difference in } \\
\text { lower extremity muscle performance } \\
\text { between older adults who are exposed } \\
\text { to negative stereotypes of aging and } \\
\text { those in the neutral condition while } \\
\text { controlling for self-relevance. }\end{array}$ \\
\hline
\end{tabular}




\begin{tabular}{|l|l|l|}
$\begin{array}{l}\text { H9: There will be a significant } \\
\text { difference in lower extremity } \\
\text { muscle performance between } \\
\text { older adults who are exposed to } \\
\text { negative stereotypes of aging and } \\
\text { those exposed to positive } \\
\text { stereotypes of aging while } \\
\text { controlling for self-relevance. }\end{array}$ & $\begin{array}{l}\text { MANCOVA } \\
\text { post hoc testing }\end{array}$ & $\begin{array}{l}\text { There was no significant difference in } \\
\text { lower extremity muscle performance } \\
\text { between older adults who are exposed } \\
\text { to negative stereotypes of aging and } \\
\text { those exposed to positive stereotypes } \\
\text { of aging while controlling for self- } \\
\text { relevance. }\end{array}$ \\
\hline
\end{tabular}

Even though the Cognitive Age Scale was used as a covariate in our study, an additional MANCOVA analysis was run to ensure our results were not confounded by those who did not self-identify with the older age group. All participants who did not rate themselves as 65 years of age or older on the Cognitive Age Scale were removed from data analysis, but the results of MANCOVA testing still were not significant, $F=.616$, $p$. $=.72$. There was no difference between the three groups on the dependent measures.

Separate multiple regression analyses were performed to determine whether the difference from pretest to post test on each of the three variables could be predicted by age, gender, socioeconomic status, race, education, and perceived social support. No significant relationship was found between the standing balance test $[\mathrm{F}(6,40)=.692$, $\mathrm{p}=.66]$, the timed 4-meter walk $[\mathrm{F}(6,91)=.898, \mathrm{p}=.51]$ or the chair stand test $[\mathrm{F}(6,91)$, $\mathrm{p}=1.656, \mathrm{p}=.16]$ and the sociodemographic variables. Table 14 presents the results of multiple regression testing and Table 15 for the outcomes of hypotheses testing (H10H15). Tolerance statistics were above .5 and VIF values were well below 10 , so we can safely assume there were no issues with multicollinearity. Evaluation of histograms and normal probability plots showed the assumptions of homoscedasticity and linearity were also met. 
A second group of multiple regression analyses were performed to determine

whether self-relevance interacted with the manipulation to predict physical performance.

No significant relationship was found between the standing balance test $[F(5,40)=1.254$,

Table 14: Results of Multiple Linear Regression Testing

\begin{tabular}{|c|c|c|c|c|}
\hline Variable & $\begin{array}{c}\text { Sum of } \\
\text { Squares }\end{array}$ & df & F-value & P-value \\
\hline $\begin{array}{c}\text { Standing Balance } \\
(\mathrm{n}=40)\end{array}$ & 1086.54 & 6 & .692 & .66 \\
\hline $\begin{array}{c}\text { Timed 4-meter } \\
\text { walk } \\
(\mathrm{n}=91)\end{array}$ & 2.497 & 6 & .898 & .51 \\
\hline $\begin{array}{c}\text { Chair stand test } \\
(\mathrm{n}=91)\end{array}$ & 19.627 & 6 & 1.656 & .16 \\
\hline
\end{tabular}

Table 15. Results of Hypotheses Testing (H10-H15)

\begin{tabular}{|c|c|c|}
\hline Hypothesis & Statistical test & Results \\
\hline $\begin{array}{l}\text { H10: There will be a } \\
\text { significant association between } \\
\text { age and amount of change in } \\
\text { physical performance after } \\
\text { exposure to stereotypes of } \\
\text { aging while controlling for } \\
\text { gender, socioeconomic status, } \\
\text { race, education, and perceived } \\
\text { social support. }\end{array}$ & $\begin{array}{l}\text { Multiple Linear } \\
\text { Regression }\end{array}$ & $\begin{array}{l}\text { There was no significant } \\
\text { association between age and } \\
\text { amount of change in physical } \\
\text { performance after exposure to } \\
\text { stereotypes of aging while } \\
\text { controlling for gender, } \\
\text { socioeconomic status, race, } \\
\text { education, and perceived } \\
\text { social support. }\end{array}$ \\
\hline $\begin{array}{l}\text { H11: There will be a } \\
\text { significant association between } \\
\text { gender and amount of change } \\
\text { in physical performance after } \\
\text { exposure to stereotypes of } \\
\text { aging while controlling for age, } \\
\text { socioeconomic status, race, } \\
\text { education, and perceived social } \\
\text { support. }\end{array}$ & $\begin{array}{l}\text { Multiple Linear } \\
\text { Regression }\end{array}$ & $\begin{array}{l}\text { There was no significant } \\
\text { association between gender } \\
\text { and amount of change in } \\
\text { physical performance after } \\
\text { exposure to stereotypes of } \\
\text { aging while controlling for } \\
\text { age, socioeconomic status, } \\
\text { race, education, and perceived } \\
\text { social support. }\end{array}$ \\
\hline $\begin{array}{l}\text { H12: There will be a } \\
\text { significant association between } \\
\text { socioeconomic status and }\end{array}$ & $\begin{array}{l}\text { Multiple Linear } \\
\text { Regression }\end{array}$ & $\begin{array}{l}\text { There was no significant } \\
\text { association between } \\
\text { socioeconomic status and }\end{array}$ \\
\hline
\end{tabular}




\begin{tabular}{|c|c|c|}
\hline $\begin{array}{l}\text { amount of change in physical } \\
\text { performance after exposure to } \\
\text { stereotypes of aging while } \\
\text { controlling for age, gender, } \\
\text { race, education, and perceived } \\
\text { social support. }\end{array}$ & & $\begin{array}{l}\text { amount of change in physical } \\
\text { performance after exposure to } \\
\text { stereotypes of aging while } \\
\text { controlling for age, gender, } \\
\text { race, education, and perceived } \\
\text { social support. }\end{array}$ \\
\hline $\begin{array}{l}\text { H13: There will be a } \\
\text { significant association between } \\
\text { race and amount of change in } \\
\text { physical performance after } \\
\text { exposure to stereotypes of } \\
\text { aging while controlling for age, } \\
\text { gender, socioeconomic status, } \\
\text { education, and perceived social } \\
\text { support. }\end{array}$ & $\begin{array}{l}\text { Multiple Linear } \\
\text { Regression }\end{array}$ & $\begin{array}{l}\text { There was no significant } \\
\text { association between race and } \\
\text { amount of change in physical } \\
\text { performance after exposure to } \\
\text { stereotypes of aging while } \\
\text { controlling for age, gender, } \\
\text { socioeconomic status, } \\
\text { education, and perceived } \\
\text { social support. }\end{array}$ \\
\hline $\begin{array}{l}\text { H14: There will be a } \\
\text { significant association between } \\
\text { education and amount of } \\
\text { change in physical } \\
\text { performance after exposure to } \\
\text { stereotypes of aging while } \\
\text { controlling for age, gender, } \\
\text { socioeconomic status, race, and } \\
\text { perceived social support. }\end{array}$ & $\begin{array}{l}\text { Multiple Linear } \\
\text { Regression }\end{array}$ & $\begin{array}{l}\text { There was no significant } \\
\text { association between education } \\
\text { and amount of change in } \\
\text { physical performance after } \\
\text { exposure to stereotypes of } \\
\text { aging while controlling for } \\
\text { age, gender, socioeconomic } \\
\text { status, race, and perceived } \\
\text { social support. }\end{array}$ \\
\hline $\begin{array}{l}\text { H15: There will be a } \\
\text { significant association between } \\
\text { perceived social support and } \\
\text { amount of change in physical } \\
\text { performance after exposure to } \\
\text { stereotypes of aging while } \\
\text { controlling for age, gender, } \\
\text { socioeconomic status, race, and } \\
\text { education. }\end{array}$ & $\begin{array}{l}\text { Multiple Linear } \\
\text { Regression }\end{array}$ & $\begin{array}{l}\text { There was no significant } \\
\text { association between perceived } \\
\text { social support and amount of } \\
\text { change in physical } \\
\text { performance after exposure to } \\
\text { stereotypes of aging while } \\
\text { controlling for age, gender, } \\
\text { socioeconomic status, race, } \\
\text { and education. }\end{array}$ \\
\hline
\end{tabular}

$\mathrm{p}=.29]$, the timed 4-meter walk $[\mathrm{F}(5,91)=.903, \mathrm{p}=.48]$ or the chair stand test $[\mathrm{F}(5,91)$, $\mathrm{p}=.497, \mathrm{p}=.78]$ and the interaction with self-relevance and the manipulation. Tolerance statistics were above .5 , so we can safely assume there were no issues with 
multicollinearity. Evaluation of histograms and normal probability plots showed the assumptions of homoscedasticity and linearity were also met.

During the debriefing, participants were asked if they felt the objects represented a certain group of people. Twenty-five percent of those who were exposed to negative stereotypes of aging responded "no", 31\% responded "older adults", 19\% responded "handicapped", and 13\% responded "older adults who are handicapped". Of the $75 \%$ who responded that the objects did represent a certain group of people, only two noted the association at the time of testing. The remaining participants reported they did not notice the association until they were asked the question at debriefing. None of the older adults exposed to positive stereotypes of aging responded that the objects represented a certain group of people. No one was able to identify the purpose of the study or thought their behavior was affected by the objects.

ICC values for test-retest reliability were 0.93 for timed four meter walk suggesting excellent reliability for this measure. 


\title{
CHAPTER 5: DISCUSSION
}

\author{
Interview
}

Older adults were interviewed in order to choose the objects representing positive and negative stereotypes of aging for both the pilot and main studies. They were asked to list all objects that come to mind when thinking about the older adult population. The theme of the seven objects representing negative stereotypes of aging are all visible or physical signs of what our culture believes is "inevitable decline" associated with aging. The theme of five of the seven objects representing positive stereotypes of aging (crafts, crossword puzzles, movies, books, and albums) are leisure activities. Leisure activities are associated with the common stereotype of "freedom," as it denotes older adults have more leisure time due to retirement. The theme of one of the objects (grandchildren) is a way to connect to the future by teaching, sharing experiences and imparting wisdom, and the other (Medicare) is the ability to stay healthy affordably. These themes are consistent with some of the common stereotypes listed in Table 1 but are not inclusive of the list as a whole (Chasteen et al., 2002, Thornton, 2002).

\section{Pilot Study}

The pilot study investigated whether exposure to the objects chosen by older adults noted above actually activated stereotypes of aging. The results of the pilot study indicate exposure to these objects did activate aging stereotypes. Those who were exposed to 
objects representing aging stereotypes were more likely to develop stereotypical words in a word sentence completion task.

The results of our pilot study are consistent with the results of the Kay et al. (2004) study that showed objects or images of objects associated with the business world activated the concept of competition. Material anthropologists have long claimed material objects carry values, ideas, and emotions implicitly (Dant, 1999; Graves-Brown, 2000). Objects are more than just the sizes, shapes, textures, and other distinguishing features seen visually. They go beyond this basic description. Objects acquire symbolic values as humans use them and these symbolic values are shaped by human use over the years (Graves-Brown, 2000). The results of the pilot study suggest that objects have implicit meaning and can activate stereotypes of aging associated with those meanings.

Several of the objects representing negative stereotypes of aging (especially the walker, cane, and wheelchair) may have activated the construct of disability instead of, or in addition to, the construct of aging. Results of Chi Square testing revealed that those who were exposed to objects representing negative stereotypes of aging were not more likely to develop stereotypes of disability on a word completion task. From these results, it appears the construct of disability was not activated. Even though several of the individual objects could have represented stereotypes of disability, when taken as a group they did not appear to activate disability stereotypes. For example, a walker could implicitly represent both stereotypes of aging and disability but the addition of grey hair attaches meaning to the other objects as a group and implies aging. 
During the debriefing, $43 \%$ of participants reported the objects representing negative stereotypes of aging reflected either the handicapped or older adults who are handicapped. It appears that at least explicitly, the objects chosen may represent stereotypes of disability, even though implicitly according to the pilot they did not activate these stereotypes. Since the purpose of the main study was to determine the effect of implicit stereotypes on physical performance, it was more important that implicit stereotypes of disability were not activated.

\section{Main Study}

The main study investigated the effects of aging stereotypes on the physical performance of older adults and attempted to fill some current gaps in the literature. There is a dearth of information on the effect of stereotype activation on physical performance. Those studies which have been completed have used a limited definition of physical performance and their dependent measures have not been documented as reliable and valid (Hausdorff et al., 1999; Levy 2000). Research has not accounted for psychosocial variables which can moderate the effects of stereotype activation on behavior. The current study also included a neutral priming condition, a pretest, and expanded recruitment efforts to be representative of typical older adults in the United States.

The results of this study do not support our hypotheses that there will be significant differences in gait speed (H1-H3), and lower extremity muscle performance (H7-H9) between older adults exposed to positive stereotypes, negative stereotypes, or the neutral condition. Our hypotheses regarding standing balance (H4-H6) could not be confirmed or 
denied due to issues with a ceiling effect. The results of our study did not support our second group of hypotheses $(\mathrm{H} 10-\mathrm{H} 15)$ which predicted that age, gender, socioeconomic status, race, education, and perceived social support are associated with the amount of change in physical performance after exposure to aging stereotypes.

The fact that there was no difference in gait speed (H1-H3) and lower extremity muscle performance (H7-H9) between older adults exposed to positive stereotypes, negative stereotypes, or neutral objects is intriguing. According to the literature, aging stereotypes can affect behavior (Hausdorff et al, 1999; Levy 1996; Levy et al., 19992000; Levy, 2000) and our pilot study indicated that exposure to objects representing older adults did activate stereotypes of aging.

Our results mostly contradict the literature on the effect of aging stereotypes on physical performance. Hausdorff et al. (1999) found a significant difference between the positively and negatively primed groups with regards to gait speed and swing time. Within group differences found exposure to positive stereotypes of aging improved gait speed and swing time, while exposure to negative stereotypes did not result in any change. Our results also indicate that exposure to negative stereotypes of aging does not result in a change in physical performance. However, we also did not find a change in those who were exposed to positive stereotypes. Levy (2000) established that exposure to aging stereotypes changed the attributes of older adults' handwriting. Participants' handwriting samples appeared "older" after exposure to negative stereotypes of aging and "younger" after exposure to positive stereotypes. 
In the current study, participants were aware they were being tested on the physical performance measures. They were told the research was a study on performance and that their total score on the SPPB would determine whether they were at risk for becoming disabled. In the Hausdorff et al. study (1999), participants were timed while walking to and from the room. Their outcome measure was not a screen for any chronic condition with which they may have been motivated to perform well. In the Levy (2000) study, handwriting analyses were taken from a demographic survey and recollection task. Participants were unaware they were being tested.

Although we did not document the number, many participants verbalized they were determined to perform better on the post test, especially when they did not perform as well as they wished on the pretest. In reviewing the data, $47 \%$ of the participants improved their time by more than $5 \%$ from pretest to post test on the timed four meter walk and $53 \%$ improved their time more than $5 \%$ on the chair stand test, no matter to which group they were assigned. These improvements can be attributed to increased motivation to do better the second time around or possibly due to a practice effect.

In addition, even though participants were instructed not to discuss the purpose of the study with others, many participants mentioned wanting to perform better on the SPPB than their peers. Participants were consciously aware they were being tested on these measures and that these measures were a screen for disability. The participants more likely expended greater effort in processing information associated with the physical performance measures since they were motivated to do well. Increased motivation may 
have created a conflicting cue which competed with the activated stereotype and then modified or blocked the effect of that stereotype.

There is evidence in the literature to back this claim. Even though our social environment can shape behavior, moderating factors (in this case: a competing goal) can override automatic behavior. Macrae and Johnston (1998) found when participants were primed with the concept of helpfulness, they were more likely to assist someone picking up accidently dropped objects than those who were not primed. However, when some participants in the helpfulness group were told they were running late for the next appointment, they were less likely than those who were told they were on time to assist in picking up the objects. Running late was a competing goal which created a conflicting cue.

Stereotypes more likely influence physical tasks that are simple and unmonitored than tasks where a conflicting cue is present (Macrae \& Johnston, 1998). In the Hausdorff et al. (1999) and Levy (2000) studies, the activated stereotype was the main cue to guide behavior and the participants assimilated to that stereotype. In our pilot study where exposure to objects of aging did activate stereotypes, participants were told procedures for the main study were being piloted. No goals interfered with the stereotype to behavior link which is probably why participants were more likely to develop stereotypical words.

Fortunately, behavior is flexible. When conflicting cues are present, they have the potential to moderate behavior. What determines how the selection is made is that the cue with the higher level of activation will ultimately end up influencing behavior. Bargh (2006) reports that one's current goal will almost always be the cue with the highest level 
of activation. In our main study, motivation was most likely activated at a higher level than the aging stereotype. Motivation influenced behavior overall, which may be why we did not find significant differences between the three groups. In addition, the goal to strive for good performance may have improved performance from pretest to post test in a large number of participants in all groups.

Self-focus is another possible mediator in the stereotype to behavior link in the current study. Participants were aware they were being tested and most likely focused their attention on the timed tasks. It has been shown that increasing attention to a behavior can eliminate the effect of a stereotype since one becomes aware of optional ways to behave (Dijksterhuis andVan Knippenberg, 2000).

Some contend increasing the consciousness of a task can result in a stereotype threat reaction (Steele \& Aronson, 1995). When someone is consciously aware of a negative stereotype, it can produce an anxiety reaction since that person becomes fearful of conforming to the stereotype. Anxiety then interferes with performance and ultimately the person assimilates to the stereotype. The participants in all groups were consciously aware they were being tested on a physical performance measure. Since common stereotypes of older adults are poor balance, walking slowly, and being weak; the older adults in the current study could have become fearful and anxious of conforming to those stereotypes. The results of our study do not support the idea of stereotype threat since so many participants improved their performance at post test.

Even though it is possible that motivation and self-focus contributed to the lack of significance in our study, there are other differences between the published literature on 
the effect of stereotype activation on physical performance and our study which could account for the difference in results. Our participants were exposed to stereotypes of aging in a more real to life situation, whereas the other studies have been conducted in a laboratory setting using word primes. Strict experimental controls can limit the generalizability of results to real life situations. It is possible that stereotypes activated in a lab setting can influence behavior but those activated in real life situations do not. In order to test automatic effects, researchers block out any situation where participants have any control on behavior, but in the real world, conscious control is present in everyday life (Wegner \& Bargh, 1998). The use of word primes which activate stereotypes implicitly over computer screens is very contrived since we are rarely ever exposed to stereotypes this way in the real world.

Exposure to primes in our study may not have been long enough to change physical performance even though according to our pilot study, it was long enough to activate stereotypes. Participants in the Hausdorff et al. (1999) study received 20 minutes of total exposure to the primes. The task in the Levy study (2000) appeared to take longer than the average of 3 minutes and 3 seconds of exposure in our study. Literature has shown that exposure to primes for as little as 2 minutes can activate stereotypes (Dijksterhuis \& Van Knippenberg, 1998) but increasing time of exposure can result in more pronounced behavioral effects (Srull \& Wyer, 1979). Recent primes tend to decrease over time and can diminish relatively quickly (Higgins \& Brendyl, 1995). Increasing the frequency of primes by increasing the length of exposure can improve priming effects by delaying this 
decay. Stronger activation can also improve accessibility of the stereotype and increase the likelihood of its use.

The objects in the current study were presented in a room (often a fairly empty room) in senior centers or senior housing units. The objects were not embedded within an environment in which they are typically found in everyday situations. Kay et al. (2004) embedded their objects in a room typically found in the business world; one which contained a boardroom table where negotiations would normally take place. The strength of stereotype activation may have been stronger if the objects were embedded within a more natural environment. For example, the objects representing negative stereotypes of aging could have been embedded within a lab simulating a doctor's office or physical therapy gym. The objects representing positive stereotypes of aging could have been embedded within a lab simulating someone's bedroom or living room.

Longer exposure to stereotypes or placing the objects in a natural environment could increase the level of activation of the stereotype, making it stronger than the alternate cue from motivational factors. Theoretically, strength of the stereotype activation could be increased enough so that motivation does not affect the stereotype to behavior link. However, when there is a conflict between automatic behavior and motivation, the literature supports the idea that one's current goal or motivational state will always "win out" while that goal is still active (Cohen, Dunbar, \& McClelland, 1990; Greenwald 1998; Ferguson \& Bargh, 2004).

Another difference between the published literature on physical performance and the current study is that primes in the published studies were activated subliminally via a 
computer in a laboratory setting. Our primes were activated supraliminally in a more real life fashion in senior centers and senior housing units. Supraliminal primes have been documented to be stronger than subliminal primes (Bargh \& Chartrand, 2002) but the research supporting this idea has been completed using words and not objects as in the current study. There is preliminary evidence to suggest using primes other than words, may have the opposite effect. Ebert (2006) found that stereotype activation using faces was stronger using subliminal primes.

\section{Effect of Stereotypes on Behavior}

Not only are our results inconsistent with the literature on physical performance (Hausdorff et al., 1999; Levy 2000), they are inconsistent with much of the literature on the effect of implicit activation of aging stereotypes on behavior in general (Levy, 1996; Hess et al., 2003; Hess et al., 2004; Levy, 1999-2000). There were several methodological changes made in the current study which could account for these differences. Motivation, awareness of the testing procedure, type of stereotype activation, and length of primes as discussed above could all explain the differences. Other research may also have found non-significant results if these changes were made.

Changes in physical performance could require stronger activation of stereotypes than changes in cognitive tasks like memory, or behavioral tasks like changes in social judgment and decisions. Handwriting is also a more cognitive related task which may be more susceptible to the effects of stereotypes than more gross motor tasks such as explored in the current study. It is possible that cognitive processes may be more easily influenced by stereotypes than physical properties like physical performance because of 
the neurophysiological characteristics that govern their movement. The structures and pathways in the brain responsible for all these tasks differ and may react in varying ways. The neurophysiological literature on stereotype activation is in its infancy and no literature was found to support this idea.

Only $6 \%$ of the literature on stereotype activation and its effect on behavior is double blinded (Horton et al., 2008). In the current study, the evaluators were unaware of the purpose of the study and to which group the participants were assigned. When evaluators or participants are aware of group assignment, bias can occur and affect the validity of results. And lastly, the use of quota sampling resulted in a more representative sample of the older adult population in the United States with regards to gender, and race which makes our study more generalizable to the older adult population in general.

\section{Self-relevance}

People are only affected by stereotypes if they self-identify with the group being stereotyped (Levy, 1996; Hess et al, 2003; Hess et al, 2004; Stein 2002; Wheeler et al., 2001; Dijksterhuis \& Bargh 2001; Wheeler \& Petty 2001). According to our model, the link between stereotype activation and behavior should go through relatively unchanged, except that individuals who highly identify with the stereotyped group have stereotypes more chronically accessible. Chronically accessible stereotypes are more capable of activation and do not require as strong a prime as those which are not chronically accessible (Bargh et al., 1986). Those who identify with the older adult population tend to be more sensitive to stimuli and a lower level of activation is needed for a response. 
People who do not identify with the older adult population are less sensitive to stimuli and these stimuli are processed less vigilantly.

Participants in the current study scored 62.8 on average on the Cognitive Age Scale. As a group, they did not place themselves in what is socially defined in the United States as being an older adult (over the age of 65). In fact, more than half the participants (52\%) rated themselves younger than 65 . Older adults frequently report feeling younger than their chronological age and their own goals in life are more consistent with adults younger than themselves (Heckhausen, 1997). Even on an implicit level, individuals younger than 75 are more likely to identify with the young (Hummert, Garstka, O'Brien, \& Greenwald, 2002). At first thought, it is possible that participants in our study were not affected by stereotypes of aging since so many of them did not self-identity with the older adult age group. Since they did not identify themselves as being old, the stereotypes may have been non-relevant. Results of the second MANOCVA analysis which included only those who identified with being an older adult as well as the results of the second regression analysis which evaluated whether self-relevance interacts with the manipulation to predict physical performance show this is not the case.

Individual older adults in our study may not have found the primes to be self-relevant, even though the objects were chosen by a group of older adults to represent stereotypes of aging. Older adults tend to view their peers in a less positive light than themselves (Pinquart, 2002). In the pilot, when the older adults chose objects representing negative stereotypes of aging, they may have chosen ones that do not represent the group as a whole. As an example, only $4.6 \%$ of the older population uses a walker, $3.0 \%$ uses a 
wheelchair, and $10.2 \%$ uses a cane (National Rehabilitation Information Center, 2000) and yet older adults chose these objects to represent the older adult population. At the debriefing, several older adults commented that the objects representing negative stereotypes did not relate to them. Almost all of the participants were healthy older adults who did not use walkers, canes, or wheelchairs so it may be that only one or 2 of the objects were self-relevant (i.e. glasses or grey hair).

In the positively primed group, the exact types of albums, books, types of crafts, movies, or picture of another person's grandchild may not have been self-relevant to how they personally view positive aspects of aging. It is probable that all individuals did not find the primes self-relevant, thereby the response to the stereotype stimulus may have been suppressed (Higgins 1996).

\section{Theory}

The results of the study are not consistent with ideomotor theory. Exposure to stereotypes did not have an effect on the physical performance of older adults. In the current study, older adults were primed with either positive or negative stereotypes of aging using material objects. According to ideomotor theory, gait speed, standing balance, and lower extremity muscle performance should be consistent with the type of stereotype activation. Those exposed to negative stereotypes of aging should have lower performance than those who were primed with positive stereotypes or those in the neutral condition. Those exposed to positive stereotypes of aging should have performed better than those who were primed with negative stereotypes or those in the neutral condition. That did not happen. 
Current ideomotor theory states that a tendency toward a behavior will occur following activation of a stereotype (Wheeler \& Petty, 2001). Current theory does not account for any factor which could moderate the stereotype to behavior link. A new model was constructed for the current study which was based on ideomotor theory but considered that a psychosocial factor could moderate this link. Upon reflecting on our results, it is possible that the proposed model was not inclusive enough since it only considered self-relevance as a modifying factor and not other traits like motivation or self-focus. Whether someone assimilates, contrasts, or does not respond to a stereotype is multifaceted. Features of the person, the environment, and the type of stereotype most likely all have the capacity to influence the perception to behavior link and this link is probably not moderated through a single psychosocial variable like self-relevance as in our study.

John Bargh (2006) concludes that priming research over the past 25 years has shown stereotypes have an effect on a wide range of psychological occurrences in the laboratory. However, he points out that perceptual, motivational, and behavioral effects have mainly been studied separately from each other in the lab setting. He challenges researchers to study these effects with more complexity and in more real life situations. As mentioned earlier, there are most likely multiple factors competing for the control of behavior. So far most investigators have placed participants in laboratory environments where things are so tightly controlled, participants may not encounter any competing factors.

Based on the results of the study, a new model is proposed that takes into account some of these complexities. Figure 4 shows the new model. Motivation and self-focus 


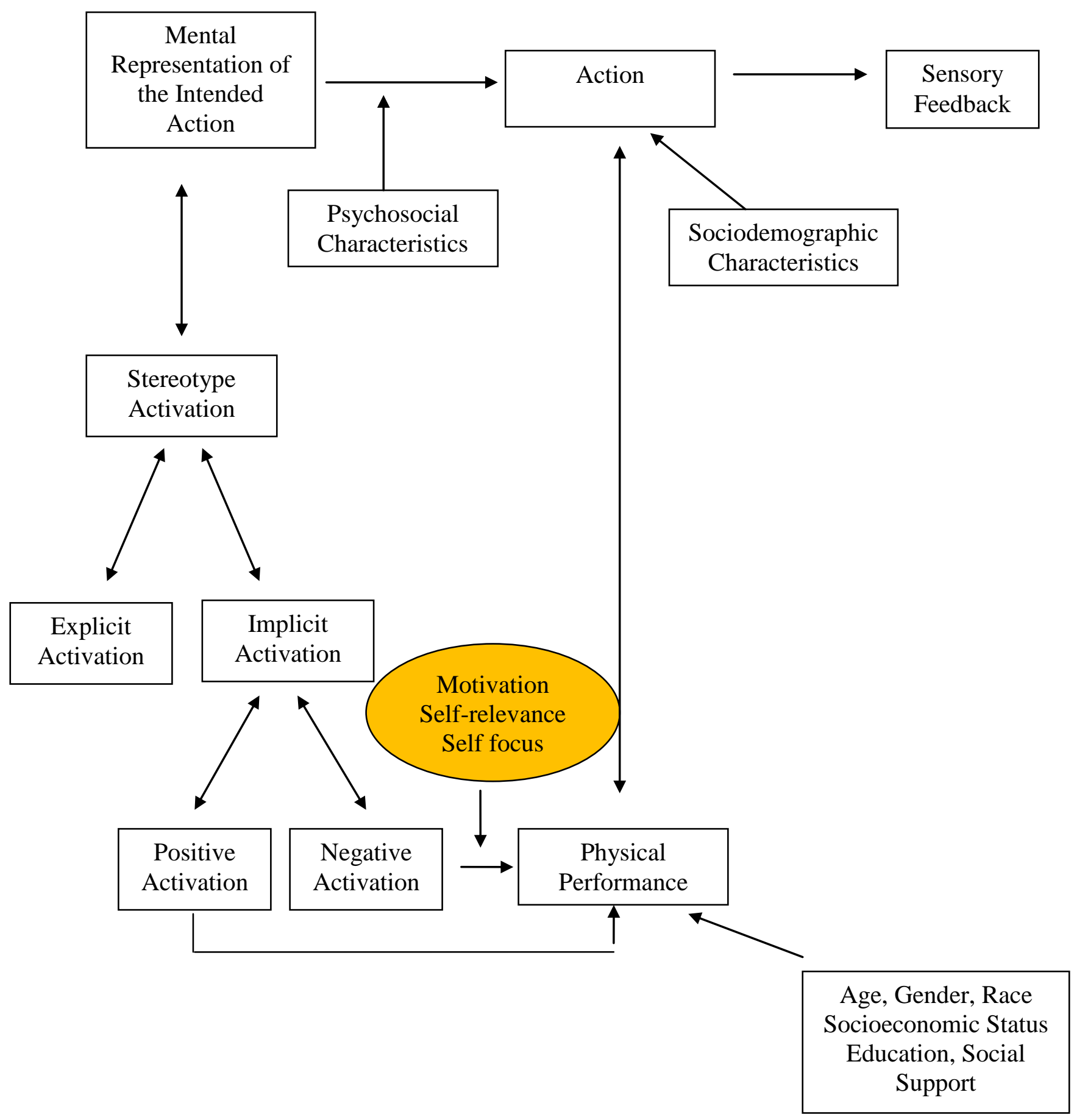

Figure 4: Proposed Model for Future Study with Additional Psychosocial Characteristics 
were added as psychosocial characteristics which could moderate the stereotype to behavior link based on assumptions gathered from the current study. Since these traits were not explicitly measured, further research is needed to test this updated model. Even then, this new model is most likely still very simplistic. Future additions will be necessary as more and more research addresses the complexities associated with the effect of stereotypes on behavior. The new additions are placed in a circle box and are highlighted.

\section{Association of Sociodemographic Factors and Change in Performance}

With regards to the second research question, it is not surprising that the difference from pretest to post test on each of the three variables could not be predicted by age, gender, socioeconomic status, race, education, and perceived social support (H10-H15). Based on the results of MANCOVA testing, it does not appear that any changes from pretest to post test were due to the effect of stereotypes. Any changes from pretest to post test can be explained by practice effects, competition to do better, or variability which is common when taking a test more than once. There is no reason to believe that age, gender, socioeconomic status, race, education, and perceived social support would be associated with any of these three factors.

\section{Recruitment}

The recruitment procedures in the current study were highly successful. We were able to recruit 48 participants for the pilot study from four different facilities over four afternoons and 96 participants for the main study from nine different facilities over 15 full days. We did not have to utilize our alternate plan to recruit participants from either 
Albany or Lake Placid, New York. It was anticipated we would have difficulty recruiting ethnic minorities, but the percentage of ethnic minorities who participated $(7.4 \%$ of the total sample) is consistent with the population of minorities in the Capital Region area $(8.3 \%)$

The two factors which appeared to be most successful in recruitment were the use of a trusted community member and the $\$ 10$ renumeration fee. Trusted community members were administrators at the recruitment facilities who were well liked by the older adults. When the trusted community member specifically asked the older adults to participate, they often did so. Instilling trust in potential participants is crucial in recruitment efforts, especially when recruiting older adults and those from ethnic minorities (Arean et al., 2003; Arean \& Gallagher-Thomson, 1996; Austin-Wells et al., 2006). Once people participated, they often recruited other members by telling them they would be reimbursed $\$ 10$ and receive a book about exercise and physical activity for something that was not a lot of time or work.

The participants also appeared to trust the researchers, especially as we spent more time in a facility. On the day of data collection, we set up recruitment tables in high traffic areas, stayed all day, and in some cases returned on another day. Potential participants seemed to warm up to us the longer we stayed. In fact, many people who originally did not wish to participate later agreed. Many of the facilities were utilized in other research projects and are where we bring students for senior health fairs. Some of the participants were familiar to the researchers and were willing to participate again. 
Use of an older adult peer recruiter did not appear to be as successful in recruiting participants as the trusted community member or by word of mouth recruitment. In fact, we discontinued use of the older adult recruiter after a few days. The participants appeared to trust the administrator and their own peers more than the peer recruiter.

Face to face recruitment yielded many more participants than use of fliers. Face to face recruitment has been found to be more successful than other methods of recruitment (Arean et al., 2003; Polit \& Beck, 2004; Resnick et al., 2003; Zhu et al., 2000), since it allows potential participants to gain more knowledge about the research, give them the ability to ask more informed questions, and it facilitates trust.

Data collection took place at senior centers or senior housing units which made it very convenient for the older adults. We also gave participants the option of receiving the results of the research as an incentive to participate. Only a small minority of the participants $(11.5 \%)$ were interested in receiving the results so this probably did not have a major role in fostering recruitment.

\section{Limitations}

The results of this study must be interpreted with some caution due to several limitations. A major limitation is the uncontrolled factors, in addition to self-relevance, which may have influenced the results of the study. As was discussed earlier, it is possible that factors like motivation and self-focus could have affected the stereotype to behavior link. One way to control for the effect of motivation is to ensure that the participants are unaware they are being tested. It is feasible to time the participants without their knowledge during the timed four-meter walk, as they could be timed while 
walking in and out of the testing area. However, it would be extremely difficult to measure balance or lower extremity muscle performance without their knowledge. Not telling the participants their physical performance is being measured results in additional deception, which may be an ethical concern.

Another way to decrease motivation is to change the environment. The use of senior centers and senior housing units in only two localized areas of the state may have created a competitive environment because the participants knew each other well and wanted to perform better than their peers. Recruiting participants from different areas and making them travel to one testing center could decrease the likelihood of competitive behavior but would increase the difficulty of recruitment. Adding motivation as a covariate is probably the best way to account for motivation. Following testing, participant could fill out a reliable and valid motivational scale to determine how motivated they were to perform on the physical tests. All potential threats to internal validity of the study are described in Table 16.

Table 16: Potential Threats to Internal Validity

\begin{tabular}{|l|l|l|}
\hline \multicolumn{1}{|c|}{ Threat } & $\begin{array}{l}\text { Planned methodology to control } \\
\text { for the threat }\end{array}$ & \multicolumn{1}{|c|}{$\begin{array}{c}\text { Threats noted after completion of } \\
\text { the study }\end{array}$} \\
\hline History & $\begin{array}{l}\text { Participants were randomly } \\
\text { assigned into three groups } \\
\text { (including a control group) which } \\
\text { controls for the effect of history. } \\
\text { If an event occurs, it should occur } \\
\text { equally in all three groups. } \\
\text { History is usually not an issue } \\
\text { when measures are taken within a } \\
\text { short period of time. }\end{array}$ & None noted. \\
\hline Selection & $\begin{array}{l}\text { Participants were randomly } \\
\text { assigned into three groups } \\
\text { (including a control group) which }\end{array}$ & $\begin{array}{l}\text { The groups did not differ in any } \\
\text { baseline characteristics except for } \\
\text { race. Those who were exposed to }\end{array}$ \\
\hline
\end{tabular}




\begin{tabular}{|c|c|c|}
\hline & $\begin{array}{l}\text { usually controls for selection } \\
\text { biases. }\end{array}$ & $\begin{array}{l}\text { positive stereotypes of aging were } \\
\text { more likely to be African American } \\
\text { or Asian than those in the other } 2 \\
\text { groups. The groups did not differ on } \\
\text { any of the pretest dependent } \\
\text { measures. }\end{array}$ \\
\hline Maturation & $\begin{array}{l}\text { Participants were randomly } \\
\text { assigned into three groups } \\
\text { (including a control group) which } \\
\text { controls for the effect of } \\
\text { maturation. Any change that } \\
\text { occurs should occur evenly in all } \\
\text { three groups. The time between } \\
\text { pretest and post test } \\
\text { measurements is so short that } \\
\text { there should not be any changes } \\
\text { in the participant's physical } \\
\text { performance due to maturation. }\end{array}$ & None noted. \\
\hline Testing & $\begin{array}{l}\text { Testing is usually more of an } \\
\text { issue when pretest data is from } \\
\text { self report. }\end{array}$ & $\begin{array}{l}\text { Our dependent variables, although } \\
\text { taken twice were objective measures } \\
\text { and not self report measures. } \\
\text { However, participants may have } \\
\text { performed better on the post test } \\
\text { measures due to a practice effect. } \\
\text { Due to random assignment and a } \\
\text { control group, the practice effect } \\
\text { should have occurred evenly in all } \\
\text { three groups. }\end{array}$ \\
\hline Instrumentation & $\begin{array}{l}\text { The dependent variables utilized } \\
\text { in the study were measures which } \\
\text { have been found to be highly } \\
\text { reliable. }\end{array}$ & $\begin{array}{l}\text { ICC values for test-retest reliability } \\
\text { for the four meter walk in the } \\
\text { current study were } .93 \text {. }\end{array}$ \\
\hline Mortality & & $\begin{array}{l}\text { Attrition was minimal. One } \\
\text { participant was dropped from the } \\
\text { study due to a possible language } \\
\text { barrier. }\end{array}$ \\
\hline Compensatory rivalry & $\begin{array}{l}\text { The intervention was very similar } \\
\text { between the three groups and one } \\
\text { group should not appear more } \\
\text { desirable than another. } \\
\text { Participants were instructed not } \\
\text { to discuss the study with others. }\end{array}$ & $\begin{array}{l}\text { Participants from the same facilities } \\
\text { did speak with one another about the } \\
\text { dependent measures and appeared } \\
\text { motivated to perform better than } \\
\text { their peers. }\end{array}$ \\
\hline $\begin{array}{l}\text { Diffusion of } \\
\text { treatment }\end{array}$ & $\begin{array}{l}\text { Participants were instructed not } \\
\text { to discuss the intervention with } \\
\text { others. }\end{array}$ & $\begin{array}{l}\text { Participants did not appear to } \\
\text { discuss the intervention with each } \\
\text { other. }\end{array}$ \\
\hline Selection interact & $\begin{array}{l}\text { Random assignment into three } \\
\text { groups controls for the effect of }\end{array}$ & None noted \\
\hline
\end{tabular}




\begin{tabular}{|c|c|c|}
\hline & $\begin{array}{l}\text { selection interactions since if it } \\
\text { occurs, it should occur equally in } \\
\text { all } 3 \text { groups. }\end{array}$ & \\
\hline Confounding factors & $\begin{array}{l}\text { The effect of self-relevance was } \\
\text { statistically controlled for in the } \\
\text { study. }\end{array}$ & $\begin{array}{l}\text { It appears like other factors may } \\
\text { have affected the stereotype } \\
\text { activation to performance link (self } \\
\text { focus, motivation) and should have } \\
\text { been controlled for. }\end{array}$ \\
\hline
\end{tabular}

A second major limitation of the study is that the balance measure had a ceiling effect. Forty-four percent of the participants were able to maintain tandem stance for 60 seconds. Due to this high number, the balance measure was deleted as a variable from data analysis. In the future, more challenging balance measures like single limb stance should be considered, or the sample could be changed to include people that are less likely to hold tandem stance for the full 60 seconds.

Generalizability of our results is limited to community dwelling adults over the age of 65 who meet our selection criteria. By using healthy seniors who frequent senior centers, we may have biased the results as these particular seniors may be immune to the effect of stereotypes. It is possible that other subgroups of the older adult population are more susceptible.

The use of the specific objects in the current study may not have adequately primed stereotypes. Even though our pilot suggests stereotypes were activated, there is a $5 \%$ chance that an error was made since a .05 alpha level was selected. There is no other research available to confirm that these specific objects actually activate aging stereotypes. It is also possible that the length of exposure to stereotype activation was not long enough to actually change behavior although it activated stereotypes in the pilot. 
Those who were exposed to positive stereotypes of aging were exposed longer (206 seconds) than those exposed to negative stereotypes of aging (178 seconds) or the neutral condition (165 seconds). In the matching test, the number of words in the description for each of the three conditions was similar so it is unlikely that this is what caused the uneven exposure. The difference may come from the second test where the participants had to line up the objects according to height. The objects in the positive condition were more similar in height than those in the other conditions, so it took the participants longer to complete the task. Also, past literature has found that people do tend to respond longer to positive stereotypes of aging (Levy, 1996; Hess 2003).

In everyday life stereotypes are activated in multiple ways, not just by being exposed to objects representing the positive and negative aspects of aging. The generalizability of this study is limited to use of objects but it is important to remember that stereotypes are activated in many other ways as well. In addition, the use of the objects representing negative stereotypes of aging may have primed more than one stereotype. Objects such as walkers and canes not only activate stereotypes of aging, they may activate stereotypes of physical disability. Since physical disability is actually a component of the aging stereotype, it may not be much of an issue.

Even though use of objects simulates real life situations, data was collected in a contrived setting which added some artificiality. The intervention included a single exposure to stereotypes whereas, in the real world, they occur over time. The physical performance measures were also tested artificially as people usually do not stand up from a chair five times as quickly as they can. Testing in this manner may not represent older 
adults' natural behavior. These factors also limit the generalizability of the results. This study only evaluated the effect of stereotype activation on physical performance in the short term.

During the study, multiple evaluators completed the pretest and post test measures with the older adults and more than one person provided the intervention. Even though all procedures were standardized and all personnel were trained, precision could be affected by the use of multiple people. The study also occurred across different settings and even though an attempt was made to standardize the room in which older adults were exposed to the stereotypes, they were not all identical.

The use of concealment and withholding all information from participants for informed consent is controversial (Fraenkel \& Wallen, 2000; Polit \& Beck, 2004). In this case, the participants were initially told the study deals with performance but they were not given the specifics until data collection was complete. This information was withheld since it could affect performance on the dependent measures. Specific details were provided to all participants after data had been collected. The researcher was not made aware of any negative circumstances as a result of concealment.

Concealment in this case was not unethical since the risk to the participants in this study was very small. A onetime exposure to stereotypes as given in the current study does not have long lasting effects. To ensure that the activation of negative stereotypes did not have a long term effect on the participants, seven participants underwent a second post test to ensure that activation of negative stereotypes did not have a long term effect on them. Visual inspection of the post tests during the course of data collection revealed 
that the participants' performance was very similar on the second post test when compared to the first post test.

Future research should address the limitations of the current study. There are a variety of cognitive and motivational factors which can impact behavior and moderate the stereotype to behavior link (Wheeler \& Patty, 2001). There is a probability that there is an interplay between conscious and unconscious processes during behavior that can be initiated by one and moderated by the other. The effect of stereotype activation on physical performance is a complex picture. Some processes are more likely to occur in certain situations which may account for why different methodology in the different studies can result in different findings (Wheeler \& Petty, 2001). Future research should make an attempt to determine the relative contribution of each as well as evaluate the effect of motivation, self-focus, and other psychosocial variables which can moderate the stereotype to behavior link.

More rigorous research is needed to validate which objects represent negative and which represent positive stereotypes of aging. Once these objects are identified, it is important to determine whether these objects hold the same implicit meanings to all older adults. Objects may not have commonly agreed meanings and may not mean the same thing to all individuals (Campbell, 1996). Other real life situations which can activate aging stereotypes also need to be identified. The optimal time one should be exposed to stereotypes of aging for the optimal effect on behavior needs to be determined, and lastly, the effect of stereotype activation on different subgroups of the older adult population should be evaluated. 


\section{Conclusion}

Our findings do not support that physical performance is affected by exposure to implicit stereotypes of aging in a more real world setting. In real world settings, there are multiple factors competing for the control of behavior which are not present in lab settings and which may lessen the effect of stereotype activation on behavior. 
REFERENCES 


\section{REFERENCES}

Adorno, T. M., Frenkel-Brunswik, E., Levinson, D. J., \& Sanford., R. N. (1950). The Authoritarian personality. New York. NY: Harper and Row.

Allport, G. W. (1954). The nature of prejudice. Garden City, NY: Doubleday.

Alvidrez, J., Azocar, F., \& Miranda, J. (1996). Demystifying the concept of ethnicity for psychotherapy researchers. Journal of Consulting and Clinical Psychology, 64(5), 903-908.

American College of Sports Medicine. (2005). ACSM's guidelines for exercise testing and prescription $\left(7^{\text {th }}\right.$ ed): Lippincott Williams \& Wilkins.

American Physical Therapy Association. (2001). Guide to physical therapist practice (2nd ed.). Alexandria, VA: American Physical Therapy Association.

Arean, P. A., Alvidrez, J., Nery, R., Estes, C., \& Linkins, K. (2003). Recruitment and retention of older minorities in mental health services research. The Gerontologist, 43(1), 36-44.

Arean, P. A., \& Gallagher-Thomson, D. (1996). Issues and recommendations for the recruitment and retention of older ethnic minority adults in clinical research. Journal of Consulting and Clinical Psychology, 64(5), 875-880.

Arkes, H. R., \& Tetlock, P. E. (2004). Attributions of implicit prejudice, or "would Jesse Jackson 'fail' the implicit association test?" Psychological Inquiry, 15(4), 257-278. 
Aronson, J., \& Steele, C. M. (2005). Stereotypes and the fragility of academic competence, motivation, and self-concept. In A. J. Elliot \& C. S. Dweck (Eds.), Handbook of competence and motivation. New York, NY: Guilford Press.

Aronson, J., Quinn, D. M., Spencer, S. J. (1998). Stereotype threat and the academic underperformance of minorities and women. In: Prejudice: The target's perspective. Swim, Janet K. (Ed.); Stangor, Charles (Ed.); San Diego, CA, US: Academic Press, 1998. pp. 83-103.

Asakawa, T., Koyano, W., Ando, T., \& Shibata, H. (2000). Effects of functional decline on quality of life among the Japanese elderly. International Journal of Aging and Human Development, 50(4), 319-328.

Atkinson, H. H., Rosano, C., Simonsick, E. M., Williamson, J. D., Davis, C., Ambrosius, W. T., et al. (2007). Cognitive function, gait speed decline, and comorbidities: The health, aging, and body composition study. The Journals Of Gerontology, 62A(8), 844-850.

Austin-Wells, V., G. J. McDougall, J., \& Becker, H. (2006). Recruiting and retaining an ethically diverse population of older adults in a longitudinal intervention. Educational Gerontology, 32(2), 159-170.

Baars, B. J. (1988). Volition as ideomotor control of thought and action. In B. J. Baars (Ed.), A cognitive theory of consciousness (pp. 246-297). Cambridge: Cambridge University Press.

Baars, B. J. (1992). A new ideomotor theory of voluntary control. In B. J. Baars (Ed.), Experimental slips and human error. Exploring the architecture of volition (pp. 93- 
120). New York, NY: Plenum Press.

Banaji, M. R., \& Greenwald, A. G. (1995). Implicit gender stereotyping in judgments of fame. Journal of Personality and Social Psychology, 68(2), 181-198.

Banaji, M. R., Hardin, C., \& Rothman, A. J. (1993). Implicit stereotyping in person judgment. Journal of Personality and Social Psychology, 65(2), 272-281.

Banfield, J. F. (2003). The effects of an elderly stereotype prime on reaching and grasping actions. Social Cognition, 21(4), 299-319.

Barak, B. (1987). Cognitive age: A new multidimensional approach to measuring age identity. International Journal of Aging and Human Development, 25(2), 109-128.

Bargh, J. A. (1989). Conditional automaticity: Varieties of automatic influence in social perception and cognition. In J. S. Uleman \& J. A. Bargh (Eds.), Unintended thought (pp. 3-51). New York: Guilford Press.

Bargh, J. A. (1994). The four horsemen of automaticity: Awareness, intention, efficiency and control in social cognition. In R. S. Wyer \& T. K. Srull (Eds.), The handbook of social cognition. Vol. 2. Basic processes (pp. 1-40). Hillsdale, NJ: Erlbaum.

Bargh, J. A. (1997). An automaticity of every day life. In R. S. Wyer (Ed.), Advances in social cognition (pp. 1-61). Hillsdale, NJ: Erlbaum.

Bargh, J. A. (2006). Agenda 2006. What have we been priming all these years? On the development, mechanisms, and ecology of nonconscious social behavior. European Journal of Social Psychology, 36(2), 147-168.

Bargh, J. A., Bond, R. N., Lambardi, W. J., \& Tota, M. E. (1986). The additive nature of chronic and temporary sources of construct accessibility. Journal of Personality and 
Social Psychology, 50(5), 869-878.

Bargh, J. A., Chaiken, S., Raymond, P., \& Hymes, C. (1996a). The automatic evaluation effect: Unconditional automatic attitude activation with a pronunciation task. Journal of Experimental Social Psychology, 32(1), 104-128.

Bargh, J. A., \& Chartrand, T. L. (1999). The unbearable automaticity of being. American Psychologist, 54(7), 462-479.

Bargh, J. A., \& Chartrand, T. L. (2002). The mind in the middle. A practical guide to priming and automaticity research. In. (Ed.), Handbook of research methods in social and personality psychology. (pp. 253-285).

Bargh, J. A., Chen, M., \& Burrows, L. (1996b). Automaticity of social behavior: Direct effects of trait concept and stereotype activation on action. Journal of Personality and Social Psychology, 71(2), 230-244.

Bargh, J. A., \& Ferguson, M. J. (2000). Beyond behaviorism: On the automaticity of higher mental processes. Psychological Bulletin, 126(6), 925-945.

Barta-Kvitek, S., Shaver, B., Blood, H., \& Shepard, K. (1986). Age bias: Physical therapists and older patients. Journal of Gerontology, 41(5), 706-709.

Baum, S. K., \& Boxley, R. L. (1983). Age identification in the elderly. The Gerontologist, 23(5), 532-536.

Baumeister, R. F., Bratslavsky, E., Muraven, M., \& Tice, D. M. (1998). Ego depletion: Is the active self a limited resource? Journal of Personality and Social Psychology, $74(5), 1252-1265$.

Beauchamp, M. R., Bray, S. R., \& Albinson, J. G. (2002). Pre-competition imagery, self- 
efficacy and performance in collegiate golfers. Journal of Sports Science, 20(9), 697705.

Bennett, I. J., Howard, J. H., \& Howard, D. V. (2007). Age-related differences in implicit learning of subtle third-order sequential structure. Journals of Gerontology. Psychological Sciences and Social Sciences, 62B(2), 98-103.

Bigler, R. S., \& Liben, L. S. (2006). A developmental intergroup theory of social stereotypes and prejudice. In R. Kail (Ed.), Advances in child development and behavior (Vol. 34, pp. 39-89). San Diego, CA: Elsevier Academic Press.

Blair I. V. \& Banaji, M.R. (1996). Automatic and controlled processes in stereotype priming. Journal of Personality and Social Psychology, 70(6), 1142-1163.

Blair, A., Hall, C., \& Leyshon, G. (1993). Imagery effects on the performance of skilled and novice soccer players. Journal of Sports Science, 11(2), 95-107.

Boduroglu, A., Yoon, C., Luo, T., \& Park, D. C. (2006). Age-related stereotypes: A comparison of American and Chinese cultures. Gerontology, 52(5), 324-333.

Boles, M., Getchell, W. S., Feldman, G., McBride, R., \& Hart, R. G. (2000). Primary prevention studies and the healthy elderly: Evaluating barriers to recruitment. Journal of Community Health, 25(4), 279-292.

Bonnet, M., Decety, J., Requin, J., \& Jeannerod, M. (1997). Mental stimulation of an action modulates the excitability of spinal reflex pathways in man. Cognitive Brain Research, 5(3), 221-228.

Bowd, A. D. (2003). Stereotypes of elderly persons in narrative jokes. Research on Aging, 25(1), 22-35. 
Bramlett-Soloman, S., \& Subramanian, G. (1999). Nowhere near picture perfect: Images of the elderly in life and ebony magazine ads. Journalism \& Mass Communication Quarterly, 76(3), 565-572.

Branch, L. G., Wetle, T. T., Scherr, P. A., Cook, N. R., Evans, D. A., Hebert, L. E., et al. (1988). A prospective study of incident comprehensive medical home care use among the elderly. American Journal of Public Health, 78(3), 255-259.

Brass, M., Bekkering, H., \& Wrinz, W. (2001). Movement observation affects movement execution in a simple response task. Acta Psychologica, 106(1/2), 3-22.

Braun, S. M., Beurskens, A. J., Borm, P. J., Schack, T., \& Wade, D. T. (2006). The effects of mental practice in stroke rehabilitation: A systematic review. Archives of Physical Medicine and Rehabilitation, 87(6), 842-852.

Brewer, M. B. (1988). A dual process model of impression formation. In R. S. Wyer \& T. K. Srull (Eds.), Advances in social cognition Vol 1 (pp. 1-36). Hillsdale, NJ: Erlbaum. Brewer, M. B., \& Lui, L. (1984). Categorization of the elderly by the elderly. Personality and Social Psychology Bulletin, 10(4), 585-595.

Brown, R. (1995). Prejudice: Its social psychology. Oxford, England: Blackwell.

Buccino, G., Binkofski, F., Fink, G. R., Fadiga, L., Fogassi, L., Gallese, V., et al. (2001). Action observation activates premotor and parietal areas in somatotopic manner: An f-MRI study. European Journal of Neuroscience, 13(2), 400-404.

Campbell, C. (1996). The meaning of objects and the meaning of actions. Journal of Material Culture, 1(1), 93-105.

Carpenter, W. B. (1874). Principles of mental physiology. New York: Appleton. 
Carver, C. S., Ganellen, R. J., Froming, W. J., \& Chambers, W. (1983). Modeling: An analysis in terms of category accessibility. Journal of Experimental Psychology, 19(5), 403-421.

Celejewski, I., \& Dion, K. K. (1998). Self-perception and perception of age groups as a function of the perceiver's category membership. International Journal of Aging and Human Development, 47(3), 205-216.

Chan, L., Beaver, S., MacLehose, R. F., Amitabh, J., Maciejewski, M., \& Doctor, J. N. (2002). Disability and health care costs in the Medicare population. Archives of Physical Medicine and Rehabilitation, 83(9), 1196-1201.

Chanowitz, B., \& Langer, E. J. (1981). Premature cognitive commitment. Journal of Personality and Social Psychology, 41(6), 1051-1063.

Chartrand, T. L., \& Bargh, J. A. (1996). Automatic activation of impression formation and memorization goals: Nonconscious goal priming reproduces effects of explicit task instructions. Journal of Personality and Social Psychology, 71(3), 464-478.

Chartrand, T. L., \& Bargh, J. A. (1999). The chameleon effect: The perception-behavior link and social interaction. Journal of Personality and Social Psychology, 76(6), 893910.

Chasteen, A. L., Schwartz, N., \& Park, D. C. (2002). The activation of aging stereotypes in younger and older adults. The Journals of Gerontology: Series B Psychological Sciences and Social Sciences, 57B(6), 540-547.

Chen, M., \& Bargh, J. A. (1997). Nonconscious behavioral confirmation processes: The self-fulfilling consequences of automatic stereotype activation. Journal of 
Experimental Social Psychology, 33(5), 541-560.

Clow, K. A., \& Esses, V. M. (2005). The development of group stereotypes from descriptions of group members: An individual difference approach. Group Processes \& Intergroup Relations, 8(4), 429-445.

Cohen, J. D., Dunbar K., \& McClelland. (1990). On the control of automatic processes: A parallel distributed processing account of the Stroop effect. Psychological Review, 97(3), 332-361.

Congressional Budget Office. (1999). CBO memorandum: Projections for expenditures for long-term care services for the elderly. Washington, D. C.: Congressional Budget Office.

Cunnigham, W. A., Johnson, M. K., Gatenby, J. C., Gore, J. C., \& Banaji, M. R. (2003). Neural components of social evaluation. Journal of Personality and Social Psychology, 85(4), 639-649.

Cunnigham, W. A., Johnson, M. K., Raye, C. L., Gatenby, J. C., Gore, J. C., \& Banaji, M. R. (2004). Separable neural components in the processing of black and white faces. Psychological Science, 15(12), 806-813.

Dant, T. (1999). Material culture in the social world: Values, activities, lifestyles. Philadelphia, PA: Open University Press.

Dasgupta, N., \& Greenwald, A. G. (2001). On the malleability of automatic attitudes: Combating automatic prejudice with images of admired and disliked individuals. Journal of Personality and Social Psychology, 81(5), 800-814.

Decety, J., Jeannerod, M., Germain, M., \& Pastene, J. (1991). Vegetative response during 
imagined movement is proportional to mental effort. Behavioral Brain Research, $42(1), 1-5$.

Decety, J., Perani, D., Jeannerod, M., Bettinardi, V., Tadary, B., Woods, R., et al. (1994). Mapping motor representations with pet. Nature, 371(6498), 600-602.

Decker, A. M., \& Thompson, C. (2004). Preventative practice: Implications for older adults. GeriNote, 14(4).pg

Demi, A. S., \& Warren, N. A. (1995). Issues in conducting research with vulnerable families. Western Journal of Nursing Research, 17(2), 188-202.

Devine, P. G. (1989). Stereotypes and prejudice: Their automatic and controlled components. Journal of Personality and Social Psychology, 56(1), 5-18.

Dickstein, R., \& Deutsch, J. E. (2007). Motor imagery in physical therapist practice. Physical Therapy, 87(7), 942-953.

Dijksterhuis, A., Aarts, H., Bargh, J. A., \& Van Knippenberg, A. (2000). On the relation between associative strength and automatic behavior. Journal of Experimental Social Psychology, 36(5), 531-544.

Dijksterhuis, A., \& Bargh, J. A. (2001). The perception-behavior expressway: Automatic effects of social perception on social behavior. In Advances in experimental social psychology vol 33 (pp. 1-40): Academic Press.

Dijksterhuis, A., \& Van Knippenberg, A. (1998). The relation between perception and behavior, or how to win a game of trivial pursuit. Journal of Personality and Social Psychology, 74(4), 865-877.

Dijksterhuis, A., Spears, R., \& Lepinasse, V. (2001). Reflecting and deflecting 
stereotypes: Assimilation and contrast in impression and automatic behavior. Journal of Experimental Social Psychology, 37(4), 286-299.

Dijksterhuis, A. P., \& Van Knippenberg, A. D. (2000). Behavioral indecision: Effect of self-focus on automatic behavior. Social Cognition, 18(1), 55-74.

Dimberg, U. (1990). Facial electromyography and emotional reactions. Psychophysiology, 27(5), 481-494.

Dimberg, U., \& Lundquist, L. O. (1990). Gender differences in facial reactions to facial expressions. Biological Psychology, 30(2), 151-159.

Dimberg, U., \& Thunberg, M. (1998). Rapid facial reactions to emotional facial expressions. Scandinavian Journal of Psychology, 39(1), 39-45.

Dimberg, U., Thunberg, M., \& Elmehed, K. (2000). Unconscious facial reactions to emotional facial expressions. Psychological Sciences, 11(1), 86-91.

Dimberg, U., Thunberg, M., \& Grunedal, S. (2002). Facial reactions to emotional stimuli: Automatically controlled emotional responses. Cognition and Emotion, 16(4), 449471.

Dovidio, J. F., Kawakami, K., Johnson, C., Johnson, B., \& Howard, A. (1997). On the nature of prejudice: Automatic and controlled processes. Journal of Experimental Social Psychology, 33(5), 510-540.

Easton, R. D., \& Schor, R. E. (1975). Information processing analysis of the chevreul pendulum illusion. Journal of Experimental Psychology: Human Perception and Performance, 1(3), 231-236.

Ebert, J. P. (2006). Subliminally priming 'white supremacist' images heightens anti-black 
bias. Presented at the 7th annual meeting of the Society for Personality and Social Psychology.

Ellis, S. R., \& Morrison, T. G. (2005). Stereotypes of aging: Messages promoted by agespecific paper birthday cards available in Canada. International Journal of Aging and Human Development, 61(1), 57-73.

Elsner, B., \& Hommel, B. (2001). Effect anticipation and action control. Journal of Experimental Psychology: Human Perception and Performance, 27(1), 229-240.

Elsner, B., Hommel, B., Mentschel, C., Drzezga, A., Prinz, W., Conrad, B., et al. (2002). Linking actions and their perceivable consequences in the human brain. NeuroImage, 17(1), 364-372.

Everard, K. M., Lach, H. W., Fisher, E. B., \& Baum, M. C. (2000). Relationship of activity and social support to the functional health of older adults. Journal of Gerontology: Social Sciences, 55B(4), S208-S212.

Fadiga, L., Fogassi, L., Pavesi, G., \& Rizzolatti, G. (1995). Motor facilitation during action observation. A magnetic stimulation study. Journal of Neurophysiology, 73(6), 2608-2611.

Fazio, R. H. (1986). How do attitudes guide behavior? In R. M. Sorrentino \& E. T. Higgins (Eds.), Handbook of motivation and cognition (Vol. 1, pp. 204-243). New York: Guilford.

Fazio, R. H., Jackson, J. R., Dunton, B. C., \& Williams, C. J. (1995). Variability in automatic activation as an unobtrusive measure of racial attitudes: A bona fide pipeline? Journal of Personality and Social Psychology, 69(6), 1013-1027. 
Federal Interagency Forum for Aging Related Statistics. (2008). Older Americans 2008. Key indicators of well being. Washington, D. C.: Federal Interagency Forum on Aging Related Statistics.

Feldman, S. (1999). Please don't call me 'dear': Older women's narratives of health care. Nursing Inquiry, 6, 269-276.

Ferguson, M. J., Bargh, J. A. (2004). Liking is for doing: The effects of goal pursuit on automatic evaluation. Journal of Personality and Social Psychology, 87(5), 557-572.

Ferrucci, L., Guralnik, J. M., Pahor, M., Corti, M. C., \& Havlik, R. J. (1997). Hospital diagnosis, Medicare charges, and nursing home admissions in the year when older persons become severely disabled. Journal of the American Medical Association, 277(9), 728-734.

Field, A. (2005). Discovering statistics using SPSS (2nd ed.). London: Sage Publications.

Fishbein, M., \& Ajzen, I. (1980). Understanding attitudes and predicting behavior. Englewood Cliffs, NJ: Prentice Hall.

Fiske, S. T., \& Neuberg, S. L. (1990). A continuum of impression formation, from category-based to individuating processes: Influences of information and motivation on attention and interpretation. In M. P. Zanna (Ed.), Advances in experimental social psychology (Vol. 23, pp. 1-74). New York: Academic.

Fraenkel, J. R., \& Wallen, N. E. (2000). How to design and evaluate research in education (4th ed.). Boston: McGraw Hill.

Fried, L. P., \& Guralnik, J. M. (1997). Disability in older adults: Evidence regarding significance, etiology, and risk. Journal of the American Geriatrics Society, 45(1), 92- 
100.

Fried, T. R., Bradley, E. H., Williams, C. S., \& Tinetti, M. E. (2001). Functional disability and health care expenditures for older persons. Archives of Internal Medicine, 161(21), 2602-2607.

Fuchs, V. (1999). Health care for the elderly: How much? Who will pay for it? Health Affairs, 18(1), 11-21.

Gallese, V., Fadiga, L., Fogassi, L., \& Rizolatti, G. (1996). Action recognition in the premotor cortex. Brain, 119(2), 593-609.

Gilbert, D. T., \& Dixon, J. G. (1991). The trouble of thinking: Activation and application to stereotypic beliefs. Journal of Personality and Social Psychology, 60(4), 509-517.

Giles, H., Fox, S., \& Smith, E. (1993). Patronizing the elderly; intergenerational evaluations. Research on Language and Social Interaction, 26(2), 129-149.

Gill, T. M., Williams, C. S., \& Tinetti, M. E. (1995). Assessing risks for the onset of functional dependence among older adults: The role of physical performance. Journal of the American Geriatrics Society, 43(6), 603-609.

Golub, S.A., Filipowica, A., \& Langer, E. J. (2002). Acting your age. In T. D. Nelson (Ed.), Ageism. (pp. 277-294). Cambridge, MA: MIT Press.

Graves-Brown, P. M. (2000). Matter, materiality and modern culture. London, England: Routledge.

Greenwald, A. G. (1970a). A choice reaction time test of ideomotor theory. Journal of Experimental Psychology, 86(1), 20-25.

Greenwald, A. G. (1970b). Sensory feedback mechanisms in performance control: With 
special reference to the ideomotor mechanism. Psychological Review, 77(2), 73-97.

Greenwald, A. G. (1972). On doing two things at once: Time sharing as a function of ideomotor compatibility. Journal of Experimental Psychology, 94(1), 52-57.

Greenwald, A. G. (1980). The totalitarian ego: Fabrication and revision of personal history. American Psychologist, 35(7), 603-618.

Greenwald, A. G., \& Banaji, M. R. (1995). Implicit social cognition: Attitudes, selfesteem, and stereotypes. Psychological Review, 102(1), 4-27.

Greenwald, A. G., McGhee, D. E., \& Schwartz, J. L. K. (1998). Measuring individual differences in implicit cognition: The implicit association test. Journal of Personality and Social Psychology, 74(6), 1464-1480.

Greenwald, A. G., \& Shulman, H. G. (1973). On doing two things at once: Elimination of the psychological refractory period effect. Journal of Experimental Psychology, 101(1), 70-76.

Grossman, E., Donnelly, M., Price, R., Pickens, D., Morgan, V., Neighbor, G., et al. (2000). Brain areas involved in perception of biological motion. Journal of Cognitive Neuroscience, 12(5), 711-720.

Groupp, E., Haas, M., Fairweather, A., Granger, B., \& Attwood, M. (2005). Recruiting seniors with chronic low back pain for a randomized controlled trial of selfmanagement program. Journal of Manipulative and Physiological Therapeutics, 28(2), 97-102.

Guralnik, J. M., Branch, L. G., Cummings, S. R., \& Curb, J. D. (1989). Physical performance measures in aging research. Journal of Gerontology, 44(5), 141-146. 
Guralnik, J. M., Ferrucci, L., Leveille, S. G., Markides, K. S., Ostir, G. V., Studenski, S., et al. (2000). Lower extremity function and subsequent disability: Consistency across studies, predictive models, and value of gait speed alone compared with the short physical performance battery. Journal of Gerontology: Medical Sciences, 55A(4), M221-M231.

Guralnik, J. M., Ferrucci, L., Simonsick, E. M., Salive, M. E., \& Wallace, R. B. (1995). Lower-extremity function in persons over the age of 70 years as a predictor of subsequent disability. The New England Journal of Medicine, 332(9), 556-561.

Guralnik, J. M., LaCroix, A. Z., Abbott, R. D., Berkman, L. F., Satterfield, S., Evans, D. A., et al. (1993). Maintaining mobility in late life. American Journal of Epidemiology, 137(8), 845-857.

Guralnik, J. M., Simonsick, E. M., \& Ferrucci, L. (1994). A short physical performance battery assessing lower extremity function: Association with self-reported disability and prediction of mortality and nursing home admission. Journal of Gerontology, 49(2), M85-M93.

Hagestad, G. O., \& Uhlenberg, P. (2005). The social separation of old and young: A root of ageism. Journal of Social Issues, 61(2), 343-360.

Harasty, A. S. (1997). The interpersonal nature of social stereotypes: Differential discussion patterns between in-groups and out-groups. Personality and Social Pscyhology Bulletin, 23(3), 270-284.

Harwood, J., \& Anderson, K. (2002). The presence and portrayal of social groups on prime-time television. Communication Reports, 15(2), 81-97. 
Hausdorff, J. M., Levy, B. R., \& Wei, J. Y. (1999). The power of ageism on physical function of older persons: Reversibility of age-related gait changes. Journal of the American Geriatrics Society, 47, 1346-1349.

He, W., Sengupta, M., Velkoff, V. A., \& DeBarros, K. A. (2005). Current population reports. $65+$ in the us: 2005. Washington, D. C.: U.S. Government Printing Office.

Heckhausen, J. (1997). Developmental regulation across adulthood: Primary and secondary control of age-related challenges. Developmental Psychology, 33(1),176187.

Henwood, K., Giles, H., Coupland, J., \& Coupland, N. (1993). Stereotyping and affect in discourse: Interpreting the meaning of elderly painful self-disclosure. In D. M. Mackie \& D. L. Hamilton (Eds.), Affect, cognition, and stereotyping: Interactive process in group perception (pp. 269-296). San Diego, CA: Academic Press Inc.

Hess, T. M., Auman, C., Colcombe, S. J., \& Rahhal, T. A. (2003). The impact of stereotype threat on age differences in memory performance. The Journals of Gerontology: Series B: Psychological Sciences and Social Sciences, 58B(1), 3-14.

Hess, T. M., Hinson, J. T., \& Statham, J. A. (2004). Explicit and implicit stereotype activation effects on memory: Do age and awareness moderate the impact of priming. Psychology and Aging, 19(3), 495-505.

Higgins, E. T. (1996). Knowledge activation: Accessibility, applicability, and salience. In E. T. Higgins \& A. W. Kruglanski (Eds.), Social psychology: Handbook of basic principles (pp. 133-168). New York: Guilford.

Higgins, E. T., \& Brendyl, M. (1995). Accessibility and applicability: Some "activation 
rules" influencing judgment. Journal of Experimental Social Psychology, 31(3), 218243.

Hilton, J. L., \& Von Hippel, W. (1996). Stereotypes. Annual Review of Psychology, 47(1), 237-271.

Hoffman, J., Sebald, A., \& Stocker, C. (2001). Irrelevant response effects improve serial learning in serial reaction time tests. Journal of Experimental Psychology: Learning, Memory, and Cognition, 27(2), 470-482.

Horowitz, B., Savino, D., \& Krauss, A. (1999). Special feature: Ageism and implications for gerontogic occupational therapy practice. Topics of Geriatric Rehabilitation, 15(2), 71-78.

Horton, S., Baker, J., Pearce, G. W., \& Deakin, J. M. (2008). On the malleability of performance. Implications for seniors. Journal of Applied Gerontology, 27(4), 446465.

Howard, J. A., \& Pike, K. C. (1986). Ideological investment in cognitive processing: The influence of social status on attribution. Social Psychology Quarterly, 49(2), 154-167.

Hubley, A. M., \& Hultsch, D. F. (1996). Subjective age and traits. Research on Aging, 18(4), 494-496.

Hull, J. G. (2002). Modeling the structure of self-knowledge and the dynamics of selfregulation. In A. Tesser, D. Stapel \& J. Woods (Eds.), Self and motivation: Emerging psychological perspectives (pp. 173-206). Washington, D. C.: American Psychological Association.

Hull, J. G., Slone, L. B., Meteyer, K. B., \& Matthews, A. R. (2002). The 
nonconsciousness of self-consciousness. Journal of Personality and Social Psychology, 83(2), 406-424.

Hummert, M. L. (1990). Multiple stereotypes of elderly and young adults: A comparison of structure and evaluations. Psychology and Aging, 5(2), 182-193.

Hummert, M. L. (1999). A social cognitive perspective on age stereotypes. In social cognition and aging: Academic press. In T. M. Hess \& F. Blanchard-Fields (Eds.), Social cognition and aging (pp. 175-196). San Diego, CA: Academic Press.

Hummert, M. L. Garstka, T. A., O’Brien, L., Greenwald, A. G., \& Mellott, D. S. (2002). Using the Implicit Association Test to measure age differences in implicit social perceptions. Psychology and Aging, 17(3),482-495.

Hummert, M. L., Garstka, T. A., \& Shaner, J. L. (1997). Stereotypes of older adults: The role of target facial cues and perceiver characteristics. Psychology and Aging, 12, 107114.

Hummert, M. L., Garstka, T. A., Shaner, J. L., \& Strahm, S. (1995). Judgments about stereotypes of the elderly: Attitudes. Age associations, and typicality ratings of young, middle aged, and elderly adults. Research on Aging, 17(2), 168-189.

Hummert, M. L., Garstka, T. A., Shaner, L. L., \& Strahm, S. (1994). Stereotypes of the elderly. Journal of Gerontology: Psychological Series, 49(5), 240-249.

Inzlicht, M., Aronson, J., Good, C., \& McKay, L. (2006). A particular resiliency to threatening environments. Journal of Experimental Social Psychology, 42(3), 323336.

Isaacs, L. W., \& Bearison, D. J. (1986). The development of children's prejudice against 
the aged. International Journal of Aging and Human Development, 23(3), 175-194.

Jackson, P. L., Lafleur, M. F., Malouin, F., Richards, C. L., \& Doyon, J. (2003).

Functional cerebral reorganization following motor sequence loading through mental practice and motor imagery. Neuroimage, 20(2), 1171-1180.

James, W. (1890/1981). Principles of psychology. New York: Holt.

Janssen, I., Shepard, D. S., Katzmarzyk, P. T., \& Roubenoff, R. (2004). The healthcare costs of sarcopenia in the United States. Journal of the American Geriatrics Society, $52(1), 80-85$.

Jeannerod, M. (1994). The representing brain: Neural correlates of motor intention and imagery. Behavioral and Brain Sciences, 17(2), 187-245.

Johnson, R. W., Toohey, D., \& Weiner, J. M. (2007). Meeting the long-term care needs of the baby boomers: How changing families will affect paid helpers and institutions. Washington, D. C.: The Urban Institute.

Jones, R. A. (1982). Perceiving other people: Stereotyping as a process of social cognition. In A. Miller (Ed.), In the eye of the beholder: Contemporary issues in stereotyping (pp. 41-91). New York, NY: Praeger.

Judd, C. M., \& Park, B. (1993). Definition and assessment of accuracy in social stereotypes. Psychological Review, 100(1), 109-128.

Judd, C. M., Ryan, C. S., \& Park, B. (1991). Accuracy in judgment of in-group and outgroup variability. Journal of Personality and Social Psychology, 61(3), 366-379.

Jussim, I., Manis, M., T. E. Nelson, T. E., \& Soffin, S. (1995). Prejudice, stereotypes, and labeling effects: Sources of bias in person perception. Journal of Personality and 
Social Psychology, 62(2), 228-246.

Karpinski, A., \& Hilton, J. L. (2001). Attitudes and the implicit association test. Journal of Personality and Social Psychology, 81(5), 774-788.

Katz, S., Ford, A. B., Moskowitz, R. W., Jackson, B. A., \& Jaffe, M. V. (1963). Studies of illness in the aged. The index of ADL: A standardized measure of biological and psychosocial function. Journal of the American Medical Association, 185(12), 914919.

Kay, A. C., Wheeler, S. C., Bargh, J. A., \& Ross, L. (2004). Material priming: The influence of mundane physical objects on situational construal and competitive behavioral choice. Organizational Behavior and Human Decision Processes, 95(1), 83-96.

Kim, J. G., \& Chung, S. T. (1998). Auditory, visual, and kinesthetic imagery and badminton service learning and performance. Journal of Sports and Exercise Psychology, 20, S67-S67.

Kite, M., \& Johnson, B. (1988). Attitudes toward older and younger adults: A metaanalysis. Psychology of Aging, 3(3), 233-244.

Kite, M. E., Deaux, K., \& Miele, M. (1991). Stereotypes of young and old: Does age outweigh gender? Psychology and Aging, 6(1), 19-27.

Kite, M. E., Stockdale, G. D., Whitley, B. E., \& Johnson, B. T. (2005). Attitudes toward younger and older adults: An updated meta-analytic review. Journal of Social Issues, 61(2), 241-266.

Knoblich, G., \& Prinz, W. (2005). Linking perception and action: An ideomotor 
approach. In Higher-order motor disorders: From neuroanatomy and neurobiology to clinical neurology (pp. 79-103). New York, New York: Oxford University Press.

Knuf, L., Aschersleben, G., \& Prinz, W. (2001). An analysis of ideomotor action. Journal of Experimental Psychology: General, 130(4), 779-798.

Kobayashi, R. B. (2004). Health information presented to older adults as a source of age stereotype priming: Effects on neuropsychological test performance and symptom reporting. Illinois Institute of Technology, Chicago.

Koch, I., Keller, P., \& Prinz, W. (2004). The ideomotor approach to action control: Implications for skilled performance. International Journal of Sport and Exercise Psychology, 2(4), 362-375.

Koch, I., \& Kunde, W. (2002). Verbal response-effect compatibility. Memory \& Cognition, 30(8), 1297-1303.

Kunda, Z., \& Oleson, K. C. (1995). Maintaining stereotypes in the face of disconfirmation: Constructing grounds for subtyping deviants. Journal of Personality and Social Psychology, 68(4), 565-579.

Kunde, W. (2001). Response-effect compatibility in manual choice reaction tasks. Journal of Experimental Psychology: Human Perception and Performance, 27(2), 387-394.

Kunde, W., Koch, I., \& Hoffman, J. (2004). Anticipated action effects affect the selection, initiation, and execution of actions. The Quarterly Journal of Experimental Psychology, 57A(1), 87-106.

Lacourse, M. G. (2005). Brain activation during execution and motor imagery of novel 
and skilled sequential hand movements. Neuro Image, 27(3), 505-519.

Lacourse, M. G., Turner, J. A., Orr, E. R., Schandler, S. L., \& Cohen, M. J. (2004).

Cerebral and cerebellar sensorimotor plasticity following motor imagery-based mental practice of a sequential movement. Journal of Rehabilitation Research and

Development, 41(4), 505-524.

Lauzen, M. M., \& Dozier, M. M. (2005). Maintaining the double standard: Portrayals of age and gender in popular film. Sex Roles, 52(7/8), 437-446.

Lee, R., \& Tuljapurkar, S. (1998). Uncertain demographic futures and social security finance. American Economic Review, 88(2), 237-241.

Levy, B. (1996). Improving memory in old age through implicit self-stereotyping. Journal of Personality and Social Psychology, 71(6), 1092-1107.

Levy, B. (2000). Handwriting as a reflection of aging self-stereotypes. Journal of Geriatric Psychology, 33(1), 81-94.

Levy, B., Ashman, O., \& Dror, I. (1999-2000). To be or not to be: The effects of aging stereotypes on the will to live. OMEGA, 40(3), 409-420.

Levy, B. R. (2003). Mind matters: Cognitive and physical effects of aging selfstereotypes. The Journals of Gerontology: Series B: Psychological and Social Sciences, 58B(4), 203-213.

Levy, B. R., \& Banaji, M. R. (2002). Implicit ageism. In T. Nelson (Ed.), Ageism: Stereotypes and prejudice against older persons (pp. 49-75). Cambridge, MA: MIT Press.

Levy, B. R., Hausdorff, J. M., Hencke, R., \& Wei, J. Y. (2000). Reducing cardiovascular 
stress with positive self-stereotypes of aging. The Journals Of Gerontology: SeriesB: Psychological and Social Sciences, 55B(4), 205-213.

Levy, B. R., Kasl, S. V., \& Gill, T. M. (2004). Image of aging scale. Perceptual and Motor Skills, 99(1), 208-210.

Levy, B. R., \& Langer, E. (1994). Aging free from negative stereotypes: Successful memory in China and among the American deaf. Journal of Personality and Social Psychology, 66(6), 989-997.

Levy, B. R., \& Myers, L. M. (2005). Relationship between respiratory mortality and selfperceptions of aging. Psychology and Health, 20(5), 553-564.

Levy, B. R., \& Slade, M. D. (2006). Physical recovery after acute myocardial infarction: Positive age self-stereotypes as a resource. International Journal of Aging and Human Development, 62(4), 285-301.

Levy, B. R., Slade, M. D., \& Kasl, S. V. (2002a). Longitudinal benefit of positive selfperceptions of aging on functional health. The Journals Of Gerontology:

Psychological Sciences and Social Sciences, 57B(5), 409-417.

Levy, B. R., Slade, M. D., Kunkel, S. R., \& Kasl, S. V. (2002b). Longevity increased by positive self-perceptions of aging. Journal of Personality and Social Psychology, 83(2), 261-270.

Lewis, C. B., \& Bottomly, J. M. (2008). Geriatric rehabilitation. A clinical approach (3rd ed.). Upper Saddle River, NJ: Pearson Education, Inc.

Lien, M., Proctor, R. W., \& Allen, P. A. (2002). Ideomotor compatibility in the psychological refractory period effect: 29 years of oversimplification. Journal of 
Experimental Psychology, 28(2), 396-409.

Lippman, W. (1922). Public opinion. New York: Harcourt, Brace.

Lotze, R. H. (1852). Medicinische psychologie oder ide physiologie dew seele. Leipzig, Germany: Weidmann'sche Buchhandlung.

Lyons, A., \& Kashima, Y. (2003). How are stereotypes maintained though communication? The influence of stereotype sharedness. Journal of Personality and Social Psychology, 85(6), 989-1005.

MacNeil, R. D., Ramos, C. I., \& Magafas, A. M. (1996). Age stereotyping among college students: A replication and expansion. Educational Gerontology, 22(3), 229-243.

Macrae, C. N., \& Johnston, L. (1998). Help, I need somebody: Automatic action and in action. Social Cognition, 16(4), 400-417.

Macrae, C. N., Milne, A. B., \& Bodenhausen, G. V. (1994). Stereotypes as energy saving devices: A peek inside the cognitive toolbox. Journal of Personality and Social Psychology, 66(1), 37-47.

Madey, S. F., \& Chasteen, A. L. (2004). Age-related health stereotypes and illusory correlation. International Journal of Aging and Human Development, 58(2), 109-126.

Madon, S. (1997). What do people believe about gay males? A study of stereotype content and strength. Sex Roles, 37(9/10), 663-685.

Mahoney, F. I., \& Barthel, D. W. (1965). Functional evaluation: The Barthel index. Maryland Medical Journal, 14(2), 61-65.

Manton, K. G., Corder, L., \& Stallard, E. (1997). Chronic disability trends in elderly United States populations: 1982-1994. Proceedings of the National Academy of 
Sciences of the United States of America, 94(6), 2593-2598.

Manton, K. G., \& Gu, X. (2001). Changes in the prevalence of chronic disability in the United States black and non-black population above age 65 from 1982-1999. Proceedings of the National Academy of Sciences of the United States of America, 98(11), 6354-6359.

Martini, E. M., Garrett, N., Lindquist, T., \& Isham, G. J. (2007). The boomers are coming: A total cost of care model of the impact of population aging on health care costs in the United States by major practice category. Health Services Research, 42(1), 201-218.

McConatha, J. T., Schnell, F., \& McKenna, A. (1999). Description of older adults as depicted in magazine articles. Psychological Reports, 85(3), 1051-1056.

McKown, C., \& Weinstein, R. S. (2003). The development and consequences of stereotypes consciousness in middle childhood. Child Development, 74(2), 498-515.

Mertler, C. A., \& Vannatta, R. A. (2002). Advanced and multivariate statistical methods. Practical application and interpretation (2nd ed.). Los Angeles: Pyrczak Publication. Miller, D. T. (1998). Material cultures: Why some things matter. London, England: UCL Press.

Miller, D. W., Leyell, T. S., \& Mazachek, J. (2004). Stereotypes of the elderly in U. S. Television commercials from the 1950s to the 1990s. International Journal of Aging and Human Development, 58(4), 315-340.

Montepare, J.M., Clements, A.E. (2001). 'Age schemas': Guides to processing information about the self. Journal of Adult Development, 8(2), 99-108. 
Mor, V., Wilcox, V., Rakowski, W., \& Hiris, J. (1994). Functional transitions among the elderly: Patterns, predictors, and related hospital use. American Journal of Public Health, 84(8), 1274-1280.

Morala, D. T., Shiomi, T., \& Maruyama, H. (2006). Factors associated with the functional status of community-dwelling elderly. Journal of Geriatric Physical Therapy, 29(3), 101-106.

National Institute on Aging. (2009). Exercise \& physical activity. Washington, DC: U. S. Department Of Health and Human Services.

National Rehabilitation Information Center. Report 14: Mobility device use in the United States (2000). National Institute on Disability and Rehabilitation Research Landover, MD.

Nelson, T. (2002). The psychology of prejudice. Needham Heights, MA: Allyn \& Bacon. Nemmers, T. M. (2004). The influence of ageism and ageist stereotypes on the elderly. Physical \& Occupational Therapy in Geriatrics, 22(4), 11-20.

Neumann, R., \& Strack, F. (2000). "Mood contagion": The automatic transfer of mood between persons. Journal of Personality and Social Psychology, 79(2), 211-223.

Newman, S., Faux, R., \& Larimer, B. (1997). Children's views on aging: Their attitudes and values. The Gerontologist, 37(3), 412-417.

Nevitt, M. C., Cummings, S. R., Kidd, S., \& Black, D. (1989). Risk factors of recurrent nonsyncopal falls: A prospective study. Journal of the American Medical Association, 261(18), 2663-2668.

Norman, D. A., \& Shallice, T. (1986). Attention to action: Willed and automatic control 
of behavior. In R. J. Davidson, G. E. Schwartz \& D. Shapiro (Eds.), Consciousness and self-regulation: Advances in research and theory (Vol. 4, pp. 1-18). New York: Plenum.

Norretranders, T. (1998). The user illusion. New York: Viking.

Nosek, B. A., Banaji, M. R., \& Greenwald, A. G. (2002). Harvesting implicit group attitudes and beliefs from a demonstration website. Group Dynamics, 6(1), 101-115.

Nuessel, F. (1982). The language of ageism. Gerontologist, 22(3), 273-275.

Nuessel, F. H. (1984/1985). Ageist language. Maledicta, 8, 17-28.

O'Brien, L. T., \& Hummert, M. L. (2006). Memory performance of late middle-aged adults: Contrasting self-stereotyping and stereotype threat accounts of assimilation to age stereotypes. Social Cognition, 24(3), 338-358.

Ostchega, Y., Harris, T. B., Hirsch, R., Parsons, V. L., Kington, R., \& Katzoff, M. (2000). Reliability and prevalence of physical performance examination assessing mobility and balance in older persons in the U.S.: Data from the third national health and nutrition examination survey. Journal of the American Geriatrics Society, 48(9), 1136-1141.

Ostir, G. V., Volpato, S., Fried, L. P., Chaves, P., \& Guralnik, J. M. (2002). Reliability and sensitivity to change assessed for a summary measure of lower body function. Results from the women's health and aging study. Journal of Clinical Epidemiology, 55(9), 916-921.

Oswald, D. L., \& Lindstedt, K. (2006). The content and function of gender selfstereotypes: An exploratory investigation. Sex Roles, 54(7/8), 447-458. 
Page, S. J., Levine, P., \& Hill, V. (2007). Mental practice as a gateway to modified constraint induced movement therapy: A promising combination to improve function. American Journal of Occupational Therapy, 61(3), 321-327.

Palmore, E. B. (1990). Ageism: Negative and positive. New York: Springer Publishing Company.

Palmore, E. B. (1999). Ageism: Negative and positive (2nd ed.). New York: Springer Publishing Company.

Penninx, B., Ferrucci, L., Leveille, S. G., Rantanene, T., Pahor, M., \& Guralnik, J. M. (2000). Lower extremity performance in nondisabled older persons as a predictor of subsequent hospitalization. The Journals Of Gerontology, 55A(11), M691-M697.

Perdue, C. W., \& Gurtman, M. B. (1990). Evidence for automaticity of ageism. Journal of Experimental Social Psychology, 26(1), 199-216.

Peterson, R. T., \& Ross, D. T. (1997). A content analysis of the portrayal of mature individuals in television commercials. Journal of Business Ethics, 16(4), 425-433.

Pinquart, M. (2002). Good news about the effects of bad old-age stereotypes. Experimental Aging Research, 28(3), 317-336.

Polit, D. F., \& Beck, C. T. (2004). Nursing research: Principles and methods (7th ed.). Philadelphia, PA: Lippincott, Williams \& Wilkins.

Portney, L. G., \& Watkins, M. P. (2008). Foundations of clinical research. Applications to practice. Upper Saddle River, NJ: Pearson Education, Inc.

Prinz, W. (1987). Ideo-motor action. In H. Heder \& A. Sanders (Eds.), Perspectives on perception and action (pp. 47-76). Hillsdale, N. J.: Lawrence Erlbaum. 
Prinz, W. (1990). A common coding approach to perception and action. In O. Neumann \& W. Prinz (Eds.), Relationships between perception and action: Current approaches (pp. 167-203). New York: Springer-Verlag.

Prinz, W. (2002). Experimental approaches to imitation. In The imitative mind: Development, evolution, and brain bases (pp. 143-162). Cambridge, U. K.: Cambridge University Press.

Provine, R. R. (1986). Yawning as a stereotypical action pattern and releasing stimulus. Ethology, 72(2), 109-122.

Puthoff, M. L., \& Nielson, D. H. (2007). Relationship among impairments in lower extremity strength and power, functional limitations and disability in older adults. Physical Therapy, 87(10), 1334-1345.

Raman, P., Harwood, J., Weis, D., Anderson, J., \& Miller, G. (2006). Portrayals of age groups in U. S. and Indian magazine advertisements: A cross-cultural comparison (in Zhang): University of Arizona, Tuscan.

Resnick, B., Concha, B., Burgess, J. G., Fine, M. L., West, L., Baylor, K., et al. (2003). Recruitment of older women: Lessons learned from the Baltimore hip studies. Nursing Research, 52(4), 270-273.

Reuben, D. B., Seeman, T. E., Keeler, E., Hayes, R. P., Bowman, L., Sewall, A., et al. (2004). The effect of self-reported and performance-based functional impairment on future hospital costs of community-dwelling older persons. The Gerontologist, 44(3), 401-407.

Rice, D. P., \& Fineman, N. (2004). Economic implication of increased longevity in the 
United States. Annual Review of Public Health, 25(1), 457-473.

Rizzolatti, G., \& Arbib, M. A. (1998). Language within our grasp. Trends in Neuroscience, 21(5), 188-194.

Rizzolatti, G., Fadiga, L., Gallese, V., \& Fogassi, L. (1996). Premotor cortex and the recognition of motor actions. Cognitive Brain Research, 3(2), 131-141.

Rizzolatti, G., Fogassi, L., \& Gallese, V. (2001). Neurophysiological mechanisms underlying the understanding and imitation of action. Nature Reviews Neuroscience, 2(9), 661-670.

Rohan, E., Berkman, B., Walker, S., \& Holmes, W. (1994). The geriatric oncology patient: Ageism in social work practice. Journal of Gerontological Social Work, 23(1/2), 201-221.

Romano, S. T., \& Bordieri, J. E. (1989). Physical attractiveness stereotypes and students' perceptions of college professors. Psychological Reports, 64(3), 1099-1102.

Rosow, I., \& Breslau, N. (1966). A Guttman health scale for the aged. Journal of Gerontology, 21(4), 556-559.

Rothermund, K. (2003). Age-stereotypes and self-views in later life: Evaluating rival assumptions. International Journal of Behavioral Development, 27(6), 549-554.

Rowe, J. W., \& Kahn, R. L. (1997). Successful aging. The Gerontologist, 37(4), 433-440.

Rowley, S. J., Kurtz-Costes, B., Mistry, R., \& Feagans, L. (2007). Social status as a predictor of race and gender stereotypes in late childhood and early adolescence. Social Development, 16(1), 150-168.

Roy, \& Harwood. (1997). Underrepresented, positively portrayed: Older adults in 
television commercials. Journal of Applied Communication Research, 25(1), 39-56.

Schmidt, D. F., \& Boland, S. M. (1986). Structure of perceptions of older adults:

Evidence for multiple stereotypes. Psychology and Aging, 1(3), 255-260.

Schultz, R., \& Fritz, S. (1987). Origins of stereotypes of the elderly: An experimental study of the self discrepancy. Experimental Aging Research, 13(4), 189-195.

Sebanz, N., Knoblich, G., \& Prinz, W. (2002). Representing others' actions: Just like one's own? Cognition, 88(3), B11-B21.

Seeman, T. E., Berkman, L. F., Charpentier, P. A., Blazer, D. G., Albert, M. S., \& Tinetti, M. E. (1995). Behavioral and psychosocial predictors of physical performance:

Macarthur studies of successful aging. Journal of Gerontology: Medical Sciences, 50A(4), M177-M183.

Seeman, T. E., Charpentier, P. A., Berkman, L. F., Tinetti, M. E., Guralnik, J. M., Albert, M., et al. (1994). Predicting changes in physical performance in a high-functioning elderly cohort: Macarthur studies of successful aging. Journal of Gerontology, 49(3), M97-M108.

Seidler, R. D. (2007). Older adults can learn to learn new motor skills. Behavioral Brain Research, 183(1), 115-122.

Shactman, D., Altman, S. H., Eilat, E., Thorpe, K. E., \& Doonan, M. (2003). The outlook for hospital spending. Health Affairs, 22(6), 12-26.

Shafer, R. (2000). Housing America's seniors. Cambridge, MA: Joint Center for Housing Studies, Harvard University.

Sherman, J. W. (1996). Development and mental representation of stereotypes. Journal of 
Personality and Social Psychology, 70(6), 1126-1141.

Shih, M., Richeson, J. A., Ambady, N., Fujita, K., \& Gray, H. M. (2002). Stereotype performance boosts: The impact of self-relevance and the manner of stereotype activation. Journal of Personality and Social Psychology, 83(3), 638-647.

Shumway-Cook, A., Guralnik, J. M., Phillips, C. L., Coppin, A. K., Ciol, M. A., Bandinelli, S., et al. (2006). Age-associated declines in complex walking task performance: The walking INCHIANTI toolkit. Journal of the American Geriatrics Society, 55(1), 58-65.

Sibbritt, D. W., Byles, J. E., \& Regan, C. (2007). Factors associated with decline in physical functional health in a cohort of older women. Age and Ageing, 36(4), 382388.

Smith, E. R., Stewart, T. L., \& Buttram, R. T. (1992). Inferring a trait from a behavior has long-term, highly specific effects. Journal of Personality and Social Psychology, 62(5), 753-759.

Spencer, S. J., Fein, S., Wolfe, C. T., Fong, C., \& Dunn, M. A. (1998). Automatic activation of stereotypes: The role of self-image threat. Personality and Social Psychology Bulletin, 24(11), 1139-1152.

Srull, T. K., \& Wyer, R. S. (1979). The role of category accessibility in the interpretation of information about persons: Some determinants and implications. Journal of Personality and Social Psychology, 37(10), 1660-1672.

Srull, T. K., \& Wyer, R. S. (1980). Category accessibility and social perception: Some implications for the study of person memory and interpersonal judgments. Journal of 
Personality and Social Psychology, 38(6), 841-856.

Stanley, M. A., Beck, J. G., \& Zebb, B. J. (1998). Psychometric properties of the MSPSS in older adults. Aging \& Mental Health, 2(3), 186-193.

Steele, C. M., \& Aronson, K. (1995). Stereotype threat and the intellectual test performance of African Americans. Journal of Personality and Social Psychology, 69(5), 797-811.

Stein, R., Blanchard-Fields, F., \& Hertzog, C. (2002). The effects of age-stereotype priming on the memory performance of older adults. Experimental Aging Research, 28(2), 169-181.

Stephan, W. G., Ageyev, V., Coates-Shrider, L., Stephan, C. W., \& Abalakina, M. (1994). On the relationship between stereotypes and prejudice: An international study. Personality and Social Psychology Bulletin, 20(3), 277-284.

Studenski, S., Perera, S., Wallace, D., Chandler, J. M., Duncan, P. W., Rooney, E., et al. (2003). Physical performance measures in the clinical setting. Journals of the American Geriatrics Society, 51(3), 314-322.

Suthers, K., \& Seeman, T. (2004). The measurement of physical functioning in older adult populations. Washington, D.C.: National Institute of Aging.

Tamir, R., Dickstein, R., \& Huberman, H. (2007). Integration of motor imagery and physical practice in group treatment applied to subjects with Parkinson disease. Neurorehabilitation and Neural Repair, 21(1), 68-75.

Tamura, R., \& Kameda, T. (2006). Are facial expressions contagious in the Japanese? Japanese Journal of Psychology, 77(4), 377-382. 
Taylor, A., Sluckin, W., Davies, D. R., Reason, J. T., Thomson, R., \& Colmam, A. M. (1982). Voluntary behavior. In Introducing psychology (2nd ed., pp. 381-398). Middlesex, England: Penguin Books.

Thornton, J. E. (2002). Myths of aging or ageist stereotypes. Educational Gerontology, 28(4), 301-312.

Tiggemann, M., \& Rothblum, E. D. (1988). Gender differences in social consequences of perceived overweight in the United States and Australia. Sex Roles, 18(1-2), 75-86.

Tsai, C., Kuo, W., Hung, D., \& Tzeng, O. (2006). A common coding framework in selfother interaction. Experimental Brain Research, 175(2), 353-362.

Tulving, E., Schacter, D. L., \& Stark, H. A. (1982). Priming effects in word-fragment completion are independent of recognition memory. Journal of Experimental Psychology, Learning, Memory, and Cognition, 8(4), 336-342.

Tunney, N., Billings, K., Blakely, B. G., Burch, D., Hill, M., \& Jackson, K. (2006). Mental practice and motor learning. Physical and Occupational Therapy in Geriatrics, 24(3), 63-80.

Uchino, B. N., Cacioppo, J. T., \& Kiecolt-Glaser, J. K. (1996). The relationship between social support and physiological processes: A review with emphasis on underlying mechanisms and implications for health. Psychological Bulletin, 119(3), 488-531.

Unger, J. B., Johnson, C. A., \& Marks, G. (1997). Functional decline in the elderly: Evidence for direct and stress-buffering protective effects of social interactions and physical activity. Annals of Behavioral Medicine, 19(2), 152-160.

United States Census Bureau. (2003). Facts for features. Retrieved February 1, 2008, 
from http://www.census.gov/Press-Release/www/2003/cb03-ff06.html

United States Department of Health and Human Services. (2000). Healthy people 2010: Understanding and improving health. 2nd. Retrieved July 1, 2008, from http://www.healthypeople.gov/

Uotinen, V., Rantanen, T., Suutama, T., \& Ruoppila, I. (2006). Change in subjective age among older people over an eight-year follow-up: "getting older and feeling younger". Experimental Aging Research, 32(4), 381-393.

Verbrugge, L. M., \& Jette, A. M. (1994). The disablement process. Social Sciences and Medicine, 38(1), 1-14.

Wegner, D. M., \& Bargh, J. A. (1998). Control and automaticity in social life. In D. Gilbert, S. T. Fiske, \& G. Lindzey (Eds.), Handbook of social psychology (4th ed, Vol. 1, pp. 446-496). New York: McGraw-Hill.

Wheeler, S. C., Blair, W., Jarvis, G., \& Petty, R. E. (2001). Think unto others: The self destructive impact of negative racial stereotypes. Journal of Experimental Social Psychology, 37(2), 173-180.

Wheeler, S. C., \& Petty, R. E. (2001). The effects of stereotype activation on behavior: A review of possible mechanisms. Psychological Bulletin, 127(6), 797-826.

Wilson, I. B., \& Cleary, P. D. (1995). Linking clinical variables with health-related quality of life. Journal of the American Medical Association, 273(1), 59-65.

Winograd, C. H., Lemsky, C. M., Nevitt, M. C., Nordstrom, T. M., Stewart, A. L., Miller, C. J., et al. (1994). Development of a physical performance and mobility examination. Journal of the American Geriatrics Society, 42(7), 743-749. 
Wolinsky, F. D., Callahan, C. M., Fitzgerald, J. F., \& Johnson, R. J. (1993). Changes in functional status and the risks of subsequent nursing home placement and death. Journals of Gerontology. Psychological Sciences and Social Sciences, 48(3), S94S101.

Wolinsky, F. D., Callahan, C. M., \& Johnson, R. J. (1992). The risk of nursing home placement and subsequent death among older adults. Journal of Gerontology, 47(4), S173-S182.

Wolinsky, F. D., \& Johnson, R. J. (1991). The use of health services by older adults. Journals of Gerontology. Psychological Sciences and Social Sciences, 46(6), S345S347.

Yang, Z., Norton, E. C., \& Stearns, S. C. (2003). Longevity and health care expenditures: The real reason older people spend more. Journals of Gerontology. Psychological Sciences and Social Sciences, 58(1), S2-10.

Yoon, C., Hasher, L., Feinberg, F., Rahhal, T. A., \& Winocur, G. (2000). Cross-cultural differences in memory: The role of culture-based stereotypes about aging. Psychology of Aging, 15(4), 694-704.

Yzerbyt, V., Rocher, S., \& Schadron, G. (1997). Stereotypes as explanations: A subjective essentialistic view of group perception. In R. Spears, P. J. Oakes, N. Ellemers \& S. A. Haslam (Eds.), The social psychology of stereotyping and group life (pp. 20-50). Cambridge, MA: Blackwell Publishers Ltd.

Zebrowitz, L. A., Montepare, J. M., \& LooLee, H. (1993). They don't all look alike: Individuated impressions of other racial groups. Journal of Personality and Social 
Psychology, 65(1), 85-101.

Zhang, Y. B., \& Agard, A. (2004). Cultural values in television commercials featuring older adults. Hallym International Journal of Aging, 6(3), 167-183.

Zhang, Y. B., Harwood, J., Williams, A., Ylanne-McEwen, V., Wadleigh, P. M., \& Thimm, C. (2006). The portrayal of older adults in advertising. Journal of Language and Social Psychology, 25(3), 264-282.

Zhu, K., Hunter, S., Bernard, L. J., \& Payne-Wilks, K. (2000). Recruiting elderly African American women in cancer prevention and control studies: A multifaceted approach and its effectiveness. Journal of the National Medical Association, 92(4), 169.

Zijdewind, I., Toering, S. T., Laan, O. V., \& Diercks, R. L. (2003). Effects of imagery motor training on torque production of ankle plantarflexor muscles. Muscle \& Nerve, $28(2), 168-173$.

Zimet, G. D., Dahlem, N. W., Zimet, S. G., \& Farley, G. K. (1988). The Multidimensional Scale of Perceived Social Supports. Journal of Personality Assessment, 52(3), 30-41. 


\section{APPENDIX A}

Screening Instrument 
Screening Instrument

Study ID \#

DOB:

Circle their response.

1. Can you walk more than 13 feet?

Yes. Go to question \#2.

No. Thank them and explain that they do not meet the criteria for this particular study.

2. Can you stand without holding on to anything?

Yes. Go to question \#3.

No. Thank them and explain that they do not meet the criteria for this particular study.

3. Can you stand up from a chair five times in a row?

Yes. Go to question \#4.

No. Thank them and explain that they do not meet the criteria for this particular study.

4. Are you fluent in English?

Yes. Go to question \#5.

No. Thank them and explain that we do not have an interpreter available.

5. In the last 3 months, have you been hospitalized or gone to your doctor with any condition affecting your heart or blood pressure?

Yes. If they had a myocardial infarction (heart attack), percutaneoustransluminal coronary angioplasty, or coronary bypass surgery (open heart surgery). Thank them and explain that they do not meet the criteria for this particular study.

No. Go to question 6.

6. Using a Snellen eye chart, are they able to read line 2 ?

Yes. Enroll the participant.

No. Thank them and explain that they do not meet the criteria for this particular study. 


\section{APPENDIX B}

Table of Contents for the Peer Recruiter Training 
Table of Contents for Peer Recruiter Training

Training Agenda:

The training for the older adult peer recruiter is taught in a single module which takes the recruiter through every step of the recruitment process and teaches the recruiter some important things about working with research participants before the study begins.

Table of Contents:

I. Introduction

A. Background and purpose of the study

B. The research team

II. Initial Contact with Potential Participants

A. Recruitment strategies

B. Answering questions

C. Avoiding refusals

III. Use of the Screening Instrument

IV. Arranging Data Collection Appointments

A. Scheduling

B. The demographic survey

V. Informed Consent

VI. Ethics and Confidentiality

VII. Documentation Procedures 


\section{APPENDIX C}

Newsletter Announcement 


\section{Physical performance study looking for participants}

We are seeking adults over the age of 65 to participate in a physical performance study. The study, led by James Cotter, PhD and Gabriele Moriello PT, MS, GCS from Virginia Commonwealth University and The Sage Colleges will evaluate the physical performance of older adults. Participants will be asked to go undergo a one-time, 1 hour evaluation session (date to be announced) at the Testing requires travel to the and participants will be compensated $\$ 10$ for travel expenses.

People interested in participating must be 65 years of age or older who live independently in the community, can walk at least 13 feet, can stand without holding onto anything, can rise from a chair 5 times and can follow directions in English. Participants cannot have a history of a heart attack, angioplasty, or coronary artery bypass surgery within the past 3 months. Participants cannot be legally blind.

To participate, and for more information on the study, contact Gabriele at (518) 244-2063 or morieg@sage.edu.

If you are not 65 years of age or older, please feel free to pass this information along to someone who is. Thank you! 


\title{
APPENDIX D
}

\author{
Recruitment Flier
}




\section{VOLUNTEERS NEEDED}

for a research study

\section{"Physical Performance of Adults"}

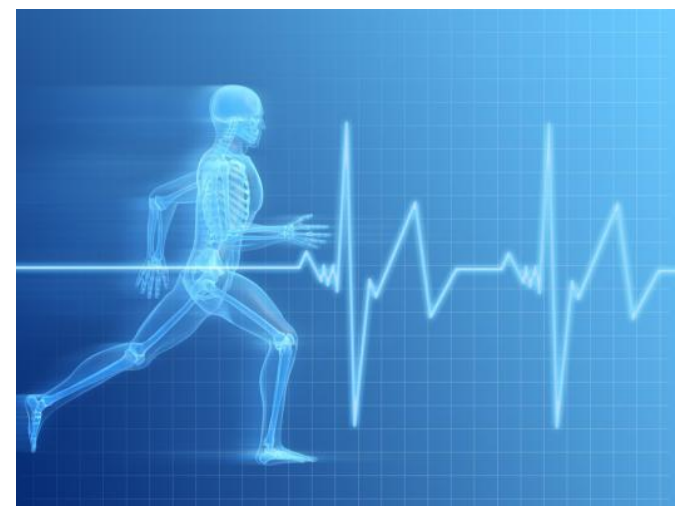

The study is open to adults 65 and older

\section{The purpose of the study is to better understand how adults function.}

Participation involves completing tests of standing balance, walking, chair stands, visual perception, and common associations.

Time commitment: One visit lasting approximately $1 \frac{1}{4}$ hours. You will be reimbursed for your time and travel expense.

The research will be conducted at

For additional information, contact Gabriele Moriello: (518) 244-2063 or e-mail Gabriele at morieg@ sage.edu 
APPENDIX E

Object Survey 


\section{Survey}

List all objects that come to mind when you think about older adults.

1.

\begin{tabular}{|c|c|c|c|c|c|c|}
\hline $\begin{array}{c}1 \\
\text { Negative }\end{array}$ & 2 & 3 & 4 & 5 & 6 & $\begin{array}{l}7 \\
\text { Positive }\end{array}$ \\
\hline $\begin{array}{c}1 \\
\text { Negative }\end{array}$ & 2 & 3 & 4 & 5 & 6 & $\begin{array}{c}7 \\
\text { Positive }\end{array}$ \\
\hline
\end{tabular}

3.

\begin{tabular}{lllllll}
\hline & & & & & & \\
\hline 1 & 2 & 3 & 4 & 5 & 6 & 7 \\
Negative & & & & & & Positive
\end{tabular}

4.

\begin{tabular}{ccccccc}
\hline 1 & 2 & 3 & 4 & 5 & 6 & 7 \\
Negative & & & & & & Positive
\end{tabular}


5.

\begin{tabular}{ccccccc}
\hline 1 & 2 & 3 & 4 & 5 & 6 & $\begin{array}{c}7 \\
\text { Positive }\end{array}$
\end{tabular}

6.

\begin{tabular}{lllllll}
\hline 1 & 2 & 3 & 4 & 5 & 6 & 7
\end{tabular}

Negative

Positive

7.

\begin{tabular}{lllllll}
\hline 1 & 2 & 3 & 4 & 5 & 6 & 7
\end{tabular}

Negative

Positive

8.

\begin{tabular}{ccccccc}
\hline 1 & 2 & 3 & 4 & 5 & 6 & $\begin{array}{c}7 \\
\text { Positive }\end{array}$
\end{tabular}




\section{APPENDIX F}

Table of Contents for Training the People Providing the Intervention 
Table of Contents for Training the People Providing the Intervention

\section{Training Agenda}

The training for the people providing the intervention is taught in a single module which takes each person through every step of the intervention process and teaches them some important things about working with research participants before the study begins.

Table of Contents:

I. Introduction

1. Background

2. The research team

II. The Intervention Protocol

III. Practice session

IV. Informed Consent

V. Ethics and Confidentiality

VI. Documentation Procedures

VII. Evaluation of the person performing the intervention by the PI 
APPENDIX G

Intervention Script 


\section{Intervention Script}

\section{Read aloud:}

For this part of the study, you will be performing two separate tasks. The first task will test common associations and the second task will test visual perception.

For the first task, you will match seven objects with their corresponding descriptions. As you can see, each object is numbered from 1-7. Please read the description of each object and place the corresponding number next to it on this form.

For the second task, you will use the same seven objects that you used in the first task.

This time you will place the objects from shortest to tallest with the shortest objects on the left and the tallest objects on the right. 


\section{APPENDIX H}

Word Fragment Completion Task: Aging Stereotypes 
Please fill in the blanks to make complete words.

$$
\begin{aligned}
& \text { Example: } \mathbf{T} \_\mathbf{P} \\
& \text { 1. } \mathbf{S E} \_\mathrm{LE} \\
& \text { 2. } \quad \mathbf{R}-\ldots \mathbf{E} \\
& \text { 3. } \quad \mathbf{T}_{-} \mathbf{P} \\
& \text { 4. } \mathrm{S}-\mathrm{OW} \\
& \text { 5. } \mathbf{A}-\mathbf{T}-\mathbf{R} \\
& \text { 6. } \quad \text { L }- \text { E L Y } \\
& \text { 7. } S-M P L- \\
& \text { 8. } \mathbf{S} \mathbf{H}-\mathbf{L} \\
& \text { 9. } \quad \mathbf{H}-\mathbf{T} \\
& \text { 10. } S \mathbf{H}-\mathbf{R}- \\
& \text { 11. }-\mathrm{L} \mathrm{L} \\
& \text { 12. } \mathrm{W}-\mathrm{K}
\end{aligned}
$$




$$
\begin{aligned}
& \text { 13. } \quad \mathbf{P}-\mathbf{N} \mathbf{E} \\
& \text { 14. } \quad F \quad L-T \\
& \text { 15. C O N F } \ldots \text { E D } \\
& \text { 16. } P-C \mathrm{~K} \\
& \text { 17. } \mathbf{A}-\mathbf{T} \\
& \text { 18. D E C L _ E } \\
& \text { 19. B }-{ }_{-} \mathrm{K} \\
& \text { 20. } S_{-} \mathbf{D}_{-} \\
& \text {21. } \mathbf{C} \mathbf{R}-\ldots \mathrm{Y} \\
& \text { 22. } \mathbf{B} \mathbf{R}--\mathrm{Z} \mathbf{E} \\
& \text { 23. } \quad \mathbf{F} \mathbf{R}-\mathbf{T}^{-} \\
& \text {24. H E }- \text { L E S S }
\end{aligned}
$$




\section{APPENDIX I}

Survey to Identify Older Adult Stereotypes 


\section{Survey}

List all words that come to mind when you think about older adults.

1.

2.

3.

4.

5.

6. 
7.

8.

9.

10.

11.

12.

13.

14. 


\section{APPENDIX J}

Word Fragment Completion Task: Disability Stereotypes 
Please fill in the blanks to make complete words.

Example: $\mathbf{T} \_\mathbf{P}$

25. $\quad$ B - - T E R

26. $\mathbf{P} \mathbf{R}-\mathbf{E}$

27. $\mathbf{T}_{-} \mathbf{P}$

28. $\quad \mathrm{V}$ I $\mathrm{C} \quad \mathrm{T}$

29. $\mathbf{A}-\mathbf{T}-\mathbf{R}$

30. C R I _ $\ldots$ L E

31. $\quad$ _ $-M$ P L

32. $\mathbf{S H}-\mathbf{L}$

33. $\mathbf{H}-\mathbf{T}$

34. $\mathbf{S} \mathbf{H}-\mathbf{R}$

35. $\mathbf{R}$ E T A

36. $\mathbf{L}-\mathbf{E}$ 


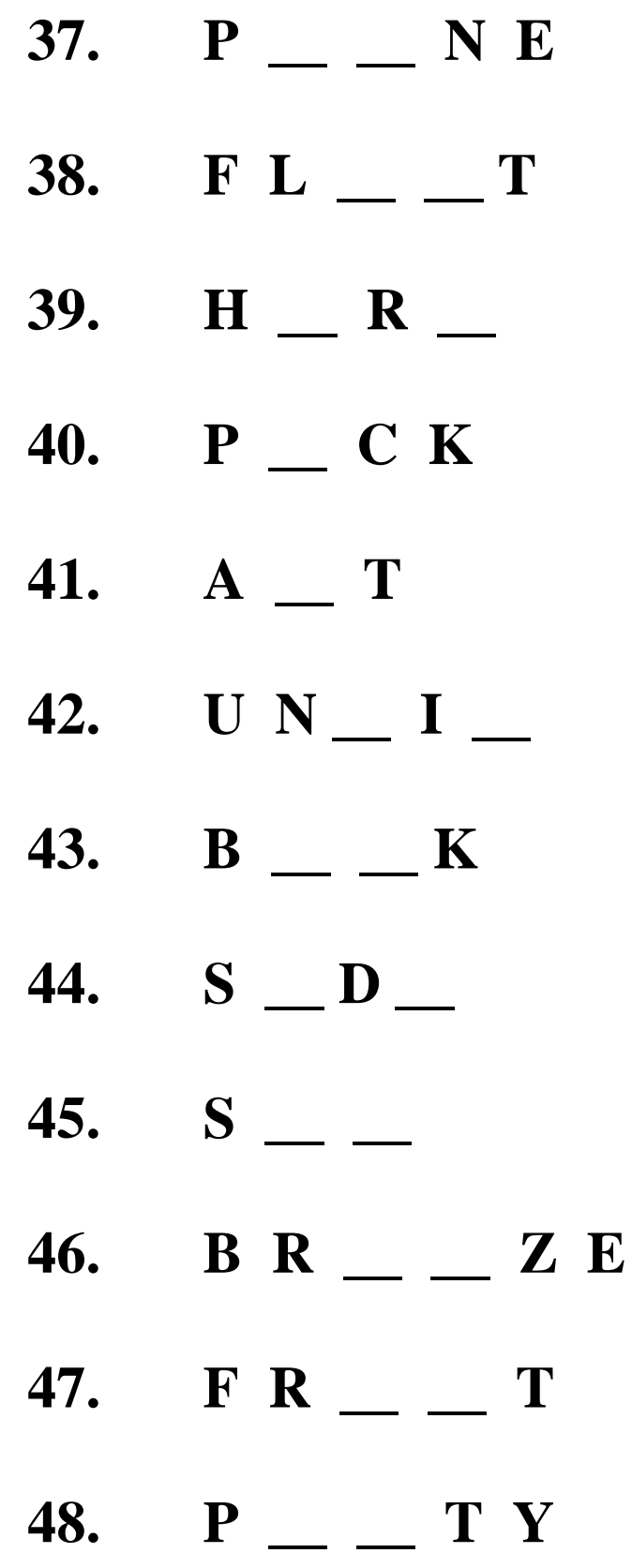




\section{APPENDIX K}

Survey to Identify Disability Stereotypes 


\section{Survey}

\section{List all words that come to mind when you think about someone who is disabled.}

1.

2

3

4

5

6 


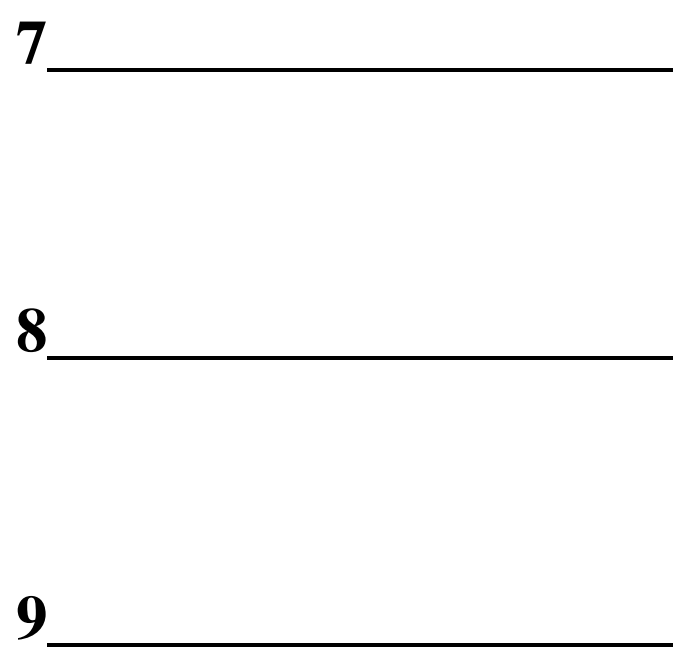

10

11

12

13

14 
APPENDIX L

Table of Contents for the Evaluator Training 
Table of Contents for the Evaluator Training

\section{Training Agenda}

The training for the evaluators is taught in a single module which takes each evaluator through every step of the evaluation process and teaches the evaluator some important things about working with research participants before the study begins.

Table of Contents:

I. Introduction

1. Background

2. The research team

II. Overview of the Short Physical Performance Battery

III. Videotape of the Short Physical Performance Battery (developed by the authors)

IV. Practice session

V. Informed Consent

VI. Ethics and Confidentiality

VII. Documentation Procedures

VIII. Evaluation of the evaluator by the PI 


\title{
APPENDIX M
}

\author{
Evaluation Instructions
}




\section{Evaluation Instructions}

\section{Balance test}

The tests of balance provide an assessment of the participants' ability to hold three basic standing positions with the eyes open. No equipment other than a stopwatch, script, or score sheet is needed.

These positions are the side-by-side stand, semi tandem, and full tandem stand and are performed in this order. Participants taking this test must be able to stand unassisted without using a cane or a walker. Don't assume that a participant who arrives for testing using a cane or walker can't stand unassisted. Ask them is they can stand without the device and are willing to try the test, If they say yes, you can assist them to assume the correct position for testing.

For each position, the examiner first describes and then demonstrates the appropriate stand. The participant then assumes the correct foot position while supported by the examiner. Once the participant appears to be steady, ask if he or she is ready. When they say yes, the examiner relinquishes support, says "Ready, begin," and starts timing. The timing is continued until the participants moves his or her feet, grasps the examiner for support or 10 seconds have elapsed (for the side-by-side or semi tandem stand) or 30 seconds (for the tandem stand). Record any time less than 10 seconds (for the side-byside or semi tandem stand) or less than 30 seconds (for the tandem stand) to the nearest hundredth of a second.

The first position tested is the side-by-side. In this balance test, participants are requested to stand for 10 seconds with their feet together in a side-by-side position. Participants who are unable to hold the side-by-side stand for 10 seconds do not proceed further with the balance tests and are given a score of 0 for this portion of the battery. Participants who successfully complete the side-by-side test receive 1 point and proceed to the semitandem balance test.

In the semi-tandem balance test, each participant starts with the heel of one foot placed to the side of the big toe of the other foot. Either foot can be placed in the forward position. Participants who successfully hold the semi-tandem position for 10 seconds are given 1 additional point and proceed to the final balance test. Those who fail to hold the position for 10 seconds receive no points and do not perform the tandem balance test.

The final position evaluated in the balance tests is the tandem position. To assume the tandem position, the heel of one foot is placed directly in front of the toes of the other foot. Either foot can be placed in the forward position. The test will be capped at 60 seconds. Participants who hold the position for 10 seconds or greater are awarded 2 
additional points. Those who hold the position for 3 to 9.99 seconds are given 1 additional point. Holding the position for less than 3 seconds results in no points.

Complete the score sheet. If a specific maneuver was not attempted, you should explain why no attempt was made. Select one of the options on the score sheet. It is critical but sometimes very difficult to distinguish between someone who is unable and therefore unwilling to try a test and a person who simply refuses to do the test because they are not interested in participating. This judgment rests with the examiner. A participant who is unable to perform the test is scored a zero for that particular test.

Post test: Follow the identical instructions as above EXCEPT: only complete the subtest that they completed last and cap the time at 60 seconds.

\section{Gait speed test}

In this test, the participant's ability to walk 4 meters is assessed. For the test, you will need a stopwatch, the script, the score sheet, and a marked walking course. If the test is being done in a new location, then a course must be laid out on the floor. The walking course should be unobstructed and include at least an extra one-half meter on each end.

Participants are instructed to walk their usual speed, and timing is stopped when the first foot completely crosses the 4-meter mark. Record the time to the nearest hundredths of a second. The faster of the two timed walks is used for scoring purposes.

A cane or walker may be used during the walk, but is people with such devices can walk short distances without them; they should be encouraged to do so. Many people with assistive devices use them only when they walk outdoors or for long distances indoors. Doing the test without the device provides a much more accurate assessment of the functional limitations for the participant. Ask the participant if she ever walks at home without a device. Then ask the participant if she thinks she can walk a short distance for the test. Participants who normally use assistive devices should be watched particularly closely during the test to prevent falling.

Scoring of the gait speed test is based on established categories of completion times that were previously shown to divide the older population into four equal groups. Participants who require more than 8.70 seconds to complete the walk receive 1 point; participants whose completion times fall in the range of 6.21-8.70 receive 2 points; participants who finish in 4.82-6.20 receive 3 points. Participant who finish the walk in less than 4.82 seconds receive the full 4 points. Inability to complete the walk in less than 60 seconds results in a score of 0 .

Post test: Follow the identical instructions as noted above. 


\section{Chair stand test}

To perform this test, you will need a stopwatch, the script, a score sheet, and a straight backed chair with a hard seat. In this test, participants are first instructed to fold their arms across their chest and to try to stand up one time from an armless chair placed against a wall. The chair should be placed next to the wall.

If the participants are successful rising from the chair once, they are then asked to stand up and sit down 5 times as quickly as possible. Timing begins as soon as the command to sit is given and continues until the participant straightens at the end of the fifth stand. Record the time to the nearest hundredths of a second.

Scoring of the chair stand test is based on established categories of completion times of five repetitions that have been shown to divide the older population into four equal groups. Participants who require more than 16.70 but less than 60 seconds receive 1 point. Participants who fall in the range 13.70-16.69 seconds receive 2 points, while those in the range 11.20-13.69 seconds receive 3 points. Participants who finish the 5 repetitions in less than 5 seconds receive the full 4 points. Inability to complete the test in less than 60 seconds results in a score of 0.

Post test: Follow the identical instructions as noted above. 


\section{APPENDIX N}

Demographic Survey 
Study ID\#:

Personal Information Sheet

Please complete all of the following information.

Date of Birth:

Primary MD:

Gender (circle one): Male

Female

Race/Ethnicity (circle one): White, Not of Hispanic Origin

Black, African American, or Negro

American Indian or Alaskan Indian

Asian (Asian Indian, Chinese, Japanese, Korean, Vietnamese)

Pacific Islander

Other (specify)

Education:

No high school diploma or GED

High school diploma or GED

Some college but no bachelor's degree

Bachelor's degree or higher

Socioeconomic Status

$<\$ 20,000$

(total household income

$\$ 20,000-\$ 34,999$

from all sources during

$\$ 35,000-\$ 49,999$

$\$ 50,000-\$ 99,999$

$>\$ 100,000$ 


\section{APPENDIX O}

Cognitive Age Scale 
Study ID \#:

Circle your response.

Please specify which of these age decades you FEEL you really belong to: Preteens, teens, twenties, thirties, forties, fifties, sixties, seventies, eighties, and nineties.

1. I FEEL as though I am in my.......

$\begin{array}{llllllllll}\text { Preteens } & \text { Teens } & 20 \mathrm{~s} & 30 \mathrm{~s} & 40 \mathrm{~s} & 50 \mathrm{~s} & 60 \mathrm{~s} & 70 \mathrm{~s} & 80 \mathrm{~s} & 90 \mathrm{~s}\end{array}$

2. I LOOK as though I am in my ......

$\begin{array}{llllllllll}\text { Preteens } & \text { Teens } & 20 \mathrm{~s} & 30 \mathrm{~s} & 40 \mathrm{~s} & 50 \mathrm{~s} & 60 \mathrm{~s} & 70 \mathrm{~s} & 80 \mathrm{~s} & 90 \mathrm{~s}\end{array}$

3. I DO most things as though I were in my.....

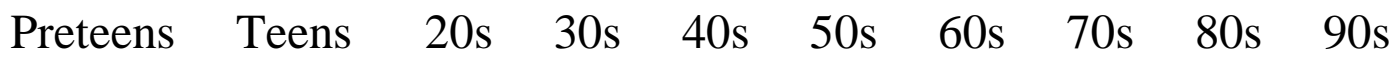

4. My INTERESTS are mostly those of a person in his/her.....

$\begin{array}{llllllllll}\text { Preteens } & \text { Teens } & 20 \mathrm{~s} & 30 \mathrm{~s} & 40 \mathrm{~s} & 50 \mathrm{~s} & 60 \mathrm{~s} & 70 \mathrm{~s} & 80 \mathrm{~s} & 90 \mathrm{~s}\end{array}$ 
Scoring: Feel/Age, Look/Age, DO/Age, and Interest Age are independently scored through the midpoints of each age-decade (preteens, teens, 20s, 30s, etc.) as respondent identifies with. To illustrate, an individual who responds to the Feel/Age statement "I FEEL as though I am in my...." With 30s, receives a score of 35 years for Feel/Age.

The Cognitive Age score is computed through a simple average of the four age dimension scores.

COGNITVE AGE $=($ FEEL/AGE + LOOK/AGE + DO/AGE + INTEREST/AGE $) / 4$ 
APPENDIX P

Multidimensional Scale of Perceived Social Support 


\section{Study ID \#}

\section{Multidimensional Scale of Perceived Social Support}

Instructions: We are interested in how you feel about the following statements. Read each statement carefully. Indicate how you feel about each statement.

$\begin{array}{ll}\text { Circle the "1" } & \text { if you Very Strongly Disagree } \\ \text { Circle the "2" } & \text { if you Strongly Disagree } \\ \text { Circle the "3" } & \text { if you Mildly Disagree } \\ \text { Circle the "4" } & \text { if you are Neutral } \\ \text { Circle the "5" } & \text { if you Mildly Agree } \\ \text { Circle the "6" } & \text { if you Strongly Agree } \\ \text { Circle the "7" } & \text { if you Very Strongly Agree }\end{array}$

Very

Strongly

Strongly

Mildly
Disagree Neutral

Mildly Strongly

Very

Disagree

Disagree

Agree

Strongly

1. There is a special person who is around when I am in need.

2

3

4

5

6

7

2. There is a special person with whom I can share joys and sorrows.

3. My family really tries to help me.

2

3

4

5

6

4. I get the emotional help \& support

I need from my family.

2

3

4

5

6

1

2

3

4

5

6

7

5. I have a special person who is a real source of comfort to me.

6. My friends really try to help me.

1

2

3

4

5

6

7. I can count on my friends when things go wrong.

2

3

4

5

6

8. I can talk about my problems with my family.

3

4

5

6

9. I have friends with whom I can share my joys and sorrows.

3

4

5

6

7

10. There is a special person in my life who cares about my feelings.

3

4

5

6

7

11. My family is willing to help me make decisions.

12. I can talk about my problems with my friends.

2

3

3

4




\section{$\underline{\text { Scoring Information }}$}

To calculate mean scores:

Significant Other Subscale: Sum across items 1, 2, 5, \& 10, then divide by 4.

Family Subscale: Sum across items 3, 4, 8, \& 11, then divide by 4 .

Friends Subscale: Sum across items 6, 7, 9, \& 12, then divide by 4 .

Total Scale: Sum across all 12 items, then divide by 12 . 


\section{Appendix Q}

\section{Informed Consent Forms for Pilot Study}


Dear

We would like you to participate in our research study. The purpose of this pilot research is to investigate the functioning of adults. The main investigators for this project are Dr. John Cotter PhD, and Gabriele Moriello PT, MS, GCS.

You have been asked to participate in this project since the project involves itself with community dwelling adults without significant medical histories. It will require one session of approximately 15 minutes and will take place at a convenient community location.

Prior to participation in this study, you will be asked to provide demographic information and sign the informed consent form. All data will be kept confidential. You are not obligated to participate in this study and may withdraw from the study at any time without penalty.

On the day of data collection, you will be required to complete two tests; one will test common associations while the second tests visual perception. During the first test, you will be exposed to seven objects which will be numbered from 1-7. You will read a description of each object and place the number of the object next to its description. During the second test, you will place the objects in terms of their height from shortest on the left to tallest on the right. Upon completion, you will be debriefed regarding the nature of the study.

There are no identifiable risks associated with this pilot study. The information gained from this pilot study may benefit others who have similar characteristics to yourself.

If you have any questions regarding this study or your participation in this study, you may contact Gabriele Moriello at (518) 244- 2063 at any time. If you would like a copy of this completed study, please include your address on the informed consent form. Your contribution to this study is greatly valued. Thank you for considering participating in this research study.

Sincerely,

Gabriele Moriello PT, MS, GCS 


\section{RESEARCH SUBJECT INFORMATION AND CONSENT FORM}

\section{TITLE: Physical performance of adults}

\section{VCU IRB NO.:}

This consent form may contain words that you do not understand. Please ask the study staff to explain any words that you do not clearly understand. You may take home an unsigned copy of this consent form to think about or discuss with family or friends before making your decision.

\section{PURPOSE OF THE STUDY}

You are being asked to participate in a pilot study for Ms. Moriello's dissertation at Virginia Commonwealth University. The purpose of this project is to investigate the functioning of adults.

\section{DESCRIPTION OF THE STUDY AND YOUR INVOLVEMENT}

If you decide to be in this research study, you will be asked to sign this consent form after you have had all your questions answered and understand what will happen to you.

For this study, you will be required to complete three tests; one will test common associations, the second tests visual perception, and the third tests and the third will test visual and recognition processing of words. During the first test, you will be exposed to seven objects which will be numbered from 1-7. You will read a description of each object and place the number of the object next to its description. During the second test, you will place the objects in terms of their height from shortest on the left to tallest on the right. During the third test, you will complete a word fragment task in which you have to create words out of word fragments. This study will require one session of approximately 15 minutes. Upon completion, you will be debriefed regarding the specific nature of the study.

Significant new findings developed during the course of the research which may relate to your willingness to continue participation will be provided to you.

\section{RISKS AND DISCOMFORTS}

There are minimal potential risks to participating in this study. There is a slight chance that you may get upset by your performance on the measures.

\section{BENEFITS TO YOU AND OTHERS}


You may not get any direct benefit from this study, but the information we learn from people in this study may help others who have similar characteristics to yourself.

\section{COSTS}

There are no costs for participating in this study other than the time you will spend completing the tasks which should not exceed 15 minutes.

\section{PAYMENT FOR PARTICIPATION}

None

\section{ALTERNATIVES}

The alternative is to not participate in the study.

\section{CONFIDENTIALITY}

Potentially identifiable information about you will consist of your date of birth, gender, race/ethnicity, education, and socioeconomic status. Data is being collected only for research purposes and your data will be identified by ID numbers, not names, and stored separately in a locked research area. Access to all data will be limited to study personnel. A data and safety monitoring plan is established.

We will not tell anyone the answers you give us; however, information from the study and the consent form signed by you may be looked at or copied for research or legal purposes by Virginia Commonwealth University or The Sage Colleges.

What we find from this study may be presented at meetings or published in papers, but your name will not ever be used in these presentations or papers.

\section{IF AN INJURY HAPPENS}

Virginia Commonwealth University, the VCU Health System, and The Sage Colleges do not have a plan to give long-term care or money if you are injured because you are in the study.

If you are injured because of being in this study, tell the study staff right away. The study staff will arrange for short-term emergency care or referral if it is needed.

Bills for treatment may be sent to you or your insurance. Your insurance may or may not pay for taking care of injuries that happen because of being in this study. 


\section{VOLUNTARY PARTICIPATION AND WITHDRAWAL}

You do not have to participate in this study. If you choose to participate, you may stop at any time without any penalty. You may also choose not to answer particular questions that are asked in the study.

Your participation in this study may be stopped at any time by the study staff without your consent. The reasons might include:

- the study staff thinks it necessary for your health or safety;

- you have not followed study instructions; or

- . administrative reasons require your withdrawal.

\section{QUESTIONS}

In the future, you may have questions about your participation in this study. If you have any questions, complaints, or concerns about the research, contact:

Gabriele Moriello

John J. Cotter

(518) 244-2063

(804) 828-1914

morieg@ sage.edu

jcotter@vcu.edu

If you have any questions about your rights as a participant in this study, you may

contact:

Office for Research

Virginia Commonwealth University

800 East Leigh Street, Suite 113

P.O. Box 980568

Richmond, VA 23298

Telephone: 804-827-2157

Dr. John Tribble, Dean

Sage Graduate School

45 Ferry Street

Troy, New York 12180

(518) 244-2264

tribbj@sage.edu

You may also contact this number for general questions, concerns or complaints about the research. Please call this number if you cannot reach the research team or wish to talk to someone else. Additional information about participation in research studies can be found at http://www.research.vcu.edu/irb/volunteers.htm. 


\section{CONSENT}

I have been given the chance to read this consent form. I understand the information about this study. Questions that I wanted to ask about the study have been answered. My signature says that I am willing to participate in this study.

\begin{tabular}{lll}
\hline Participant name printed & Participant signature Date
\end{tabular}

Name of Person Conducting Informed Consent

Discussion / Witness ${ }^{3}$

(Printed)

Signature of Person Conducting Informed Consent

Date

Discussion / Witness

Investigator Signature (if different from above)

Date $^{4}$

IF YOU WOULD LIKE TO RECEIVE A SUMMARY OF THE RESULTS OF THIS STUDY, PLEASE PROVIDE US WITH YOUR ADDRESS BELOW: 


\section{APPENDIX R}

Informed Consent Forms for Main Study 


\section{Dear}

We would like you to participate in our research study. The purpose of this research is to investigate the physical functioning of adult. The main investigators for this project are Dr. John Cotter PhD, and Gabriele Moriello PT, MS, GCS.

You have been asked to participate in this project since the project involves itself with community dwelling adults without significant medical histories. It will require one session of approximately one hour and 15 minutes and will take place at a convenient community location.

Prior to participation in this study, you will be asked to provide demographic information and sign the informed consent form. All data will be kept confidential. You are not obligated to participate in this study and may withdraw from the study at any time without penalty.

On the day of data collection, you will be required to complete a measure of standing balance, a timed four meter walk, and a timed test of the ability to rise from a chair five times. During the measure of standing balance, you will be timed while maintaining a side-by-side, semi-tandem, and tandem stance. During the measure of timed walking, you will be timed walking four meters at your usual pace. During the chair stand task, you will be required to stand up from a standard straight backed chair as quickly as possible five times. You will then perform additional tests. One will test common associations while the second tests visual perception. The measures of standing balance, the timed four meter walk, and the chair stand test are then repeated. This study will require one session of approximately one hour and 15 minutes. Upon completion, you will be debriefed regarding the nature of the study.

Your scores on the measures of standing balance, the timed four meter walk, and the chair stand test can determine if you are at risk for pre-clinical disability. If you would like to receive your score on these tests, you can receive them. If we determine you are at risk for pre-clinical disability, you will receive information on what you can do to prevent it. You will receive a 
$\$ 10$ compensation for any travel costs and for the time you have put into the project.

Potential risks related to your participation in the study include a very low risk of a fall during administration of the dependent measures. A physical therapist with over 5 years experience will be administrating these measures and will guard you to minimize the risk. During administration of the dependent measures, cardiovascular demands are increased. Your blood pressure, heart rate, and oxygen saturation rates will be measured prior to administering the measurements.

If you have any questions regarding this study or your participation in this study, you may contact Gabriele Moriello at (518) 244- 2063 at any time. If you would like a copy of this completed study, please include your address on the informed consent form. Your contribution to this study is greatly valued. Thank you for considering to participate in this research study.

Sincerely,

Gabriele Moriello PT, MS, GCS 


\section{RESEARCH SUBJECT INFORMATION AND CONSENT FORM}

\section{TITLE: Physical performance of adults}

\section{VCU IRB NO.:}

This consent form may contain words that you do not understand. Please ask the study staff to explain any words that you do not clearly understand. You may take home an unsigned copy of this consent form to think about or discuss with family or friends before making your decision.

\section{PURPOSE OF THE STUDY}

You are being asked to participate in a research study for Ms. Moriello's dissertation at Virginia Commonwealth University. The purpose of this project is to investigate the functioning of adults.

\section{DESCRIPTION OF THE STUDY AND YOUR INVOLVEMENT}

If you decide to be in this research study, you will be asked to sign this consent form after you have had all your questions answered and understand what will happen to you.

For this study, you will be required to complete a measure of standing balance, a timed four meter walk, and a timed test of the ability to rise from a chair five times. During the measure of standing balance, you will be timed while maintaining a side-by-side, semitandem, and tandem stance. During the measure of timed walking, you will be timed walking four meters at your usual pace. During the chair stand task, you will be required to stand up from a standard straight backed chair as quickly as possible five times. You will then perform additional tests. One will test common associations while the second tests visual perception. The measures of standing balance, the timed four meter walk, and the chair stand test are then repeated. This study will require one session of approximately one hour and 15 minutes. Upon completion, you will be debriefed regarding the nature of the study. A few participants will be asked to repeat the measures of standing balance, the timed four meter walk test, and the chair stand test a third time. These tests will require an additional 15 minutes of your time is you are randomly chosen to do so.

Significant new findings developed during the course of the research which may relate to your willingness to continue participation will be provided to you. 


\section{RISKS AND DISCOMFORTS}

Potential risks related to your participation in the study include a very low risk of a fall during administration of the dependent measures. A physical therapist with over 5 years experience will be administrating these measures and will guard you to minimize the risk. During administration of the dependent measures, cardiovascular demands are increased. Your blood pressure, heart rate, and oxygen saturation rates will be measured prior to administering the measurements. There is a slight chance that you may get upset by your performance on the measures.

\section{BENEFITS TO YOU AND OTHERS}

Your scores on the measures of standing balance, the timed four meter walk, and the chair stand test can determine if you are at risk for pre-clinical disability. If you would like to receive your score on these tests, you can receive them. If we determine you are at risk for pre-clinical disability, you will receive information on what you can do to prevent it. The information gained from this study may benefit others who have similar characteristics to yourself. At the completion of the study a summary of the results will be mailed to you upon request.

\section{COSTS}

There are no costs for participating in this study other than the time you will spend completing the tasks which should not exceed one hour and 15 minutes.

\section{PAYMENT FOR PARTICIPATION}

You will receive $\$ 10$ to participate in the study. It will be given to you at the end of the session.

\section{ALTERNATIVES}

The alternative is to not participate in the study.

\section{CONFIDENTIALITY}

Potentially identifiable information about you will consist of your date of birth, gender, race/ethnicity, education, socioeconomic status as well as your scores on the Multidimensional Scale of Social Support, the Cognitive Age Scale, standing balance test, timed four-meter walk test, and chair stand test. Data is being collected only for research purposes and your data will be identified by ID numbers, not names, and stored separately in a locked research area. Access to all data will be limited to study personnel. A data and safety monitoring plan is established. 
We will not tell anyone the answers you give us; however, information from the study and the consent form signed by you may be looked at or copied for research or legal purposes by Virginia Commonwealth University or The Sage Colleges.

What we find from this study may be presented at meetings or published in papers, but your name will not ever be used in these presentations or papers.

\section{IF AN INJURY HAPPENS}

Virginia Commonwealth University, the VCU Health System, and The Sage Colleges do not have a plan to give long-term care or money if you are injured because you are in the study. If you are injured because of being in this study, tell the study staff right away. The study staff will arrange for short-term emergency care or referral if it is needed. Bills for treatment may be sent to you or your insurance. Your insurance may or may not pay for taking care of injuries that happen because of being in this study.

\section{VOLUNTARY PARTICIPATION AND WITHDRAWAL}

You do not have to participate in this study. If you choose to participate, you may stop at any time without any penalty. You may also choose not to answer particular questions that are asked in the study.

Your participation in this study may be stopped at any time by the study staff without your consent. The reasons might include:

- the study staff thinks it necessary for your health or safety;

- you have not followed study instructions; or

- administrative reasons require your withdrawal.

\section{QUESTIONS}

In the future, you may have questions about your participation in this study. If you have any questions, complaints, or concerns about the research, contact:

Gabriele Moriello

(518) 244-2063

morieg@sage.edu
John J. Cotter

(804) 828-1914

jcotter@vcu.edu

If you have any questions about your rights as a participant in this study, you may contact:

Office for Research

Virginia Commonwealth University 
800 East Leigh Street, Suite 113

P.O. Box 980568

Richmond, VA 23298

Telephone: 804-827-2157

Dr. John Tribble, Dean

Sage Graduate School

45 Ferry Street

Troy, New York 12180

(518) 244-2264

tribbj@sage.edu

You may also contact this number for general questions, concerns or complaints about the research. Please call this number if you cannot reach the research team or wish to talk to someone else. Additional information about participation in research studies can be found at http://www.research.vcu.edu/irb/volunteers.htm.

\section{CONSENT}

I have been given the chance to read this consent form. I understand the information about this study. Questions that I wanted to ask about the study have been answered. My signature says that I am willing to participate in this study.

\begin{tabular}{lll}
\hline Participant name printed & Participant signature Date
\end{tabular}

Name of Legally Authorized Representative (Printed)

Legally Authorized Representative Signature

Date

Name of Person Conducting Informed Consent

Discussion / Witness ${ }^{3}$

(Printed) 
Signature of Person Conducting Informed Consent

Date

Discussion / Witness

Investigator Signature (if different from above)

Date $^{4}$

IF YOU WOULD LIKE TO RECEIVE A SUMMARY OF THE RESULTS OF THIS STUDY, PLEASE PROVIDE US WITH YOUR ADDRESS BELOW: 


\section{APPENDIX S}

Debriefing Script for Pilot Study 


\section{Debriefing for Pilot Study}

Thank you very much for participating in our pilot project today. The information gained from this pilot project will be used in our main study. The overall purpose of the main study is to explore how aging stereotypes may affect physical performance in older adults. There is growing evidence which suggests that success or failure at a task is not always related to lack of ability or incompetence. It is suggested that the power of stereotypes can affect performance either positively or negatively. We would like to discover whether stereotypes do affect factors like walking speed, balance, and the ability to get up from a chair. If they do, our next step is to figure out ways to lessen any negative effects and promote the positive effects. We may also need to figure out ways to diminish typical stereotypes about older adults. All older adults are different and do not all possess the same characteristics that are often portrayed in our society.

In this pilot project we were investigating whether exposure to objects related to older adults really does elicit stereotypes of aging. Today, you were briefly exposed to (positive, negative, or neutral) stereotypes of aging. The effects of a one time exposure to stereotypes are minimum and temporary. Your participation in the study is much appreciated since you are helping other older adults and our society.

If you have any concerns as a result of what we did today or how you performed on the measures, please let me know so that we can talk about it. Do you have any questions or concerns?

Here is my business card in case you have any questions or concerns after you leave here today. Please do not speak with your peers about this project until data collection is complete since it may contaminate the results of the study. Thank you again for taking the time to participate. 


\section{APPENDIX T}

Debriefing Script for Main Study 
Debriefing for Main Study

Thank you very much for participating in our project today. The overall purpose of this study is to explore how aging stereotypes may affect physical performance in older adults. There is growing evidence which suggests that success or failure at a task is not always related to lack of ability or incompetence. It is suggested that the power of stereotypes can affect performance either positively or negatively. We would like to discover whether stereotypes do affect factors like walking speed, balance, and the ability to get up from a chair. If they do, our next step is to figure out ways to lessen any negative effects and promote the positive effects. We may also need to figure out ways to diminish typical stereotypes about older adults. All older adults are different and do not all possess the same characteristics that are often portrayed in our society.

Today, you were briefly exposed to (positive, negative, or neutral) stereotypes of aging. The effects of a one time exposure to stereotypes are minimum and temporary. Your participation in the study is much appreciated since you are helping other older adults and our society.

If you have any concerns as a result of what we did today or how you performed on the measures, please let me know so that we can talk about it. Do you have any questions or concerns?

Here is my business card in case you have any questions or concerns after you leave here today. Please do not speak with your peers about this project until data collection is complete since it may contaminate the results of the study. Thank you again for taking the time to participate. 


\section{VITA}

Gabriele R. Moriello was born on January 9, 1966, in Albany, New York. She graduated from Colonie Central High School, Colonie, New York in 1984. She received her Bachelor of Science in Physical Therapy from Ithaca College, Ithaca, New York in 1988 and has been actively practicing physical therapy since graduation. She received a Master of Science in Allied Health from the University of Connecticut in 2001. She is currently an Assistant Professor in the Physical Therapy Department at The Sage College in Troy, New York. She has published two articles on the topics of stereotypes and attitudes toward older adults: Influence of an educational intervention on the attitudes of pre-allied health students' attitudes toward older adults in Gerontology \& Geriatrics Education in 2005 and Oral history in the classroom: Fostering positive attitudes toward older adults and the aging process in the Journal of Aging, Humanities and the Arts in 2009. 